\title{
Internationalization of higher education and study abroad programs at U.S. research universities: A social systems study
}

\author{
Chunmei Yao \\ West Virginia University
}

Follow this and additional works at: https://researchrepository.wvu.edu/etd

\section{Recommended Citation}

Yao, Chunmei, "Internationalization of higher education and study abroad programs at U.S. research universities: A social systems study" (2009). Graduate Theses, Dissertations, and Problem Reports. 3513. https://researchrepository.wvu.edu/etd/3513

This Dissertation is protected by copyright and/or related rights. It has been brought to you by the The Research Repository @ WVU with permission from the rights-holder(s). You are free to use this Dissertation in any way that is permitted by the copyright and related rights legislation that applies to your use. For other uses you must obtain permission from the rights-holder(s) directly, unless additional rights are indicated by a Creative Commons license in the record and/ or on the work itself. This Dissertation has been accepted for inclusion in WVU Graduate Theses, Dissertations, and Problem Reports collection by an authorized administrator of The Research Repository @ WVU.

For more information, please contact researchrepository@mail.wvu.edu. 
Internationalization of Higher Education and Study Abroad Programs at U.S. Research Universities: A Social Systems Study

\author{
Chunmei Yao
}

Dissertation submitted to the College of Human Resources and Education

at West Virginia University in partial fulfillment of the requirements

for the degree of

Doctor of Education

in

Educational Leadership Studies

Richard Hartnett, Ed. D., Chair

Daniel Hursh, Ph. D.

Ernest Goeres, Ph. D.

Susan Aloi, Ed. D.

Michael Lastinger, Ph. D.

Department of Educational Leadership Studies

Morgantown, West Virginia

2009

Keywords: Internationalization of Higher Education, International Education, Centralized Office of International Programs, Study Abroad Programs, and Social Systems Theory

Copyright 2009 Chunmei Yao 


\begin{abstract}
Internationalization of Higher Education and Study Abroad Programs at U.S. Research Universities: A Social Systems Study
\end{abstract}

Chunmei Yao

Internationalization of higher education institutions has become comprehensive and complex phenomenon in the United States since the 1990s. This trend has significantly motivated American colleges and universities involving all members within their communities to internationalize their institutions and increase their global competitiveness.

The purpose of this study was to assess institutional efforts on internationalization of higher education institutions through the lens of study abroad programs coordinated by the centralized Offices of International Programs (OIPs) at U.S. research universities. It assessed whether relationships existed between institutional input to study abroad programs through human resources and financial resources, the process of administration and coordination of study abroad programs in terms of the number of the study abroad programs, the number of exchange programs, and the number of international partnerships, and the output of these programs regarding the number of study abroad students, the number of international exchange students, and the number of faculty abroad.

A total of 230 executives who directed OIPs at research universities were surveyed through the Internet. 93 valid responses were received, representing 40.4 percent of the population. Three multiple regression models were established and significantly related to each of the outcome variables. In addition, several predict variables were significantly related to the outcome variables: (1) three predictor variables (e.g., human resources, financial resources, and the number of study abroad programs) were significantly associated with the number of study abroad students; (2) two predict variables (e.g., the number of international exchange programs and the number of international partnerships) were significantly related to the number of international exchange students; and (3) two predict variables (e.g., human resources and the number of study abroad programs) were significantly related to the number of faculty abroad. 


\section{ACKNOWLEDGEMENTS}

Writing a dissertation was a great journey with a great challenge in my life, especially for a breast cancer survivor who just finished the treatment of chemotherapy and the surgery; meanwhile, I was awarded as 2009 Dissertation Fellowship at West Virginia University and this award should be honored along with my mind, my body, and my soul.

I would like to thank my advisor Dr. Richard Hartnett, for his inspiration, guidance, and support during my entire program of study, and other outstanding committee members and professors, Dr. Ernest Goeres, Dr. Daniel Hursh, Dr. Susan Aloi, Dr. Michael Lastinger, and Dr. Richard Walls, for their tremendous help with suggestions and commentary.

In addition, I would like to express my sincere appreciation to my best friends Dr. Helen Hazi, Mr(s). Pamela and Joseph Kaehler, Mr(s). Debbi and David Pariser, Sister Rachel Blais, Ms. Cheryl Stout, Dr. Joy Saab, Dr. Gail Vanvoorhis, and Dr. Jame Abraham, for their gracious encouragement. Their friendships liked the sun shining on my daily life and motivated me to do my best to success.

It was also a gift to my father Guojun Yao and mother Shan'e Fan and an honor to both families because I was the first one to go to college, the first one to have a chance studying abroad, the first one to earn a Ph.D. Their dreams to be a well-knowledged person inspired me to challenge myself and continued studying abroad in the United States.

I owed a great debt to my husband Quanxi Wang and my daughter Annie Wang, for their great loves and support. Actually, Quanxi designed the webpage of the survey used in this study and his talent made the Internet survey go very well. Annie became more caring about me and her sweet voice always resonated around my head: "I love you most, Mom!"

Many thanks to all of you! 


\section{Table of Contents}

Chapter One: Introduction to the Study ...................................................................... 1

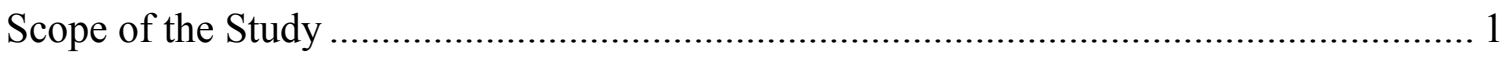

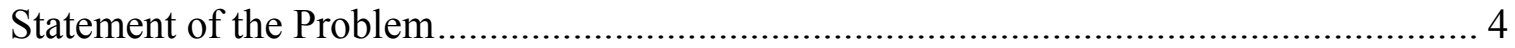

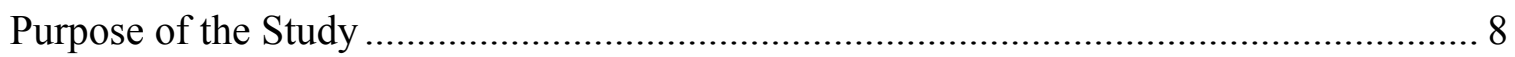

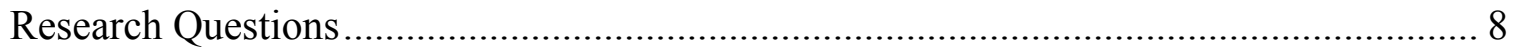

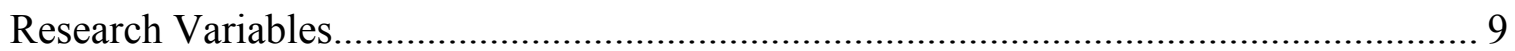

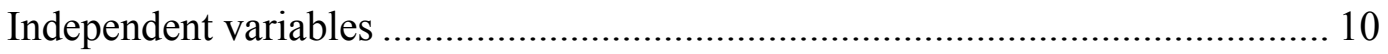

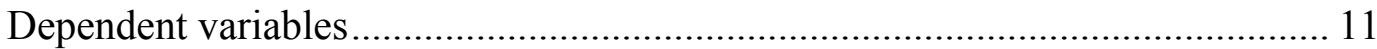

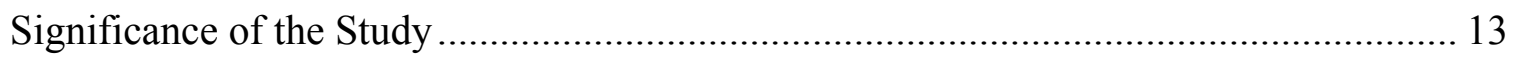

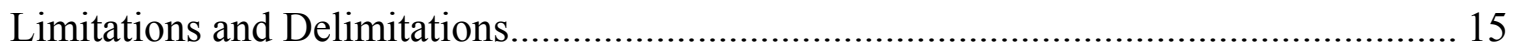

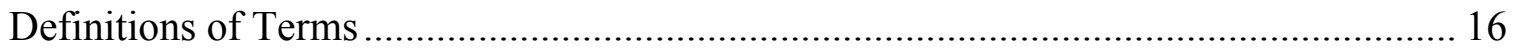

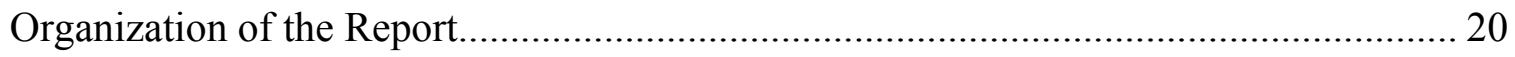

Chapter Two: Review of Related Literature.................................................................... 21

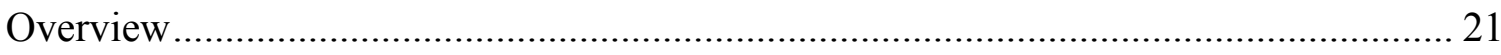

Historical Development of Internationalization of Higher Education .......................... 21

Definition of Internationalization of Higher Education .......................................... 28

Organizational Leadership of International Programs ............................................... 35

Coordinative Styles for International Programs ................................................... 37

Studies of Centralized Offices of International Programs ......................................... 44

Indicators of Assessing Internationalization of Higher Education ............................. 49

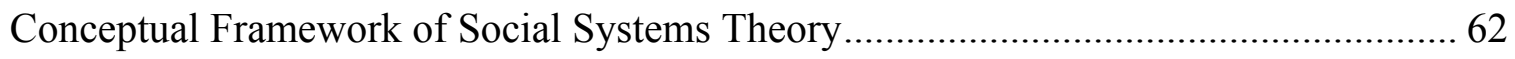

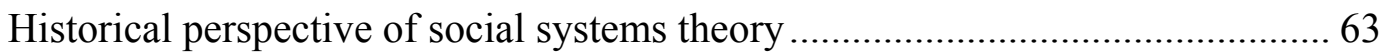




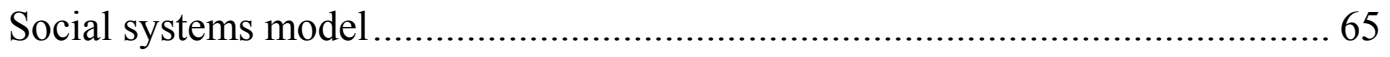

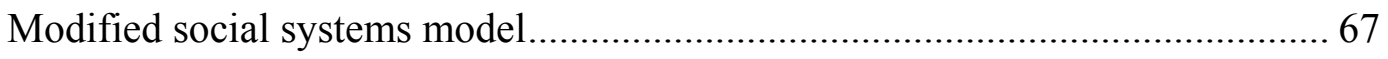

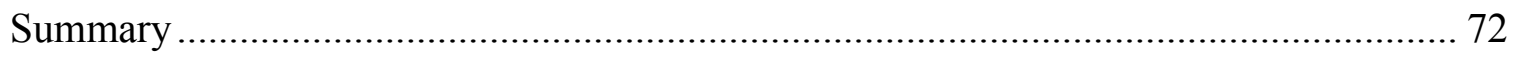

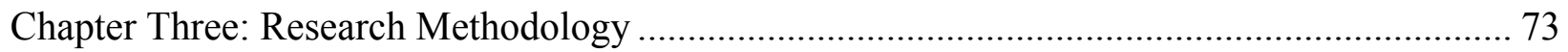

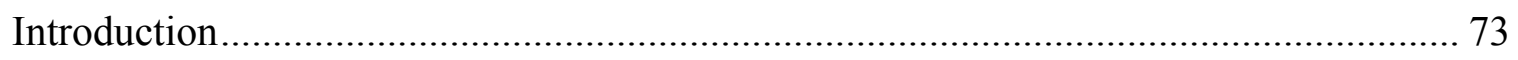

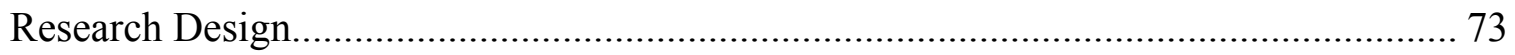

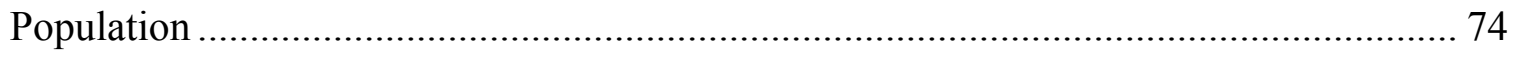

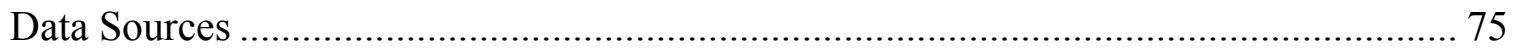

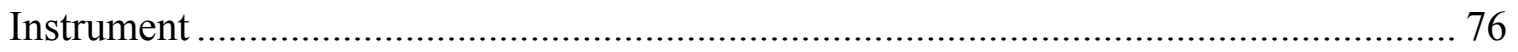

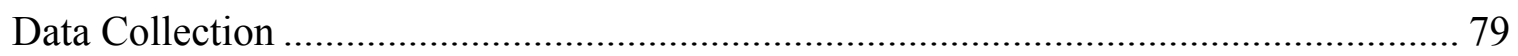

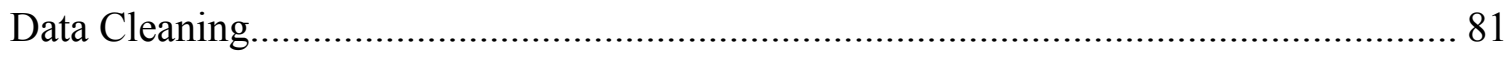

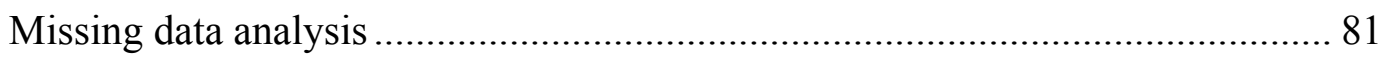

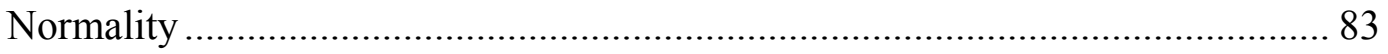

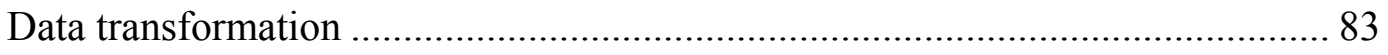

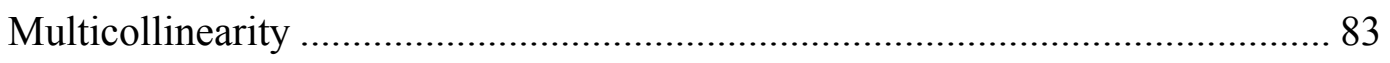

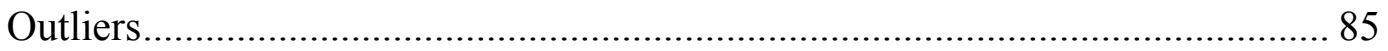

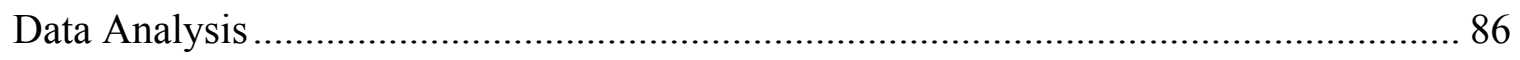

Assessing Validity and Generalization of Multiple Regression Models ........................... 88

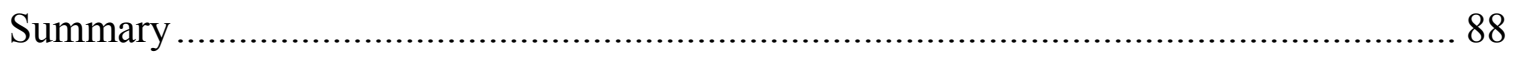

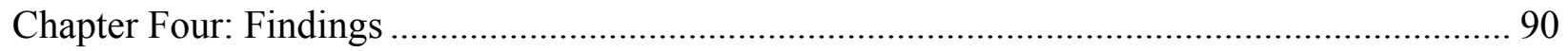

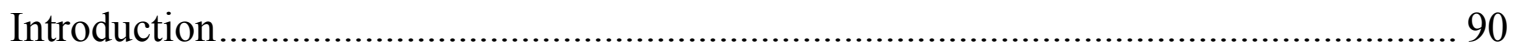

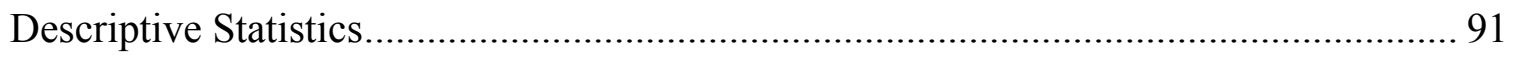

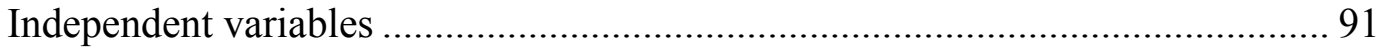




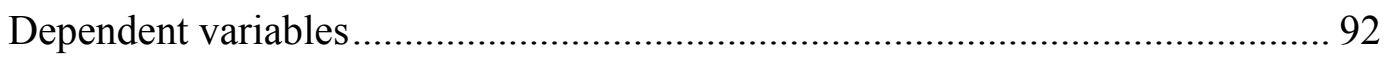

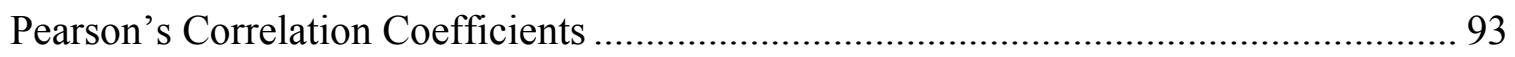

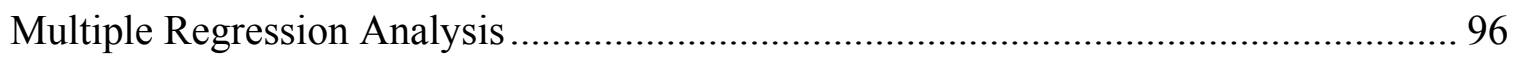

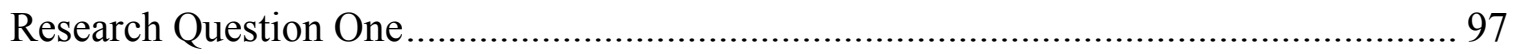

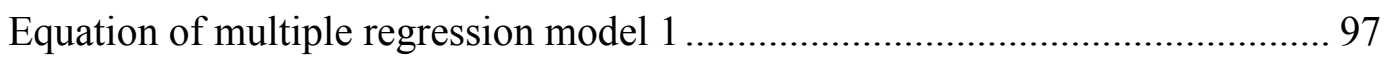

Significance of multiple regression model 1 .................................................... 98

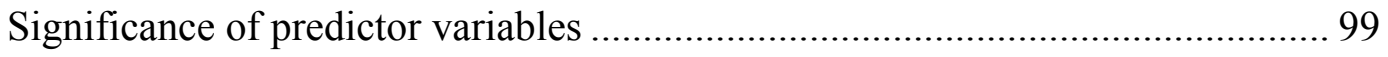

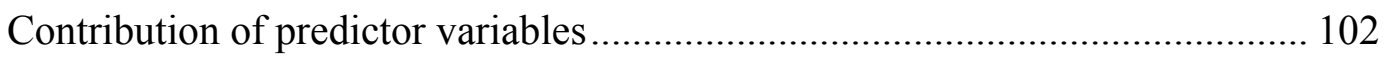

Assessing Validity of Multiple Regression Model 1 ................................................... 103

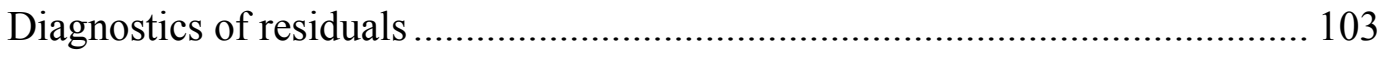

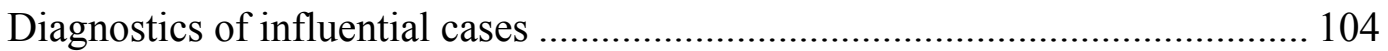

Assessing Generalization of Multiple Regression Model 1.......................................... 106

Assumptions of multiple regression analysis................................................... 106

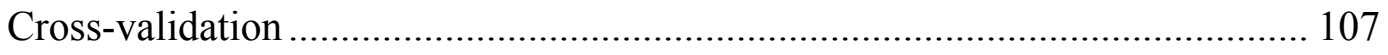

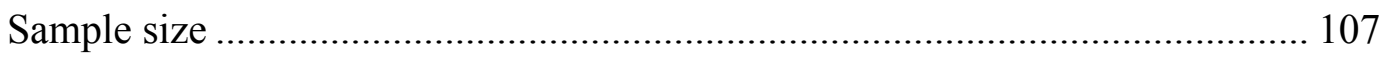

Research Question Two …………………………............................................ 108

Equation of multiple regression model 2 …..................................................... 109

Significance of multiple regression model 2 ................................................... 109

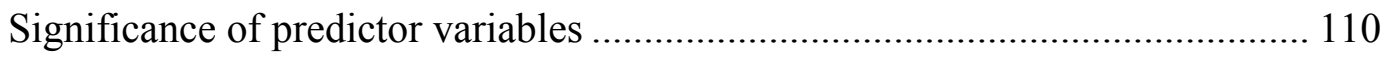

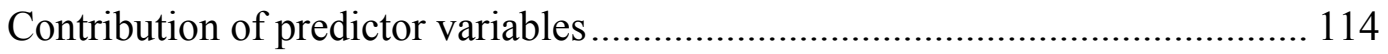

Assessing Validity of Multiple Regression Model 2 ................................................... 115

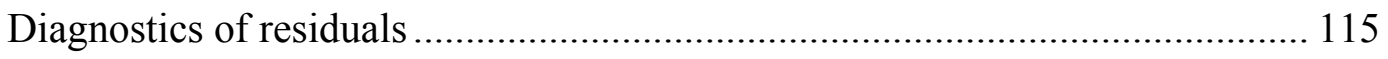

Diagnostics of influential cases .................................................................... 116 
Assessing Generalization of Multiple Regression Model 2 .................................... 117

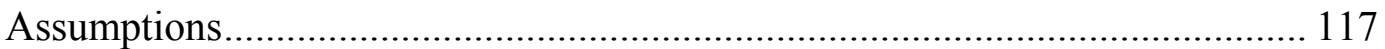

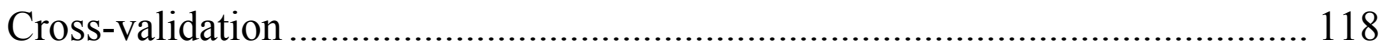

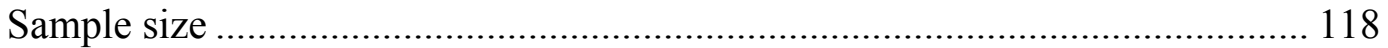

Research Question Three .................................................................................... 119

Equation of multiple regression model 3 .................................................. 119

Significance of multiple regression model 3 ........................................... 121

Significance of predictor variables ......................................................... 121

Contribution of predictor variables ......................................................... 125

Assessing Validity of Multiple Regression Model 3 ............................................. 126

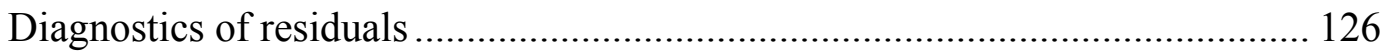

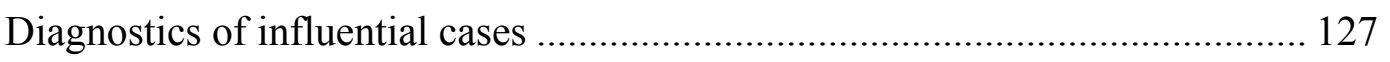

Assessing Generalization of Multiple Regression Model 3.................................... 128

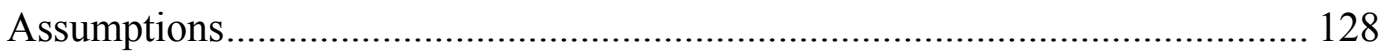

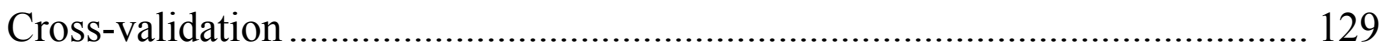

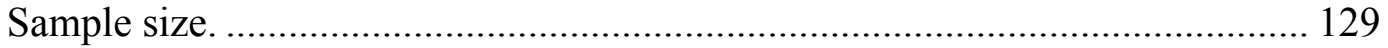

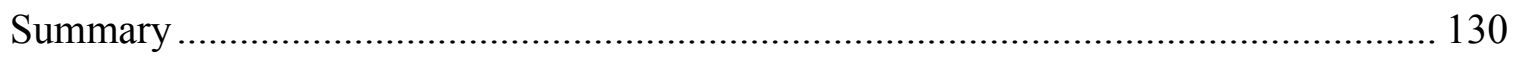

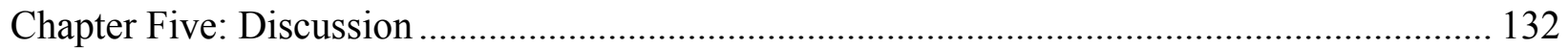

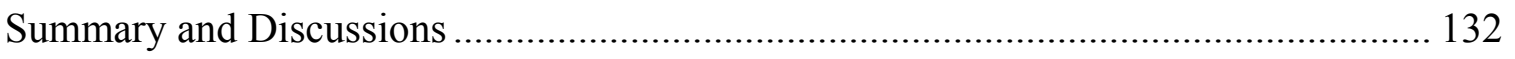

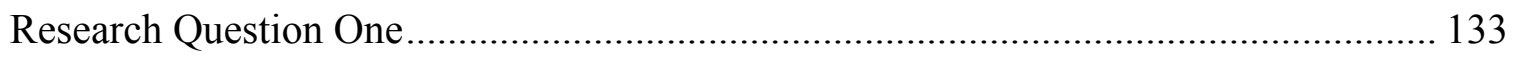

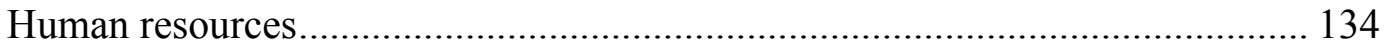

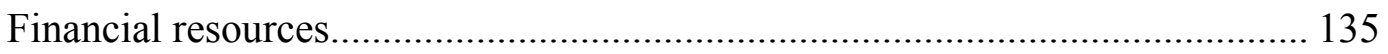

Number of study abroad programs ........................................................ 137 
Research Question Two 138

Number of exchange programs and number of international partnerships......... 138

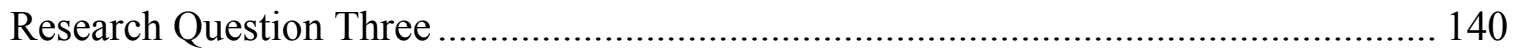

Number of study abroad programs .......................................................... 141

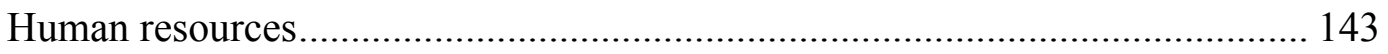

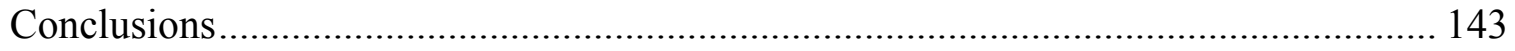

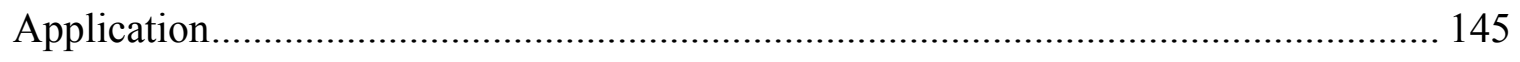

Assessing the number of study abroad students ....................................... 146

Assessing the number of exchange students ............................................ 148

Assessing the number of faculty abroad .................................................. 150

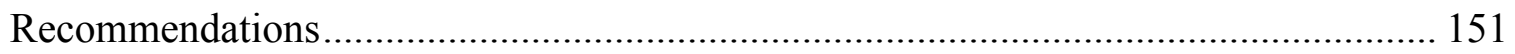

Recommendations for future studies .................................................. 151

Recommendations to OIP directors ......................................................... 153

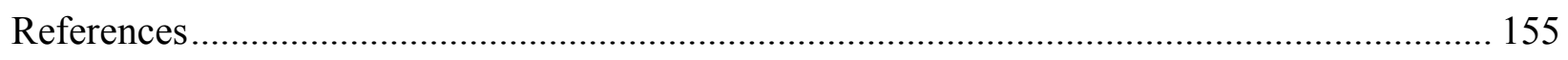

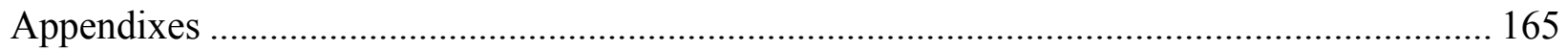

Appendix A: Cover Letters .......................................................................... 165

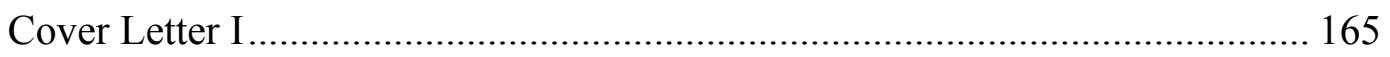

Cover Letter II.............................................................................. 166

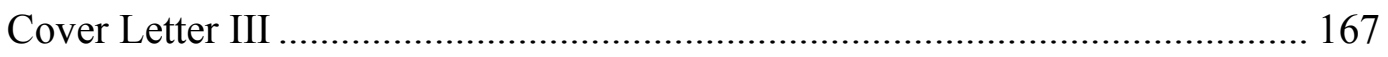

Appendix B: Statistical Abbreviations and Symbols of Research Variables ................ 168

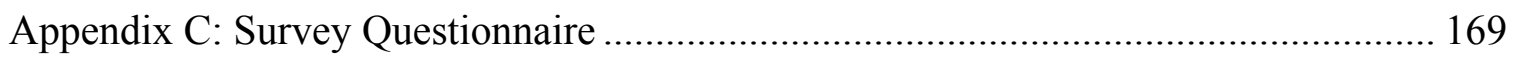

Appendix D: Histogram Plots for Independent Variables .................................... 172

Appendix E: Histogram Plots for Dependent Variables ......................................... 174 
Appendix F: Frequency Analysis for Untransformed Data .......................................... 176

Appendix G: Frequency Analysis for Transformed Data ........................................... 177

Appendix H: Level of Skewness and Kurtosis for Untransformed Data ........................ 178

Appendix I: Level of Skewness and Kurtosis for Transformed Data ............................. 179

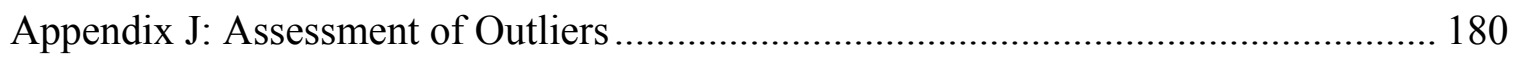

Appendix K: Histogram Plots for Standardized Residuals............................................. 181

Appendix L: Other Findings Obtained from the Internet Survey .................................. 183

Administrative structures of international education........................................ 183

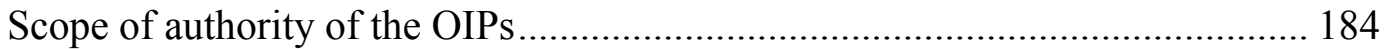

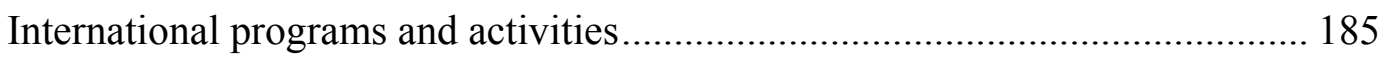




\section{List of Tables}

Table 1.1 Independent and Dependent Variables......................................................... 12

Table 2.1 Indicators of Assessing Internationalization of Higher Education .......................... 52

Table 3.1 Missing Data Analysis ................................................................................... 82

Table 3.2 Missing Value Analysis ................................................................................. 82

Table 3.3 Diagnostics of Multicollinearity for Untransformed Data ..................................... 84

Table 3.4 Diagnostics of Multicollinearity for Transformed Data ........................................ 85

Table 3.5 Research Questions and Multiple Regression Models ......................................... 87

Table 4.1 Means and Standard Deviations of Independent Variables .................................. 91

Table 4.2 Means and Standard Deviations of Dependent Variables ...................................... 93

Table 4.3 Correlation Matrix before Data Transformation .................................................... 94

Table 4.4 Correlation Matrix after Data Transformation .................................................. 95

Table 4.5 Results of Multiple Regression Model 1 ........................................................... 98

Table 4.6 Summary of Multiple Regression Model 1......................................................... 99

Table 4.7 Summary of Part and Partial Correlation Coefficients ........................................ 102

Table 4.8 Casewise Diagnostics for Multiple Regression Model 1 ....................................... 104

Table 4.9 Results of Multiple Regression Model 2 .......................................................... 109

Table 4.10 Summary of Standard Multiple Regression Model 2 ......................................... 110

Table 4.11 Summary of Multiple Regression Model 2.................................................... 113

Table 4.12 Results of Standard Multiple Regression Model 2............................................ 113

Table 4.13 Summary of Part and Partial Correlation Coefficients ....................................... 114

Table 4.14 Casewise Diagnostics of Multiple Regression Model 2..................................... 116

Table 4.15 Results of Standard Multiple Regression Model 3............................................ 120 
Table 4.16 Summary of Multiple Regression Model 3........................................................... 120

Table 4.17 Summary of Standard Multiple Regression Model 3 ……………….................... 124

Table 4.18 Results of Standard Multiple Regression Model 3..................................................... 124

Table 4.19 Summary of Part and Partial Correlation Coefficients.......................................... 125

Table 4.20 Casewise Diagnostics of the Multiple Regression Model 3..................................... 126 
Internationalization of Higher Education xii

\section{List of Figures}

Figure 2.1 Centralized Administrative Structure of International Programs ............................... 43

Figure 2.2 Systems-Environment Model (Hoy \& Miskel, 1996) ………………........................ 67

Figure 2.3 Modified Social Systems-Environment Model........................................................ 70 


\section{Chapter One}

Introduction to the Study

Scope of the Study

Currently, globalization has transformed educational, economic, scientific and technological, and socio-political sectors. Kerr (1994) and Scott (2000) point out that globalization has been manifested by a flow of technology, economy, knowledge, people, values, and ideas across borders, making national borders more permeable and workplaces more diverse. To meet the fundamental challenges of globalization, internationalization of higher education has become one way nations use to respond to the impact of globalization (Knight, 1999b). Leaders in higher education institutions worldwide have increasingly acknowledged the need to prepare globally educated graduates who can not only understand global issues, but also communicate effectively across cultures (Green, 2005).

Since World War II, internationalization of higher education institutions has expanded and become a comprehensive and complex phenomenon in the United States. This trend has significantly motivated American colleges and universities to include new institutional goals of international education in their mission statements, to adopt initiatives of international education in strategic plans, and to integrate these strategies in overall institutional functions of teaching, research, and service (de Wit, 2002; Knight, 1994, 1999a). Colleges and universities have also involved all members within their communities, including students, faculty, staff, and senior administrators, to work together to internationalize their institutions and increase their global competitiveness.

Historically, internationalization of higher education in the United States has experienced two waves since World War II. The first wave lasted from the end of World War II in 1945 to 
the end of the Cold War in the end of the 1980s; the second wave ran from the early of the 1990s to the present.

During the first wave of internationalization of higher education, institutional efforts to internationalize higher education were dominated by the "component approach" or the "activity approach" consisting of a variety of curricular and extracurricular programs and activities under the umbrella term international education (Harari, 1972, 1977; Arum \& Van de Water, 1992; de Wit, 2002). Under this approach, international education and internationalization of higher education were interchangeablely used by researchers and professional practitioners at U.S. colleges and universities.

Historically, international education included a diversity of programs, activities, and services related to international studies, international education exchange programs, and technical cooperation with third world countries. The rationale for internationalization of higher education during this period was not only to pursue peace and mutual understanding among Americans and people who live in the other parts of the world, but also to build U.S. national security and international relations with its Western allies and Eastern allies.

There were two main domains of practices under the umbrella of international education at U.S. colleges and universities during the first wave. Under the domain of curriculum, international education was found in foreign language studies, area studies, internationally focused courses, undergraduate U.S. students study and work abroad (study abroad for credit, internships abroad, and service learning abroad, or attendance at international conferences/meetings abroad), and faculty abroad activities in teaching, research, and public service. 
Under the extracurricular domain, international education included on-campus international programs and activities, such as international festivals, international residence hall programs (and/or foreign languages hall programs), buddy programs, language partner programs, and study group programs. These programs had attempted to involve U.S. undergraduate students with international students and scholars to promote mutual understanding and language learning.

As a result, many of these international programs and activities were developed independently of each other based on their own goals and directions, competing for scarce financial resources, especially since the early 1980s (de Wit, 2002). By the end of the 1980s, only one or two of the international education programs and activities dominated higher education institutions, and fewer were centrally coordinated by the Office of International Programs (OIP). At the end of the first wave, Merkx (2003) concluded that different types of institutions used different types of efforts and came up with different outcomes of internationalization, but no single set of internationalization strategies emerged as dominant in American higher education institutions.

The second wave began in the early of the 1990s. In response to the increasing economic competitiveness and globalization worldwide, internationalization of higher education increased and involved more leaders from central administration and professional staff in the process of decision-making and coordination at U.S. colleges and universities. The rationale for internationalization of higher education during this period was to strengthen U.S. world leading role in technology and economy and to increase U.S global competitiveness worldwide.

Knight (1994) defined the process approach as "integrating an international and intercultural dimension into teaching, research, and service functions of the institution" (p.7). 
She further stressed that the internationalization of higher education should be considered as an on-going process and integrated into overall functions of higher education in terms of teaching, research, and service. Since then, internationalization of higher education in the United States was guided by both the "component approach" and the "process approach," with focus more on the "process approach" in the recent decade (de Wit, 2002).

Knight's (1994) definition provided a systematic way of thinking to assess institutional efforts of internationalization of higher education, in which international programs and activities were considered as an integrated whole, not separated parts operated by different schools and centers within the institution. As Schoorman (1999) concluded, the process approach viewed institutional efforts to internationalize higher education as an on-going educational process and integrated institutional commitments to international education with the overall functions of teaching, research, and service, rather than isolated components of international programs and activities. de Wit (2002) further advocated that U.S. higher education should adopt the "process approach" into studies and practices in the field of international education, make the process of internationalization of higher education more comprehensive, and develop multifaceted strategies in teaching, research, and service.

\section{Statement of the Problem}

U.S. colleges and universities have faced many challenges for internationalization of their institutions in teaching, research, and service. Recent surveys conducted by the American Council on Education (ACE) confirmed that studies and practices in internationalization of higher education lag far behind the public rhetoric (Green \& Olsen, 2003; Hayward, 2000; Siaya \& Hayward, 2003). Other studies also addressed the following problems of internationalization 
faced by U.S. colleges and universities (Burn, 1980; Kerr, 1980, 1990, 1994; Goodwin \& Nacht, 1991; Lambert, 1992, 1993, 1995; IIE, 2007; Scherer, Beaton, Ainina, \& Meyer, 2002):

1. There is a low level of institutional commitment to internationalization of higher education. ACE surveys showed that only about one-third of institutions specified internationalization in their mission statements, less than one-third of sampled institutions stated internationalization as one of their top-five priorities in their strategic plans, and an average of seven percent of institutions had policy statements that considered international work and experience in faculty promotion and tenure evaluation (Hayward, 2000; Green \& Olsen, 2003; Siaya \& Hayward, 2003; Olsen, Green \& Hill, 2005). Kerr (1994) further pointed out that colleges and universities in the United States had not been leading the trend of internationalization; they had been going in the wrong direction.

2. Most administrative leaders did not develop strategic plans for internationalization of their institutions. Many colleges and universities did offer a variety of international programs and activities for students and faculty to enlarge their international perspective and improve their intercultural competency; however, few institutions did so systematically (Siaya \& Hayward, 2003). Green \& Olsen (2003) observed that there was a large gap between the goals and priorities of internationalization asserted in institutions' mission statements and strategic plans and the actual practices regarding development and coordination of international education programs and activities on- and off-campus.

3. Enrollment in foreign language studies has declined from 16 percent in the 1960 s to an average of 8 percent in the late 1970s, and then remained steady for more than 30 
years; among foreign language programs, only 6 percent of the total enrollment was in Asian languages, less than 2 percent in Arabic and Hebrew combined. Moreover, most undergraduate students never got beyond two years of language study, and very few achieved language proficiency at the college level (Scherer, Beaton, Ainina, \& Meyer, 2002).

4. A small number of students studying abroad. Although the number of U.S. undergraduate students studying abroad gradually increased in the recent decade, reaching eight percent in the 2006-07 academic year, the result showed that less than three percent of total undergraduate students had an opportunity to study abroad by the time they graduated, indicating that most American students never had a chance to study and work overseas (Scherer, Beaton, Ainina, \& Meyer, 2002).

5. Participation in study abroad programs is quite uneven. Students who studies abroad tended to be white, female, middle class, full-time students, majoring in foreign languages, history, and the social sciences at liberal arts colleges; underrepresented student groups were typically male, part-time students, minorities, members of lower economic classes, majoring in education, natural science, and applied and professional sciences (Lambert, 1995; IIE, 2007).

6. International students who enrolled at U.S. colleges and universities tend to be from the "wrong countries" compared to where U.S. students studied and worked abroad. Lambert (1995) studied the flow of international students in the United States and found that most international students were from the developing countries, while American students tended to learn European languages and studied abroad in Western Europe. Moreover, most international students enrolling at U.S. colleges and 
In the related literature review of internationalization of U.S. higher education, there is no systematic approach to assess the internationalization of higher education as a multifaceted process, rather than as separated strands of programs and activities. de Wit (2002) supports using the process approach to study internationalization of higher education in the United States, not just the component or activity approach (Afonso, 1990; Green \& Olsen, 2003; Harari \& Reiff, 1993; Hayward, 2000; Krane, 1994; 2003; Siaya \& Hayward, 2003). Harari and Reiff (1993) further illustrate the phenomenon:

Success appears where the concept of internationalization is accepted as integrated and multifaceted rather than as a series of unconnected strands. Failure looms where internationalization of the curriculum is attempted in isolation from the design and implementation of study-abroad programs, from the involvement of international students and their rich mosaic of cultures in the classrooms, from training and study/travel programs designed to provide faculty members with international experience and professional growth, from the involvement of international scholars in the life of the institution and surrounding community, or from a multitude of other activities such as welcoming visiting scholars, business persons, diplomats, and artists.... Where the holistic concept of internationalization is recognized and pursued, it tends to produce more effective and viable international programs. (p. 16)

Thus, administrative leaders, researchers, and professional practitioners who have worked for international dimensions at U.S. colleges and universities should develop comprehensive 
strategies to internationalize their institutions by combining those isolated international programs and activities into an integral one, should help students and faculty equip themselves with the international competency, and should enhance institutions' capacity to gain global competitiveness in the $21^{\text {st }}$ century.

In recent years, study abroad programs have been increasingly considered as one of the key approaches to enhance the status of institutionalization of U.S. higher education. To address these problems described above, a study of the institutional input, the process, and the output through study abroad programs on the basis of a social systems perspective may provide valuable insight for administrative leaders and professional practitioners at U.S. colleges and universities to enhance their capacities to internationalize their institutions.

\section{Purpose of the Study}

The purpose of this study was an attempt to use a social systems approach as a theoretical framework to assess study abroad programs through the input — process — output at U.S. research universities. This study evaluated whether there were significant relationships among (1) institutional commitment to internationalization of higher education through input of human resources and financial resources to the study abroad programs, (2) the process of establishment and coordination of study abroad programs and related activities by the centralized Office of International Programs (OIP), and (3) the output of study abroad programs at U.S. research universities.

\section{Research Questions}

The following research questions were proposed to guide this study. The overall hypothesis was to assess relationships between the combination of the input variables and the process variables and each of the output variables. Three research questions were addressed: 
1. Do the institutional input variables (e.g., human resources and financial resources) and the process variables (e.g., the number of study abroad programs, the number of exchange programs, and the number of international partnerships) have relationships with the outcome variable of the number of study abroad students?

2. Do the institutional input variables (e.g., human resources and financial resources) and the process variables (e.g., the number of study abroad programs, the number of exchange programs, and the number of international partnerships) have relationships with the outcome variable of the number of international exchange students?

3. Do the institutional input variables (e.g., human resources and financial resources) and the process variables (e.g., the number of study abroad programs, the number of exchange programs, and the number of international partnerships) have relationships with the outcome variable of the number of faculty abroad?

\section{Research Variables}

To assess the institutional efforts on internationalization of higher education at U.S. research universities through input, process, and output of study abroad programs, a modified social systems model in terms of input - process - output was used as a theoretical framework to determine whether there are relationships among these variables.

Accordingly, research variables relating to study abroad programs coordinated by the centralized OIPs at research universities were categorized into three sections: institutional input variables, process variables, and output variables. As shown in Table 1.1, input variables and process variables were considered as independent or predictor variables, and output variables were grouped as dependent or outcome variables. 
Independent variables. Independent variables include five predictor variables regarding institutional input to study abroad programs and variables in process of coordination of study abroad programs:

1. OIP Input Variables. Institutional input variables in study abroad programs include two parts: human resources and financial resources:

- Human Resources Variable (HR). Institutional input of human resources consists of three categories: (1) the number of full-time equivalent (FTE) professional staff, (2) the number of FTE support staff, and (3) the number of graduate assistants employed by the OIP; and

- Financial Resources Variable (FR). The institutional input of the financial resources includes the dollar amount of the annual budget managed by the centralized OIP and used for study abroad programs.

2. OIP Process Variables. Process variables refer to a variety of international education programs and activities established and coordinated by the centralized OIPs to enhance the status of internationalization of higher education at U.S. research universities. The process variables consist of three parts:

- Number of study abroad programs coordinated by the centralized OIP (e.g., study abroad for credit, internships abroad, and service learning abroad) (NSAProg);

- Number of exchange programs administered through the centralized OIPs (NEXProg); and

- Number of international partnerships that have been active in the recent three years (NPartner). 
Dependent variables. Dependent variables are the outcome variables of study abroad programs in general:

1. OIP Output Variables.

- Number of U.S. undergraduate students studying abroad (e.g., study abroad for credit, internships abroad, and service learning abroad) (NSAStu);

- Number of international students studying at U.S. research universities through the exchange programs administered by the OIPs (NEXStu); and - Number of faculty abroad for teaching, research, and service (NFac). 
Table 1.1

Independent and Dependent Variables

Types $\quad$ Independent Variables (Predictors)

Input Variables Human resources (HR)

Financial resources (FR)

Process Variables Number of study abroad programs (NSAProg)

Number of exchange programs (NEXProg)

Number of international partnerships (NPartner)

Types Dependent Variables (Outcomes)

Output Variables $\quad$ Number of students studying abroad (NSAStu)

Number of exchange students (NEXStu)

Number of faculty abroad for teaching, research, \& service (NFac) 
Previous studies asserted that the output variables in terms of the number of students studying abroad, the number of international exchange student enrollments, and the number of faculty abroad had medium and/or high correlations to internationalization of higher education (Afonso, 1990; Krane, 1994; Nelson, 1995).

For instance, Krane's (1994) study found that correlation coefficients of the three output variables (e.g., the number of students studying abroad, the number of international exchange student enrollments, and the number of faculty abroad) were .60, .35, and .34 $(p<.05)$ respectively; these variables were correlated significantly with international dimensions in higher education institutions. Moreover, Nelson's (1995) study also indicated that the number of study abroad programs was significantly correlated to the number of students studying abroad, especially at large institutions, with $r=.578, p<.001$ at large public institutions and with $r=.209, p<.040$ at large private institutions. These positive correlations in turn resulted in the success of the internationalization of higher education.

\section{Significance of the Study}

Internationalization of higher education is a central theme in the first decade of $21^{\text {st }}$ century at colleges and universities in the United States. Higher education policy makers and central administrative leaders at U.S. colleges and universities have realized that it is important to provide graduates with the knowledge of international competency to deal the increasing global issues. They have the obligation and responsibility to fulfill the goals of internationalization of higher education through their efforts and cooperation with faculty, students, and staff within the higher learning community.

This study examined the institutional efforts and commitments to internationalization of higher education through the input, process, and output of study abroad programs coordinated by 
centralized OIPs at U.S. research universities. Therefore, it not only presents the profile of centralized OIPs through their roles to international education, but also provides a potential model to assess how research institutions fulfill their specific goals of international education through study abroad programs.

In addition, this study can provide a complete picture for senior administrators who work for international education at their institutions of the realistic status of internationalization of higher education, as well as relationships existing among the allocation of institutional resources, international education programs and activities, and the outcome of these efforts. The results can guide international education leaders in cultivating the institutional culture with an emphasis on strategic planning, changing the policies and structure related to administration and coordination of international programs, and providing more resources and support to promote internationalization of higher education in the future.

Moreover, this study may help professional practitioners at U.S. colleges and universities to further design, develop, modify, and improve the quality of international education programs and activities on- and off- campuses as an integrated whole.

Finally, this study may provide an alternative approach for international educators and researchers to assess the status of internationalization of higher education in the United States. Previous studies on internationalization of higher education generally focused on assessing internationalization of curriculum and international programs and activities themselves. Few stressed the institutional efforts of internationalization of higher education through the lens of study abroad programs coordinated by the centralized OIP; thus, this study may provide a systematic way of thinking by using a modified social systems model (input—process — output) to examine the institutional efforts to internationalize their institutions. 


\section{Limitations and Delimitations}

1. Institutional efforts on internationalization of higher education at U.S. colleges and universities are great themes and cover a variety of aspects relating to international dimension. This study assessed the institutional efforts on internationalization of higher education only through the lens of the study abroad programs coordinated by centralized Offices of International Programs at U.S. research universities. It did not represent the whole picture of internationalization of American higher education because of the limited population and study.

2. Because there are many kinds of institutional efforts and commitments to the international education at all types of U.S. colleges and universities, this study was limited to institutional efforts to enhance the status of internationalization of higher education at research universities. Other types of higher education institutions, such as comprehensive universities, liberal arts colleges, and community colleges were excluded from this study.

3. This study did not attempt to identify and establish a general model for assessing the institutional efforts of internationalization of higher education for all types of American higher education institutions. One of the major goals of international education was to improve the international competency for undergraduate students; therefore, research universities that offer only graduate programs were also excluded from this study.

4. Data were collected only from the executive directors who work at the Office of International Programs (or the Office of International Education, the Office of Study Abroad, the Center for International Studies, and so forth) at U.S. research 
universities based on their dedication and work for study abroad programs. This specific view may not be generalized to other types of higher education institutions, such as liberal arts colleges and community colleges.

5. Data used in this study included institutional input of human resources and financial resources; the process of establishment and coordination of international education programs and activities by the OIP; and the related output of these international education programs and activities. Because of the quality of data obtained from the OIP executives, it may cause inherent limitations and shape the results of this study:

(1) some information may not be collected annually by the OIP; (2) the OIP may lack sufficient information for this study; and (3) some OIPs may have concerns and not report their information thoroughly.

6. Because data were obtained from an electronic survey during a limited period, directors of OIPs may not have been available to respond to this e-Survey by email or the website; thus, a small percentage of responses may have affect the generalization of this study to a large population.

\section{Definitions of Terms}

For better understanding of the meaning and application in this study, the essential concepts and its reference are defined below:

1. Centralized Office of International Programs: Functions as a flagship unit to lead international programs and activities on- and off-campuses through development, administration, coordination, and implementation of international education programs and activities based on the institutional mission and goals of international education. Most OIPs at U.S. research universities are located under the division of Academic 
Affairs, and supervise at least two units - the Office of Study Abroad (OSA) and the Office of International Students and Scholars (OISS); others may add more units, such as Language Institute (e.g., Intensive English Programs, English as Second Language Programs) and Fulbright Programs; a few OIPs serve only as the Office of Study Abroad.

2. Faculty Abroad: Refers to faculty members at U.S. research universities who fulfill institutional mission and functions in teaching, research, and public service in foreign countries. It can be described through international education programs and activities, such as participating in faculty-led programs, teaching abroad, conducting research abroad, providing public service abroad, and attending international conferences or meetings overseas.

3. Full-time Equivalent (FTE): Refers to student enrollment or faculty working status that accounts for both full and/or part-time, e.g., two half-time faculty members may count as one full-time faculty, and so on.

4. Globalization of Higher Education: A term that is related to internationalization of higher education institutions. It is defined as a flow of technology, economy, knowledge, people, values, and ideas across borders (de Wit, 1997; Knight, 2004). Stone (2006) defined globalization as a range of processes designed to prepare university staff and students to operate effectively within increasingly globalized contexts.

5. International Education: An umbrella term that encompasses a variety of international education programs and activities at U.S. colleges and universities. Generally speaking, it falls within the overall functions of teaching, research, and services 
including internationalization of curriculum, study abroad, recruitment of international students and visiting scholars, faculty abroad, international partnership, and so forth.

6. International Studies: Most often refers to the international education in terms of curriculum and instruction.

7. Internationalization of Higher Education: An umbrella term that stresses a process of integrating an international and intercultural dimension into the overall functions of teaching, research, and service at higher education institutions (Knight, 1994).

8. International Partnerships: Refer to a relationship established between two higher education institutions for development of inter-institutional cooperation based on the related contracts. In this study, this relationship refers only to those research institutions that have contracts with universities in foreign countries.

9. International Exchange Students: Refer to all nonresident aliens who are recruited through exchange programs and enrolled at U.S. higher education institutions for a semester or an academic year. They typically hold the J-1 visa.

10. International Visiting Scholars: Refer to faculty and researchers from institutions in other countries who come to U.S. colleges and universities to engage in studying, teaching, and researching. They typically hold the J-1 visa and stay at the U.S. institutions for a short term.

11. Office of International Programs (OIP): An administrative unit on campus that is staffed by professionals (program coordinators and advisors) to manage the international education programs and activities across campuses, such as study abroad programs, exchange programs, international students and scholars service, faculty 
abroad, and institutional partnerships with colleges and universities in other countries. Generally, there exists a diversity of names of the office dealing with international programs at U.S. research universities, such as the Center of International Studies, the Office of International Education, the Center of Oversea Programs, Office of Study Abroad, and so forth. The OIP used here serves as an umbrella term representing various titles of these offices.

12. Study Abroad Programs: Refer to U.S. undergraduate students who study at a college or universities in foreign countries to pursue academic credits, take internships abroad, do service learning abroad, and attend international conferences abroad.

13. Study Abroad Professional Practitioners: persons who hold official positions designated for advising students on study abroad and coordination of related international programs and activities; their typical titles are study abroad directors, study abroad program advisor, and study abroad program coordinator at American colleges and universities.

14. Study Abroad Support Staff: persons who hold official positions designated for administration and coordination of study abroad programs at U.S. colleges and universities; their typical titles include study abroad program assistant, accountant, secretary, and so forth.

15. OIP Annual Budget: Refers to the money allocated from the institution's central funds annually for the purpose of supporting international programs and activities administered by the OIP.

16. Social Systems Model: A theoretical, comprehensive framework to guide researchers in examining the inter-relationships among the elements within a system or an 
organization. It views an organization as a whole, comprising two or more subunits with interactions. The system receives input from the environment, transforms them through the process, delivers the outcomes into the environment, and further modifies the system through the feedback loop. This cyclical process with input-processoutput provides a framework for organizational leaders to improve performance compete with other systems, and help the organization survive.

\section{Organization of the Report}

Chapter One contains an introduction of the study, the problem statement, the purpose of the study, research questions, the significance of the study, and the limitations of the study. The remaining four chapters are organized as follows. Chapter Two is the selective literature review on internationalization of higher education at U.S. colleges and universities, including the historical development of internationalization of higher education in the United States; the definition of internationalization; the administrative structure and centralized coordinative pattern for international programs; indicators for assessing international education; and a modified social systems model to guide this study. Chapter Three describes the research methods employed in the study, including a description of the sample, research variables, the survey instrument, and data collection and analysis techniques. Chapter Four presents the findings by analyzing the variables through the standard multiple regression models. Chapter Five discusses the results, draw conclusions, and addresses recommendations for future studies. 


\section{Chapter Two}

Review of Related Literature

\section{Overview}

Internationalization is a significant phenomenon affecting higher education institutions worldwide in recent decades (Altbach \& Teichler, 2001). It is not only a challenge, but also an opportunity for colleges and universities in the United States to gain global competitiveness and keep their leading roles in the world.

This study explores institutional efforts on internationalization of higher education institutions through the cumulative works of study abroad programs coordinated by the centralized Offices of International Programs (OIPs) at U.S. research universities.

This chapter provides a synopsis of major strands of internationalization of higher education and the social systems theory. Both are interrelated and form the framework for this study. The main themes are as follows: (1) a brief history of internationalization of higher education in the United States since World War II; (2) a definition of the term of internationalization of higher education; (3) the organizational leadership of international programs; (4) coordinative patterns of international programs at U.S. colleges and universities; (5) studies on centralized office of international programs; (6) the predictors gathered from the literature review to measure the status of internationalization of higher education and study abroad programs at U.S. colleges and universities; and (7) a theoretical framework or a model generated from the social systems theory to guide this study.

\section{Historical Development of Internationalization of Higher Education}

Internationalization of higher education has always been a part of the life of the university. Historically, internationalization of higher education experienced two major waves in 
the United States. Internationalization of higher education in the United States began in the early of $20^{\text {th }}$ century, along with the founding of the Institute of International Education (IIE) in 1919 in New York City. Americans scholars were shocked by World War I and began to establish a variety of international cooperative programs for students and faculty to pursue peace and the mutual understanding among different nations, people, and cultures (IIE, 1920, 1994). Several U.S. colleges and professional associations funded scholarships to send U.S. students and faculty to study or work abroad; meanwhile, they invited international students and scholars to come to colleges in the United States to study, teach, and conduct research. The impact of the internationalization of higher education was limited because only a small number of students and scholars participated in the international exchange programs during this "awakening stage" (Halpern, 1969).

Internationalization of higher education in the United States expended rapidly after World War II. The U.S. federal government invested substantial financial resources into the field of international education to enhance the curriculum with international perspectives such as foreign language studies, area studies, and international relation studies at U.S. colleges and universities. Although the stimulation from the federal government sector did not grow stronger and later languished, the sparks of the institutional efforts on internationalization of higher education spread and increasingly became a significant phenomenon at U.S. colleges and universities.

Merkx (2003) identified two waves of institutional efforts on internationalization of U.S. higher education since World War II. The first wave began in 1946, the year immediately after World War II, and ended at the late of 1980s (after the end of the Cold War). This period was described by Merkx as a "golden time" of internationalization of U.S. higher education, which 
transformed U.S. colleges and universities almost overnight from "a cultural colony" to a metropolis, from the periphery to the center, and dominated the international dimension of higher education worldwide, both in research and practices (p. 9).

To pursue national security and to enhance mutual international relations with its allies in Western Europe, the U. S. federal government became involved deeply in the field of international education by creating and funding the Fulbright Programs through the Institute of International Education (IIE) to increase faculty and student exchanges with other countries in the world. At this stage, internationalization of higher education was more structured than the "awakening age" and was highlighted by three features: (1) the federal government invested a large amount of financial resources into higher education institutions to increase studies in the fields of foreign languages, international relations, and foreign areas; (2) this wave was largely driven by interests from faculty and students within the colleges and universities as well as by professional foundations and organizations, not the institutions themselves; and (3) the impetus behind this wave was political needs such as national security and international relations, rather than economic, social, and cultural needs (Knight \& de Wit, 1995; de Wit, 2002).

In response to the first wave, some leading colleges and universities specified their mission statements, established departments and centers for area studies and foreign language studies, built functioning administrative units for study abroad programs and provided services for international students and scholars, and developed technical assistance projects abroad with their international partners. Those international education programs and activities were generally disconnected from each other and without any interrelation (Tonkin \& Edwards, 1981).

At the end of this wave, because of the diversity of American higher education institutions and their decentralization of organizational structures in nature, different types of 
institutions worked through different efforts and came up with different outcomes of internationalization of higher education, but no single strategy of internationalization emerged as a dominant pattern in American higher education (Merkx, 2003). In summarizing the outcome of U.S. internationalization of higher education at this stage, de Wit (2002) wrote that to a large extent, American higher education developed a broad variety of activities, programs, and projects in international education, but many were developed separately and lacked clear definition, boundaries, agreements, and inter-connections.

The second wave of internationalization of U.S. higher education appeared in the early of the 1990s and has increasingly become stronger to the present, along with an increase of the economic competitiveness of the United States in the world (Lyman, 1995). The fundamental driving force was directly influenced by globalization, which caused an increase of economic competitiveness worldwide, especially between the United States and Western European countries and Japan that were reconstructed after World War II.

Internationalization of higher education at this stage was driven mainly by economic forces rather than by the political forces of the first stage. During this period, the U.S. federal government tended to withdraw the funding and the support from the international dimension in higher education, such as area studies, foreign language studies, and Fulbright Programs which were largely invested during the Cold War era, and focused more on the economic and the domestic issues.

The result of this stage was that some Western countries such as Britain, France, Germany, Canada, and Australia took over the leading role in developing internationalization strategies for higher education institutions (de Wit, 2002). In the United States, colleges and 
universities gradually began to take actions to enhance the status of internationalization of higher education: (1) citing the international education more frequently in their mission statements; (2) listing international education as one of their institutional top priorities in the strategic plan; (3) establishing an institution-wide committee or a task force working on internationalization of their institutions; (4) involving executive leaders and senior administrators were more involved in the decision making process and funding issues relating to the international education; (5) developing the international education programs and activities were well developed on- and off-campuses; and (6) hiring more professional practitioners and allocating more financial resources to support international education programs and activities.

The major driving force of internationalization of higher education at this stage came from individual students who were interested in knowing the other parts of the world, people, and cultures (Lambert, 1989a). In addition, many non-traditional constituencies such as students and faculty in professional schools and the trustees were involved (Merkx, 2003). Moreover, inter-institutional cooperation among U.S. colleges and universities and institutions in other countries provided another motivation for internationalization of U.S. higher education. For instance, since the 1990s, many U. S. colleges and universities have been besieged by high ranking officials from foreign universities in other countries, international visiting and exchange faculty for teaching and conducting research, and international students pursuing degrees. As a result, the internationalization of higher education became an integral part of academic programs and activities in all departments and schools that were open for most undergraduate students and faculty members.

By the end of the $20^{\text {th }}$ century, a significant shift took place: the mobility of students and faculty was more in the direction from the United States to Europe, rather than from Europe to 
the United States. Non-European international students in large numbers chose U.S. colleges and universities to pursue their degree programs, particularly since the middle of the 1990s (de Wit, 2002). Since 1990, the number of international students enrolled at U.S. institutions increased an average of 5 percent annually, and 68 percent of those international students were self-financed (Arnone, 2002). Lambert (1995) reported that 1,127,387 students worldwide were enrolled in higher educational institutions out of their homelands in the mid-1990s; among them, 35 percent were recruited by U.S. colleges and universities, the largest share than any other country. Other leading countries recruiting international students were France with 13.7 percent of the total international students, followed by Germany (10\%), United Kingdom (6.5\%), and Canada (3.1\%), respectively (p. 22).

In the United States, according to Open Doors report, (IIE, 2007), 582,984 international students were enrolled at colleges and universities during the 2006-07 academic year, a 10 percent increase over the previous year (IIE, 2007). Moreover, international students contribute approximately $\$ 14.5$ billion dollars to the U.S. economy, through their expenditure on tuition and living expenses. The Open Door reported that 61.5 percent of international students received the majority of their funding from personal and family sources and 13.5 percent of funding from their home country government or universities; thus, a total of two thirds of international students' primary funding sources came from outside of the United States (IIE, 2007).

Although American higher education institutions still kept the leading role in recruiting international students, the share of the total number of international student enrollments with other leading countries, such as United Kingdom, Australia, Canada, and France, has decreased in the recent decade. 
Study abroad programs at U.S. colleges and universities expanded dramatically in the recent decade. According to Merrill Lynch's calculation, the higher education market abroad was valued at $\$ 111$ billion per year (cited by Arnone, 2002). Although the number of U.S. undergraduate students studying abroad gradually increased and reached eight percent in the 2006-07 academic year, less than three percent of undergraduate students had an opportunity to study abroad before graduation (Scherer, Beaton, Ainina, \& Meyer, 2002). Moreover, participation of American students in study abroad programs was quite uneven. The students who were abroad tended to be white, female, middle class, full-time students, majoring in foreign languages, history, and social sciences at liberal arts colleges; underrepresented students were typically male, part-time students, minorities, members of lower economic classes majoring in education, natural science, applied science, and professional science.

In summary, internationalization of higher education changed the profiles of U.S. colleges and universities. During the first wave, colleges and universities were less active than private organizations and foundations because the institutional initiatives and efforts to internationalize higher education were largely driven by the federal government and private organizations rather than by the institutions themselves. Moreover, student mobility was less active than faculty mobility, and the favorite destinations of study abroad for U.S. students and faculty were European countries, especially England, France, Germany, Spain, and Italy (de Wit, 2002; Lambert, 1995; Harari, 1989).

In the second wave, internationalization of higher education evolved into a strategic process and was largely influenced by globalization (Scott, 2000). It was rooted on the economic rationale rather than on the political rationale. However, after the attack of $9 / 11$, the U.S. government set national security as a top priority, and the political rationale once again became 
one of the driving forces to encourage executive leaders, administrators, faculty, and students to work together to internationalize their institutions. In addition, student mobility increased rapidly in recent decades and their destinations focused more on non-European countries such as China, India, South Korean, and South America (IIE, 2007).

Definition of Internationalization of Higher Education

Internationalization of higher education is not a new term. It has been used for centuries in political science and governmental relations (Knight, 2003). It first appeared in conjunction with U.S. higher education at the end of the Cold War. Until in the 1990s, internationalization of higher education was commonly defined at the institutional level only in terms of a diversity of international education programs and activities, and it was interchangeable with the term international education. In the recent decade, along with the increasing influence of globalization, internationalization of higher education was redefined and applied in three levels: the educational level, the sector level, and the national level (Knight, 2003).

Terms frequently used in the study of the internationalization of U.S. higher education included international education, international studies, multicultural education, cross-cultural education, transnational education, global studies, global education, internationalization, and globalization. Each of these terms had a different emphasis in different areas for different constituencies and stakeholders (Kehm \& Teichler, 2007). Knight (2004) summarized as follows:

For some people, it means a series of international activities such as academic mobility for students and faculty; international linkages, partnerships, and projects; and new, international academic programs and research initiatives. For others, it means the delivery of education to other countries through new types of arrangements such as branch campuses or franchises using a variety of face-to-face and distance techniques. 
To many, it means the inclusion of an international, intercultural, and global dimension into curriculum and teaching learning process. Still others see international development projects, and alternatively, the increasing emphasis on trade in higher education as internationalization. (p. 6)

Most American researchers and professional practitioners tended to use the term international education as a synonym for the term internationalization of higher education; however, non-American researchers in Europe, Canada, and Australia focused more on internationalization of higher education instead of international education (de Wit, 1995, 1997, 2002; Knight, 2003). Because internationalization of higher education has increasingly gained support from researchers in the United States in the recent decade, clarification of the definition may open a new way of thinking (Arum and Van de Water, 1992; Green \& Olsen, 2003; Klasek, 1992).

Under the concept of international education, Harari $(1972,1977)$ was the first to give international education a comprehensive working definition:

International education is an all-inclusive term encompassing three major strands: (a) international content of the curricula, (b) international movement of scholars and students concerned with training and research, and (c) international arrangements engaging in educational abroad in technical assistance and educational cooperation programs. (p. 292) Further, Harari and Reiff (1993) identified 12 categories of international education programs and activities used by U.S. colleges and universities to internationalize their institutions: (1) the infusion of international content into mainstream course offerings; (2) comparative studies and interdisciplinary studies; (3) area studies; (4) international studies and intercultural studies; (5) international development studies; (6) the use of foreign languages as an 
integral part of internationalization of undergraduate education; (7) internationalization of professional schools; (8) faculty development and research in international areas; (9) international linkages and global networking of scholars; (10) involvement of international students and scholars to enrich the curriculum and the culture on campuses; (11) involvement of students studying abroad and faculty abroad for teaching, research, and services; and (12) establishment of a centralized administrative structure to coordinate international programs. Harari's (1977) classic definition clearly reflected the traditional view of American researchers and professional practitioners (Arum \& Van de Water, 1993; de Wit, 2002; Green \& Olsen, 2003; Siaya \& Hayward, 2003). It was strongly supported by American associations focusing on the administration and the practice in the international dimension of higher education, such as the Association of International Educators (formerly called NAFSA: National Association of Foreign Student Advisors), the Institute of International Education (IIE), the Association of International Education Administrators (AIEA), the Council for International Educational Exchange (CIEE), and the American Association of States Colleges and Universities (AASCU). One exception was the American Council on Education (ACE, 2008) which has been dedicated its efforts and resources to the research rather to the administration and practices in the field of internationalization of higher education.

In the mid-1990s, Knight $(1994,1999 a)$ introduced a process approach and viewed internationalization of higher education as "a process of integrating an international and intercultural dimension into teaching, research, and service functions of the institution" (p.7). She illustrated that internationalization of higher education should be considered as a process integrating the overall functions of higher education in teaching, research, and service. This 
distinguished definition was echoed by Callan (1993) and de Wit (1995) as a classic formulation of internationalization at the institutional level.

Following Knight's process approach, Schoorman (1999) defined internationalization of higher education as "an ongoing, counter-hegemonic educational process that occurs in an international context of knowledge and practice where society is viewed as subsystems of a larger, inclusive world" (p. 21). He further illustrated the two perspectives in the process of internationalization of higher education: micro perspective and macro perspective. The micro perspective featured three types of on-campus activities: university services, curriculum development (individual course, language courses, infusion, area studies, cross-cultural and international courses, and global studies), and social events (cultural activities and student involvement). The macro perspective of internationalization explored four types of international education programs and activities and their relationships, in terms of the presence of international students, study or teach abroad opportunities for U.S. students and faculty, student and faculty exchange programs, and engagement of international collaborative research (Schoorman, 2000).

Later on, internationalization of higher education was categorized by de Wit (2002) as five approaches including activity, rationale, competency, ethos, and process approaches at the institutional level (p. 117):

1. Activity Approach. It defined internationalization of higher education in terms of a variety of international education programs and activities at U.S. colleges and universities. The terms frequently used in the activity approach were international education, area studies, multicultural education, intercultural education, cross-cultural education, peace education, global education, development education, international 
studies, transnational studies, and global studies. Knight (1999a) and de Wit (2002)

concluded that under the activity approach, internationalization of higher education was used synonymously with international education in the United States.

2. Rationale Approach. This approach defined internationalization of higher education in terms of its purposes. For instance, American studies on rationales of internationalization of higher education were associated with their aspiration for peace and mutual understanding, as well as national security and international relations from the two World Wars to the Cold War. One of the recent studies of internationalization of higher education focused on recruitment of international students, particularly in United Kingdom and Australia. Terms frequently used under this approach were peace education, development education, and technical education (de Wit, 2002).

3. Ethos Approach. It focused on developing a culture and values dedicated to support international perspectives and initiatives of internationalization of higher education on campuses. Few studies were addressed by American scholars on this topic (Harari, 1989; Klasek, 1992).

4. Competency Approach. This approach defined internationalization of higher education in terms of developing new skills, attitudes, and knowledge for students, faculty, and staff. Studies focused more on improvement of intercultural competence of students and faculty, or international competence, career competence, and global competence (de Wit, 2002).

5. Process Approach. This approach addressed internationalization of higher education as a process that integrated an international perspective into the overall functions of 
higher education in teaching, research, and service (Knight, 1994, 1999a). It consisted of a wide range of academic programs and activities, institutional policies and strategies, national policies relating to internationalization of higher education, as well as its relationship with globalization. Under the process approach, internationalization of higher education became more comprehensive and meaningful. (Knight \& de Wit, 1995; de Wit, 2002; Knight, 2004)

Along with the increasing influence of global competition in societies, economy, and labor markets worldwide, Van der Wende (1994) pointed out that the concept of internationalization of higher education should be redefined and expanded into the education level, the sector level, and the national level in response to the challenge of globalization. The statement was strongly supported by Knight's new definition of internationalization of higher education with a generic application to many different countries, cultures, and educational systems worldwide (Knight, 2003, 2004).

Knight (2003) redefined internationalization of higher education as "the process of integrating an international, intercultural or global dimension into the purpose, functions or delivery of post-secondary education" (p. 2). She further stated that (1) the term process referred to internationalization as an ongoing and continuing effort; (2) the terms international, intercultural, and global dimension were intentionally used together to reflect the breadth and depth of components of internationalization. International was used to describe the relationships between and among nations, cultures, or countries; intercultural was used to address the issues of internationalization at home; and global was included to reflect a worldwide scope; and (3) integrating was specifically used to indicate that the process of internationalization should be 
embedded into policies and programs, and it should remain central and sustainable (Knight, 2004, p. 11).

Recently, the American Council on Education (ACE) officially accepted internationalization of higher education instead of international education as an umbrella term in its series of national studies of the status of internationalization at U.S. colleges and universities (Hayward, 2000; Green \& Olsen, 2003; Green, 2005; Siaya \& Hayward, 2003). The ACE (2008) concluded that although the term international education had a long history in the United States, the use of international education would make the process of internationalization of higher education marginalized and poorly integrated into the institution's priorities regarding the mission statement, the strategic plan, policies, and the administrative structure. Using internationalization of higher education defined by Knight (1999a) would illustrate broad, deep, and integrative international educational practices at U.S. colleges and universities.

In summary, this study addressed internationalization of higher education and study abroad programs at U.S. research universities. Internationalization of higher education and international education were considered as interchangeable terms under de Wit's (2002) activity approach. It functioned as an umbrella term consisting of a variety of curricular and extracurricular programs and activities, as well as institutional initiatives regarding internationalization of colleges and universities.

Within the curricular level, internationalization of higher education referred to foreign language studies, area studies, student and faculty study or work abroad (study abroad for credit, internship abroad, and service learning abroad), and internationally focused courses (majors and minors) for undergraduate students. 
Within the extracurricular level, internationalization of higher education included a diversity of programs and activities involving U.S. undergraduate students with international students and scholars for mutual understanding and language learning, such as international festivals or fairs, international centers, international residence hall programs, buddy programs, and language partner programs.

Within the institutional level, internationalization of higher education referred to institutional commitment to international education such as (1) specifying international education in the mission statement; (2) listing international education as one of the top five strategies in the strategic plan; (3) establishing a committee and a centralized Office of International Programs to coordinate international programs; (4) allocating resources to support international education programs and activities across a campus; and (5) specifying a policy statement to consider international work and experience as part of faculty promotion and tenure evaluation policy. Organizational Leadership of International Programs

By the end of the 1980s, in responding to the internationalization of higher education, four major patterns of organizational leadership for international programs emerged at U.S. colleges and universities (Merkx, 2003). At some institutions, primarily liberal arts colleges, internationalization of higher education became synonymous with study abroad programs because it was driven by students' interests for overseas experience. As a result, the official in charge of these programs became the chief international education administrator (Freeman, 1966).

The second pattern included some state universities and colleges with relatively low tuition. For these institutions, enrollments of undergraduate international students became very important motivation because the funding of the formula supported by state government was 
based on numbers of student enrollment (Lambert, 1989a, 1989b, 1993). The goals for recruitment of more international students were diverse. For some institutions, increasing student enrollment was a way for institutions to survive; for others, the primary purpose was to increase the diversity of student body. At these institutions, providing academic advising and services, such as visa issues for international students, became the chief responsibility of these institutions, and the head of these offices became international education administrators.

The third pattern emerged at land-grant institutions with strong agriculture and engineering schools, and the driving factor came from federal funding for support of international agricultural extension and development programs through Title XII of the Foreign Assistance Act of 1961 (e.g., technical assistance and development assistance). Internationalization of higher education at these universities was driven by faculty members and the official in charge of these development projects was often appointed as the chief international education administrator (Smuckler, 2003).

The fourth pattern appeared in some universities where internationalization of higher education was driven by faculty interests in international relation studies, foreign area studies, and foreign language studies that were expanded rapidly after the passage of the National Defense Education Act (NDEA) of 1958. Through the NDEA, the federal government provided substantial financial resources for studying, teaching, and conducting research on international and foreign area studies. Such international programs tended to be on an interdisciplinary basis, and later were integrated into the overall mission of the institution in terms of teaching, research, and service (Davies, 1992; Holzner \& Harmon, 1998). The chief international administrator at these institutions came from the directors of the centers of international and foreign area studies. 
Harari (1981) described an ideal leadership role of an executive who directed the Office of International Programs at U.S. colleges and universities:

[the OIP director] should report directly to the Vice President for academic affairs and not to a specific school, department, or business office. The title of the individual in charge varies somewhat but Director of International Programs or International Studies is also quite common. The title of Dean for International Programs is also used. The office should be staffed by at least one director and one full-time secretary or administrative assistant. Other staff can be added as its operational responsibilities, contracts, and grants warrant it. (p. 39)

In summary, historically, a diversity of administrative leadership roles and different perspectives and understanding of internationalization of higher education developed different organizational patterns to deal with international education programs and activities on campuses. At colleges and universities, at least one or more types of international programs and activities existed simultaneously; at most major research universities, all four types of international education programs and activities have been initiated (Merkx, 2003).

\section{Coordinative Styles for International Programs.}

With respect to the nature of international education programs and activities that required campus-wide coordination, as well as the nature of decentralization of U.S. colleges and universities in which the autonomy has been the top priority for faculty, there has been a tendency to establish a centralized administrative structure for coordination of international programs, rather than a decentralized administrative structure. It is asserted that a degree of centralization of international education programs was a symbol of an institutional commitment to the internationalization (Harari, 1981) and the centralized coordination pattern would reinforce 
the cooperation among each unit and division and make international programs become key issues to the central administration in terms of priority and policy related to international education (Burn, 1980, 1996).

Historically, two kinds of coordinative styles were existed to deal with development, coordination, and implementation of international programs at U.S. colleges and universities: the Harvard model (decentralized style) and the Yale model (centralized style) (Edwards, 2007).

The Harvard model was a typical decentralized coordination of international programs. The purpose was to "let one hundred flowers bloom," a Chinese saying meant using different approaches to develop a variety of international education programs and activities in each of schools and departments. This approach composed a series of efforts from faculty members for internationalization of the overall functions in teaching, research, and service. Originally, responses came from some faculty members who either led a group of students studying broad, or attended international conferences, or recruited international students for their programs, or invited international visiting scholars to join their research projects. This approach required all constituencies and units within Harvard (e.g., every school, division, and department, individual faculty members, and students groups) to develop their own initiatives to internationalize Harvard (Edwards, 2007, p. 4). Because it was initiated by the individual faculty member, it was easier to establish international education programs and activities with direct links to curriculum, instruction, and research.

With respect to the high degree of decentralization and autonomy of faculty members and the variety of divisions at Harvard, the decentralized coordinative pattern of international education programs and activities became very frustrating. Edwards (2007) summarized several disadvantages of this administrative pattern: (1) because internationalization of higher education 
was initiated without any coherent planning from the central administration, programs were fragmented and required consideration of human resources and financial resources to work effectively; (2) there was a great deal of duplication of international education programs and activities among different schools and departments; (3) the international partnerships were developed locally at the division level, not at the institution level; (4) it lacked coherence and connections among these international education programs and activities; and (5) it caused confusion for the international partners who puzzled over which part of the university should represent the overall institution when negotiating collaborative contracts with foreign institutions.

Conversely, Yale established a centralized coordination style with a coherent planning process and a highly centralized administrative structure. International programs at Yale established a campus-wide planning process to build a strategic plan. The initiative was also driven by individual faculty willingness and engagement in international education, but the decision-making process came from the top administration down to each division and school, individual faculty members, and students. Thus, initiatives of internationalization were strongly supported by the executive leaders and other senior administrators from the central administration.

Edwards (2007) commented that (1) the Yale style validly built an institutional plan of internationalization to respond to the market factors pressured by global competition, and (2) it focused mainly on institution-wide collective efforts to move forward the agenda of internationalization of the whole institution, rather than efforts from local divisions. One disadvantage of this approach was that all initiatives were based on the institutional goals, rather than the strengths of individual faculty members. For instance, institutional partnerships were designed based on the goals of institutional development, not on disciplinary basis of unit needs 
and individual interests. Therefore, it required senior administrators to know very well the nature of overall institutional functions and to become sensitive to the needs of individual faculty members and different divisions.

In the past decade, the institutional efforts to establish OIPs to coordinate international programs have become popular at U.S. liberal arts colleges and research universities. Studies on internationalization of higher education also stressed the need to establish a centralized administrative structure with a locus of responsibility and leadership to coordinate international programs across campuses (Harari, 1989; Lambert, 1990; Leinwand, 1983). As Harari stated:

[i]t is clear that the institution needs to have a locus of responsibility and leadership for its international activities. It ranges all the way from a very small institution where the President or the Dean might wish to play personally that role with the part-time or fulltime assistance of a faculty or staff members, all the way to a large institution with its panoply of international services and contracts and its larger staff. In all cases, however, the commitment, tangible and otherwise, of the top leadership will play a critical role in promoting the desired institutional change. (p. 6)

Currently, the names of the offices dealing with international education programs and activities vary at U.S. colleges and universities. Generally, the Office of International Programs functions as a flagship unit to accomplish the institutional goals of the internationalization through development, administration, coordination, and implementation of international education programs and activities on and off campus. The Office of International Programs usually serves as an umbrella term representing a diversity of names used by U.S. research universities to coordinate international education programs and activities across campuses; other 
names include the Office of International Education, the Center for International Studies, the Office of Oversea Programs, the Office of Study Abroad, and so forth.

At U.S. research universities, the OIP usually includes two units dealing with two aspects of international education programs and activities: importing international students to U.S. campus and exporting U.S. students to study abroad in other countries because study abroad and the presence of international students have frequently been seen as two sides of a coin and were operated under the same administrative unit to support one another (Nelson, 1995).

In addition, several subunits are under the OIP's supervision, such as the Office of Study Abroad (OSA), the Office of International Students and Scholars (OISS), the Language Institute (e.g., Intensive English Programs, or English as Second Language Programs), Office of Fulbright Programs, Office of International Cooperative Programs (OICP), and so forth. However, the most popular administrative pattern includes only two subunits - the Office of Study Abroad (OSA) and the Office of International Students and Scholars (OISS) (see Figure 2.1).

Harari (1983) defined the scope of authority and its typical responsibility of the centralized OIPs presenting at U.S. colleges and universities:

1. to support institutional efforts on internationalization of the curriculum;

2. to act as a liaison to other units within the institution to administer and coordinate international education programs and activities;

3. to administer and coordinate study abroad and exchange programs;

4. to provide services for international students;

5. to promote student, faculty, and staff engaging in international education exchanges programs and activities; 
6. to negotiate and implement contracts and grants with colleges and universities in other countries, governments, and business;

7. to cooperate with international interests in the community, including citizenshipeducation programs and business activities;

8. to support regional, national, and international associations and consortia; and

9. to prepare proposals to foreign agencies, foundations, businesses, and other entities to help implementation of the institution's international commitment; and to integrate national and international trends and opportunities and providing leadership for the institution. (p. 40) 
Figure 2.1 The Centralized Administrative Structure of International Programs

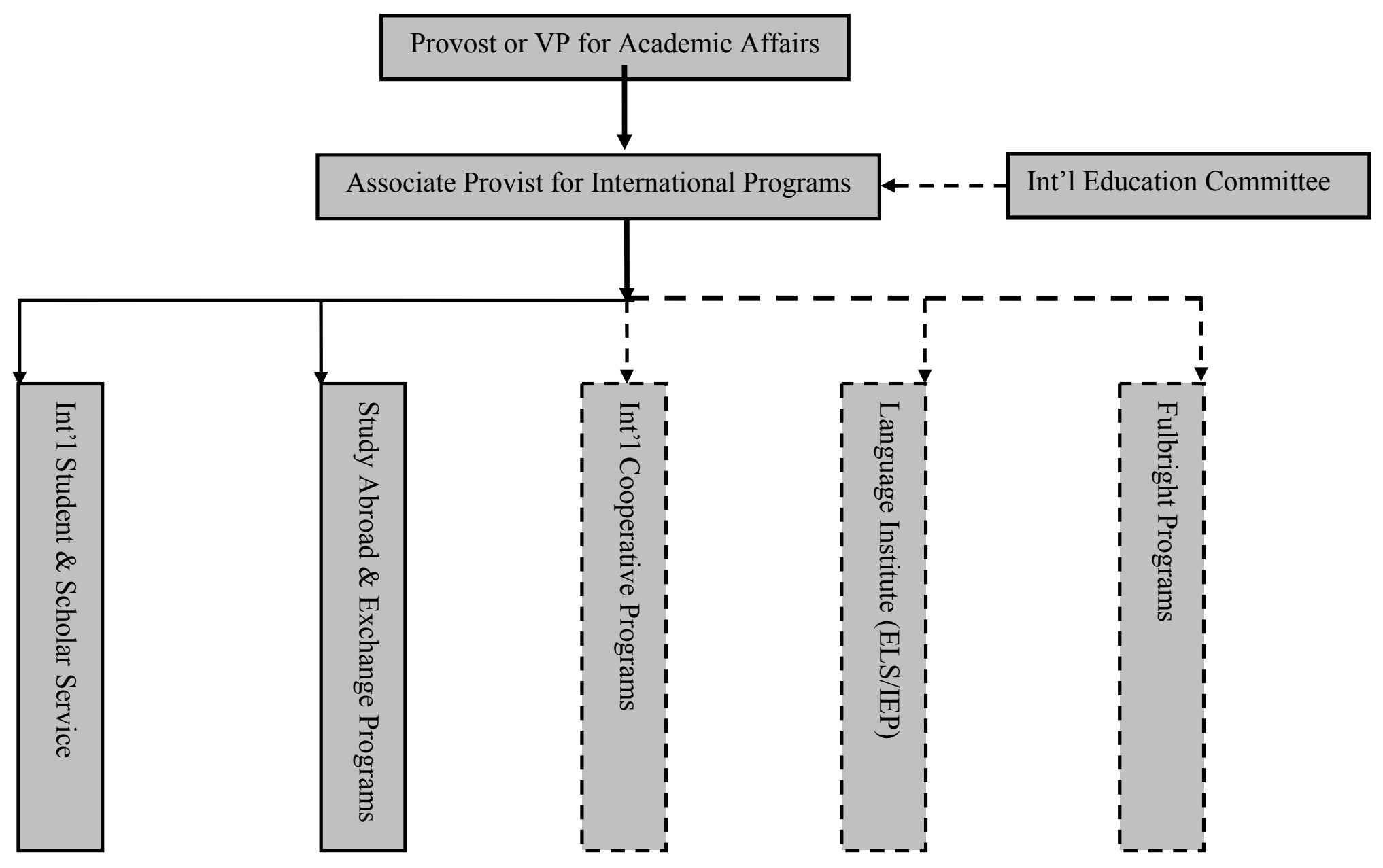


Harari's study was further supported by Wang's (1992) study that identified seven major international education programs and activities under the supervision of the OIPs at U.S. landgrant universities: (1) study abroad; (2) international students and scholars service; (3) faculty abroad; (4) international collaboration/linkages; (5) development assistance; (6) internationalization of curriculum; and (7) host international dignities. These international programs in the different divisions across campus caused conflict and competition of scarce resources.

In summary, before the 1980s, international education programs (e.g., foreign language studies, area studies, the presence of international students and scholars on campus, and study abroad and exchange programs) were well developed but isolated with each other in administration and operation at most research universities (Holzher \& Harmon, 1998; Kelleher, 1996; Tonkin \& Edwards, 1981, 1990). Since the middle of the 1990s, many administrative leaders at U.S. colleges and universities viewed internationalization of higher education as a comprehensive, systematic, and dynamic process, and began to set up a centralized structure under the leadership of the OIP to develop, administer, coordinate, and implement a variety of international education programs and activities across all divisions, schools, and units. Studies of Centralized Offices of International Programs

It was assumed that internationalization of an institution would benefit from the presence of an Office of International Programs which was properly staffed to provide a locus of information, coordination, leadership, and initiative for international education programs and activities to serve the needs of students and faculty (Leinwand, 1983).

Historically, many of the Offices of International Programs at U.S. colleges and universities were set up to respond to the passage of the International Education Act of 1966. 
Since then, the number of OIPs increased from 12 in 1964 to 186 in 1969 and an estimated 832 in 1974 (Smuckler, 2003). Among them, a centralized coordination style was not main stream.

A 1977 survey conducted by the Committee for International Studies and Programs Administrators (CISPA) indicated that of 336 responding institutions, only 29 (or $8.6 \%$ ) institutions had a campus-wide coordinative pattern for international education programs and activities; in addition, some OIPs were established under the division of academic affairs, and others were under the division of student affairs (Burn, 1980), and executives in these OIPs rarely had the chance to directly access the central administration- the power center of the university (Smuckler, 2003).

In the 1980s, two surveys conducted by Harari (1981) and Andersen (1988) showed slow progress toward the centralized administrative style of coordination of international education programs and activities. In Harari's (1981) survey, more than 50 percent of sampled institutions had an Office of International Programs to work solely on improvement of the status of internationalization (p. 5). Andersen's (1988) study further proved Harari's finding, stating that 30 percent of four-year colleges and universities had the OIP to coordinate international education programs and activities including study abroad, international student service, institutional linkages abroad, foreign language instruction, and general international curriculum on campuses (p. 7). Among these four-year institutions, 70 percent of the OIP administrators worked on a part-time basis.

Leinwand (1983) also found a need to establish a centralized administrative structure to coordinate international education programs and activities on campus to represent the responsibility of all constituencies in the institution. A properly staffed Offices of International Programs would provide a basis of information, services, coordination, leadership, and initiative 
to internationalize the institution. He further called upon senior administrators to enhance institutional commitments to international education through diverting institutional priority to internationalization and allocating additional resources to support the coordination of international programs.

Lambert (1989a, 1990) further suggested that it was necessary to establish centralized Offices of International Programs that were firmly located under academic affairs of the educational mainstream of the institution, rather than the division of student affairs.

Institutional efforts to pursue a centralized administrative structure for coordination of the international education programs and activities have increased since the 1990s at U.S. liberal arts colleges and research universities. Holzner and Harmon (1998) summarized the major results of this trend as the following:

the pursuit of centrally coordinated, integrative strategies (of international education) ... often involve the creation of a chief international education officer (with titles ranging from vice president for international affairs to vice provosts or deans or directors) with the mission to assist faculty, students, and administrators to create synergistic networks of cooperation and resource sharing for international work around existing centers of strength. (p. 42)

Increasingly, the trend to establish a campus-wide centralized OIP under academic affairs to coordinate international programs became a major theme and the top priority at U.S. colleges and universities. However, there were few studies drawing a clear picture of coordinative patterns of international programs.

A study conducted by G. Wang (1992) about the internationalization of curriculum at land-grant colleges and universities revealed that fifty-five (or $82 \%$ ) of the sampled land-grant 
institutions had centralized Offices of International Programs to coordinate campus-wide international education programs and activities. Among these sampled institutions, twenty-four OIPs had at least two subunits under their supervision, Offices of International Students and Scholars and Offices of Study Abroad Programs were the most common subunits under the authority of the centralized OIPs (p. 113).

Nelson (1995) studied the administrative patterns of study abroad programs at U.S. colleges and universities. The findings exhibited that, of the 346 responding institutions, nearly 70 percent of OIPs were established under the division of academic affairs. In addition, an average of 20 percent (or 70 out of 346) of sampled institutions reported they had OIPs with a centralized administrative structure to coordinate international programs; among these centralized Offices of International Programs, 51.42 percent were located in large public institutions. The study also indicated that over 90 percent of executive directors of OIPs strongly supported establishing a centralized administrative structure to coordinate international education programs and activities (pp. 110-150).

Recently, the ACE conducted a series of surveys to measure the status of internationalization of U.S. higher education institutions including (1) a survey of 752 colleges and universities, (2) a survey of 1,027 faculty members who taught undergraduate students in the sampled institutions, and (3) a survey of 1,290 undergraduate students in the sampled institutions.

In the final report, Siaya and Hayward (2003) pictured the reality of administrative structures of international education at U.S. colleges and universities. The report showed that on average, 76 percent of colleges and universities had at least a single office and/or multiple offices to administer international education programs on campuses, with research universities at the highest percentage (97\%), followed by comprehensive universities (92\%), liberal arts colleges 
$(83 \%)$, and community colleges $(61 \%)$ at the lowest percentage; however, still an average of 23 percent of sampled institutions had no office at all to work on international education on campuses (p. 104). At research universities, 48 percent had a single office dedicated to study abroad programs and 49 percent of research institutions had multiple offices to deal with international programs on campus (p. 65).

In addition, an average of 51 percent of sampled institutions hired full-time staff for OIPs to deal with routine administrative work, with research universities ranked in the highest percentage $(90 \%)$, followed by comprehensive universities $(65 \%)$, liberal arts colleges $(42 \%)$, and community colleges (32\%) as the least percentage (p. 105). At research universities, 90 percent hired full-time non-student staff and 55 percent had an executive to direct the Office of International Programs. However, no detailed information indicated whether these OIPs administered international education programs and activities through the campus-wide, centralized coordination pattern or through the decentralized coordination pattern. Thus, there was an increasing need to study not only the overall efforts of internationalization, but also the process of internationalization in terms of comprehensive, multifaceted, interrelated strategies of international programs and activities at U.S. colleges and universities.

In summary, studies found that the trend of establishment of centralized Offices of International Programs and hiring full time professional practitioners to administer and coordinate campus-wide international education programs and activities became a main pattern at research universities. The role of a centralized OIP was viewed as a flagship unit, collecting campus-wide efforts from a variety of constituents and different divisions leading institutions to fulfill its mission and goals. The centralized administrative pattern made it easier for the 
institution to allocate resources to support international programs and benefit the overall functions in teaching, research, and service.

\section{Indicators of Assessing Internationalization of Higher Education}

Studies that measured institutional efforts on comprehensive internationalization of U.S. colleges and universities were rare; moreover, most of these studies focused on internationalization of curriculum or the analysis of international programs and activities. Very few drew a comprehensive picture of the process of internationalization of higher education at colleges and universities in the United States. Thus, there was a need for conceptualization of the

process of internationalization as "a multifaceted package," instead of separated strands (de Wit, 2002, p. 36).

According to the review of related literature, in practice, indicators used to assess the institutional efforts for comprehensive internationalization of higher education in the United States were summarized into eight categories (see Table 2.1):

1. Institutional commitment to internationalization of higher education. This category included four parts: (1) establishing the institutional commitments of international education in the mission statement; (2) listing the international education as one of the top-five priorities in the strategic plan; (3) establishing a campus-wide committee or task force solely working for the international education; and (4) establishing a policy statement that faculty participation in international education programs and work experience related to international education were considered as part of the promotion and the tenure evaluation.

2. Institution's financial commitment to internationalization of higher education. It assessed the institution's input of human resources and financial resources to the 
study abroad programs. It represented the total dollar amount of financial resources allocated from central funding to the OIP; through the OIP's efforts of development and coordination of international education programs, the institution could produce more students with global experience.

3. Establishment of a centralized OIP to administer and coordinate international education programs and activities across campus. This category generally included: (1) the hierarchical location of the OIP (e.g., to whom the OIP executive reports) and (2) the number of professional staff and support staff employed by the OIP.

4. Internationalization of the undergraduate curriculum. This section referred to: (1) increasing student enrollment in foreign language studies, (2) offering more internationally focused courses and/or requiring more internationally focused courses for graduation, (3) internationalizing curricular contents, and (4) establishing academic majors and/or minors related to international education.

5. Undergraduate students studying abroad. Generally speaking, increasing the number of undergraduate students studying abroad was considered as one of the main ways to internationalize institutions. Study abroad programs included (1) study abroad for credit (e.g., exchange programs, faculty-led programs, and attending study abroad programs through outside agencies), (2) internships abroad, (3) service learning abroad (e.g., Peace Corps), and (4) attending international conferences/meetings in foreign countries.

6. The presence of international students on campuses. This category included (1) increasing the enrollment of international undergraduate students; (2) providing services and consultation to international students and scholars (e.g., visa and 
immigrant issues); and (3) establishing extracurricular programs and activities for enhancing mutual understanding between U.S. students and international students (e.g., international festivals, language partner programs, buddy programs, international residence hall programs).

7. Faculty abroad for teaching, research, and service (Fulbright Programs for teaching and conducting research overseas, technical assistance and development programs, attending international conferences in foreign countries).

8. Building international partnerships with institutions in other countries.

Table 2.1 below provides a summary of the indicators used to assess institutional efforts for internationalization of higher education. 
Table 2.1

Indicators of Assessing Internationalization of Higher Education

1. Institutional General Commitment to Internationalization

a. Establish international education in the mission statement;

b. List int'l education as one of the top-five priorities in the strategic plan;

c. Establish a campus-wide committee or task force for int'l education; and

d. Establish a policy statement related to faculty promotion and tenure evaluation.

2. Institution's Financial Commitment to Internationalization
a. Funds to support campus-wide international programs and activities;
b. Scholarships to support int'l students;
c. Scholarships to support U.S. students studying abroad; and
d. Incentives to support faculty abroad in teaching, research, and service.

3. Establishment of a Centralized Administrative Structure to Coordinate Int'1 Programs
a. Hierarchical location of the OIP;
b. Number of professional staff and support staff employed by the OIP; and
c. The dollar amount of the annual budget allocated from the central funds to the OIP.

4. Internationalization of Undergraduate Curriculum
a. Provide more foreign language studies for undergraduates;
b. Offer more internationally focused courses;
c. Require more internationally focused courses for graduation; and
d. Internationalize curricular contents.

5. Study and Work Abroad
a. Study abroad for credit;
b. Internships abroad;
c. Service learning abroad; and
d. Attend international conferences in foreign countries.

6. The Presence of International Students on Campuses
a. Increase recruitment of international undergraduate students;
b. Provide services and consultant to international students and scholars (e.g., visa and immigrant issues); and
c. Establish extracurricular programs and activities for enhancing mutual understanding between U.S. students and international students.

7. Faculty Abroad
a. Fulbright Programs for teaching and conducting research overseas;
b. Technical assistance and development programs; and
c. Attend international conferences in foreign countries.

8. International Partnerships 
Most of the previous studies focused on assessing international education programs and activities; few studies considered internationalization as an integrated process to fulfill the institutional mission and goals and help students gain intercultural/international competence.

Harari $(1981,1983)$ was the first to measure the status of internationalization of higher education as a multifaceted concept. Under the support of the AASCU, a comprehensive survey was undertaken to solicit information about the institutional efforts on internationalization of U.S. state colleges and universities. A total of 26 institutions (or 77.19\%) of AASCU members participated in the study. Seven predictor variables were identified to measure the institutional efforts on internationalization:

1. The institutional commitment to the international education including the institution's physical location, the existence of a university-wide committee and the centralized office, the annual operating budget from the central administration to the OIPs, and the number of external grants and contracts sought and the success rate;

2. The internationalization of the curriculum;

3. Study abroad programs;

4. The presence of international students;

5. Faculty abroad;

6. English as a second language program; and

7. International development assistance programs in developing countries.

Colleges and universities with high levels of effort to internationalize their institutions scored higher in the selected variables, and more importantly, had an Office of International Programs to coordinate international programs and activities across campuses. Those predictor variables identified by Harari (1983) were also supported by Backman's (1984) study. Indicators 
used by Backman's (1984) study included (1) internationalizing the curriculum, (2) the presence of international students, (3) student exchange programs, (4) study abroad and exchange, (5) faculty exchanges, (6) faculty training and development in international dimension, (7) English as a second language, (8) campus-based international education programs and activities, and (9) international outreach activities and development assistance projects.

Harari's (1983) study was considered more as a descriptive analysis rather than a statistical measurement. Moreover, this study used the annual operating budget of an institution to measure the institutional commitment to internationalization, rather than using the operating budget allocated from the central administration to the OIP and/or study abroad programs just because they were easily accessible. Further, Nelson (1995) used the annual operating budget allocated from the central funds to the OIP to measure the relationship between the institutional financial input and the success of study abroad programs and it indicated that nearly 70 percent of the operating budget of overall study abroad offices came from central funds of an institution (p. 133).

Harari (1983) called for further study and analysis of internationalization of higher education based on variables of institution's human resources and financial resources allocated to international education programs and activities and how these variables strengthened the international programs on campus. He encouraged researchers and professional practitioners to consider the process of internationalization as a mutual reinforcement package, rather than a fragmented or isolated approach, which has dominated the research and practices in the field of international education at U.S. colleges and universities.

Another study was conducted by Henson et al. (1990) with a combination of quantitative and qualitative analysis to assess the state of internationalization at U.S. colleges and universities. 
Data were collected through questionnaires and individual interviews with 237 administrators on 10 campuses, as well as through consulting experts in the field of international education. Additionally, 10 case studies were conducted to confirm the results of the survey.

In this study, independent research variables included (1) institutional resources allocated to support international programs, (2) international education programs and activities, (3) leadership role and management, (4) organizational structure, and (5) external environments. The findings showed that (1) the institution with a high level of internationalization exhibited well established international education programs with support from faculty and administrators, both internally and externally; (2) its curriculum was infused with internationally focused perspectives, and funds and incentives were available to encourage faculty for internationalization of curriculum; and (3) institutional commitment and leadership roles for enhancing international education were evident, and the centralized coordination of the international education programs facilitated the planning and decision-making process. As a result, the correlations of the variables were measured by the chi square statistical test at a significant level of $p<.10$. The authors did not explain the criteria used for the selection of variables nor the sampling rationale for selecting sampled institutions; therefore, it was impossible to repeat the study (Childress, 2007).

The third attempt to measure institutional efforts on internationalization at research universities was conducted by Afonso (1990), who identified seven broad categories with 14 predictor variables to assess the status of internationalization at U.S. research universities. These variables were summarized as follows:

1. Foreign language studies. It referred to (1) the number of foreign languages offered at an institution; (2) the number of graduate and undergraduate students enrolled in foreign language classes; (3) the number of undergraduate degrees in foreign 
languages conferred; and (4) the number of graduate degrees in foreign languages conferred.

2. Internationally focused curriculum, referring to the undergraduate curriculum with internationally oriented perspectives.

3. Study abroad programs, referring to the number of undergraduate students receiving academic credit for study abroad.

4. The presence of international students, including the total enrollment of graduate and undergraduate international students and the number of members of NAFSA.

5. Faculty abroad for teaching and research sponsored by the Fulbright Program.

6. Institutional development assistance.

7. Grants for advanced training and research funded by Title VI and the National Science Foundation (NSF). (pp. 35-42)

Afonso's (1990) study was the first attempt to use systematical analysis to measure the status of internationalization of higher education as a multifaceted and complex phenomenon at U.S. research universities. It provided a model of defining research variables to measure the institutional efforts on internationalization through study abroad programs coordinated by the centralized OIP.

Later on, Krane (1994) repeated Afonso's (1990) study at liberal arts colleges in the United States. Sampled institutions were divided by five categories in terms of their size, geographic location, student diversity, and financial resources (e.g., revenues and expenditures for per FTE student) that served as dependent variables, and additional 11 variables detailed as follows were selected as predictor variables to access the institutional status of internationalization: 
1. International curriculum of foreign language studies and international studies. It referred to (1) the number of foreign languages offered; (2) the total student enrollment in foreign language studies; (3) the number of undergraduate degrees granted in foreign language studies; and (4) the number of undergraduate degrees awarded in area/ethnic studies and in international relations.

2. Study abroad. It included the number of degree-seeking, full-time-equivalent students abroad for credits.

3. International students. It consisted of the total number of international graduate and undergraduate students enrolled in each institution.

4. International movement of faculty. It addressed (1) the number of U.S. faculty who taught or conducted research abroad through Fulbright Programs and (2) the number of international visiting scholars who lectured, or pursued research under the support of Fulbright Programs at U.S. institutions.

5. International education expertise or professional practitioners. This variable referred to the number of persons who held membership in the Association of International Educators (NAFSA) and the Institute of International Education (IIE) at each institution. (pp. 45-59)

Of the 11 indicators related to international education, 27 pairs of variables were significant associated at the $\alpha$-level of .05. These correlation coefficients were further used to conduct factor analysis. The higher the factor score an institution had, the higher status of the institution for internationalization.

Predictor variables with significant correlation coefficients included (1) the number of foreign languages offered (.84); (2) the number of undergraduate degrees awarded in area studies 
(.75); (3) the number of undergraduate degrees awarded in foreign languages (.65); (4) the number of foreign language enrollments (.64); (5) the number of students studying abroad for credit (.60); (6) the number of the members in the NAFSA (.43); (7) the number of visiting Fulbright international scholars (.40); (8) the number of the members in the IIE (.40); (9) the number of undergraduate degrees awarded in international relations (.37); (10) the number of international students enrolled (.35); and (11) the number of U.S. Fulbright scholars at an institution (.34).

In Krane's (1994) study, a new predictor variable used was the variable of educational and general (E \& G) expenditure per FTE student, rather than using Harari's operating budget for measuring the institutional status for international education. Krane (1994) argued that the indicator of E \& G expenditures per FTE student (the total dollar amount of budget used in the general education programs) was a better way to measure the strength of institutional input of financial resources to the study abroad programs to strengthen the outcomes of internationalization of higher education.

In summary, predictor variables or indicators used in these two studies conducted by Afonso (1990) and Krane (1994) mainly focused on measuring the output of internationalization of higher education rather than on assessing the overall process of institutional efforts on internationalization of higher education.

Nelson (1995) studied the relationship between the organizational structure and the success of study abroad programs at U.S. colleges and universities. Members of NAFSA: Association of International Education affiliated with the Section on U.S. Students Studying Abroad (SECUSSA) were surveyed by questionnaires, and 52.6 percent (or 348) of the institutions responded. The indicators used in the study included (1) the hierarchical location of 
the study abroad office (academic affairs or student affairs); (2) the presence of a centralized structure of administration and coordination of study abroad programs; (3) the number of study abroad programs; (4) the number of students studying abroad; (5) the faculty status of the director of the study abroad programs; (6) academic qualifications of the director of the study abroad office; (7) the length of time an office of study abroad had been established; and (8) the percentage of the operation budget (excluding salaries and benefits) allocated from central funds to support the study abroad office.

Finally, the 2 x 2 chi-square analysis was conducted to assess the relationships among these variables with the success of study abroad operations. Significant predictors included (1) the location of the study abroad office within academic affairs; (2) length of time an institution had established study abroad programs; and (3) use of sources other than central funds to support the study abroad programs, such as fees generated from students for study abroad service (Nelson, 1995).

With respect to using the annual operating budget to measure the success of study abroad programs, this study found that the study abroad office generally had a small amount of the operating budget to manage the study abroad programs at level 2 institutions; among them, 50.89 percent of private institutions had an annual operating budget less than $\$ 5,000$, and 38 percent of public institutions fell into this category. In addition, for large level 1 institutions, an average of 69 percent of the annual operating budget was supported by central funds; moreover, 38.9 percent of private institutions and 29.7 percent of public institutions had an annual operating budget more than $\$ 50,000$ to manage a study abroad office (Nelson, 1995).

Recently, a series of studies sponsored by the American Council on Education was viewed as new attempts to measure the overall status of institutional efforts on 
internationalization of American colleges and universities including community colleges, liberal arts colleges, comprehensive universities, and research universities. These studies considered internationalization of higher education as a transformational process, rather than as isolated programs and fragmented activities. Studies of Hayward (2000), Green and Olsen (2003), and Siaya and Hayward (2003) have mapped the landscape of institutional efforts of internationalization through measuring the following multifaceted indicators:

1. Institutional general commitment to internationalization such as (1) including international education in an institution's mission statement; (2) selecting internationalization as one of the top five priorities in an institutional strategic plan; (3) establishing a campus-wide committee or task force to work solely for international education; (4) assessing the progress of internationalization efforts in the past five years; and (5) having a policy statement in which international work could be considered for faculty promotion and tenure evaluation.

2. Institutional financial commitment to internationalization by (1) providing funds to support international programs and activities; (2) providing funds to support recruitment of international undergraduate students or providing scholarships for international undergraduate students; (3) providing scholarships for undergraduate students to participate in study and work abroad programs; (4) providing funds through grants and contracts for faculty involved in studying, teaching, and conducting research abroad; (5) providing funds for students and faculty to travel abroad or participate in international conferences and meetings; and (6) providing funds to support on-campus international activities with goals of promoting mutual understanding between international students and American students. 
3. Academic study abroad including the number of U.S. undergraduate students who study abroad, take international internships, field study, and service learning, as well as the number of these study abroad programs.

4. Internationally oriented extracurricular activities including a wide variety of extracurricular programs on campus to provide undergraduate students with opportunities to enhance their international knowledge and understanding of foreign cultures. These programs included an international center for students to discuss international issues; buddy programs; language partner programs; international festivals and events; and international resident hall that paired U.S. undergraduates and international students. (pp. 17-28)

Most of the indicators used in these studies (Hayward, 2000; Green \& Olsen, 2003; Siaya \& Hayward, 2003) emphasized the institutional efforts on internationalization of colleges and universities. The new indicators used in these studies were (1) institutional commitment to internationalization in terms of the mission statements, the strategic plan, and the policy statements related to international education; (2) financial support for international students enrolled in U.S. colleges and/or for U.S. undergraduate students studying abroad; and (3) students' participation in extracurricular activities with international focused orientations on campuses.

These studies initially viewed internationalization as a changing process of overall functions in teaching, research, and service, and provided a complete picture of the state of internationalization at U.S. colleges and universities. However, there was no further attempt to assess whether significant relationships existed among these predictors and the state of internationalization of an institution; for instance, it did not measure whether there were 
significant relationships existing among the institutional commitments to internationalization, international programs and activities coordinated by the OIP, and the outcomes of these programs.

In summary, indicators used in studies of the status of internationalization at U.S. colleges and universities were varied. These variables could be categorized into five sections: (1) institutional commitments to international programs through allocation of human resources and financial resources to support study abroad programs; (2) hierarchical location of the OIP in terms of the OIP director reporting line and the OIP's location within academic affairs; (3) the international programs and activities coordinated by the centralized OIP; (4) students and faculty abroad; and (5) the presence of international students. The study of institutional input, process, and output through the lens of study abroad programs would provide alternative ways of assessing the overall state of institutional efforts on internationalization of higher education. Conceptual Framework of Social Systems Theory

Administrators at American colleges and universities have found increasing difficulties in understanding behavioral problems within the higher education institutions during the past decades (Andes, 1970). Since the end of 1980s, the social system theory has provided a comprehensive framework to study educational organizations. When an educational organization was investigated, the institutional variables, such as psychological, historical, economic, and sociological variables and their relationships could be analyzed and measured to provide a comprehensive framework to guide the practice (Hanson, 1972, Hanson \& Meyerson, 1995). American colleges and universities are complex and dynamic organizations with decentralized structures, but they are also considered as open systems with social interactions (Andes, 1970; 
Parsons, 1965); therefore, the social systems concept may provide a theoretical framework to guide this study.

Historical perspective of social systems theory. The word "system" came from the ancient Greek, synistanai, meaning "to put together" (Carr, 1955). A system was an organized whole comprised of a set of interdependent elements. When the systems were composed of human beings with two or more actors interacting, they were called social systems (Parsons, 1951). Getzel, Liphman, and Campbell (1968) gave a detailed explanation of the concept of the social system:

[a] social system consists in a plurality of individual actors interacting with each other in a situation which has at least a physical or environmental aspect, actors who are motivated in terms of a tendency to the optimization of gratification and whose relation to their situations, including each other, is defined and mediated in terms of a system of culturally structured and shared symbols. (p.55)

The system concept had a rich history in physical science as well as in the social sciences. The concept of general system theory was first formulated by Ludwig Von Bertalanffy (19011972) in the 1930s. After World War II, a variety of theoretical systems models were introduced in the United States. Early concepts of systems theories were influenced by the closed system theory in which behavior in formal organization was explained almost exclusively inside of the organization. Theoretically, a system was closed if it was sealed off from its environment by its boundaries and there were no interactions between the system and its environment; therefore, the outside forces had no impact on internal behaviors (Hoy \& Miskel, 1987, 1996, 2001).

In the early 1960 s, organizational studies began to shift from the closed systems to the open-systems perspective through the analysis of interactions between inside elements and the 
influence of external environment. The common assumption under this perspective was that an organization was a living system consisting of complex human variables influenced by the environment (Andes, 1970, p.12). Parsons (1965) further examined the significant influence of the external environment on the system and described that an organization could be considered as a subsystem embedded within a comprehensive social system. Scott and Blau (1962) pointed out that practically, there was no completely closed or open system; closeness and openness were matters of degree. Finally, the debate rested "on the side of openness" in the 1970s (Meyer, 1978, p. 18).

In the early $1980 \mathrm{~s}$, with the increasing expansion of studies of open systems theory, three contemporary organizational thoughts emerged. Scott (1987) proposed three systems perspective to study organizational behaviors: rational-system, natural-system, and open-system. The rational-system approach emphasized the importance of organizational structure over individuals; the natural-system approach described human relations and focused more on people rather than organizational structures. However, both of these perspectives ignored the interactions between the system and its environment. The open systems theory integrated the rational and human relation perspectives into a whole and indicated the interrelationships among the organization, its subsystems, and its environment. Hoy \& Miskel $(1987,1996)$ summarized that only open systems theory could clearly explain the behavior of an organization, interrelationships within a system, and relationships with the external environment.

A higher education institution was conceptualized as a living, open social system (Andes, 1970). This conceptualization provided a theoretical framework for university administrators to better understand the behavioral issues in the institution and its subunits and how they were related in operation. 
Andes (1970) conducted a review of studies on university administration since the 1960s and found that most studies on higher education administration looked at variables with little connection to the university as a whole. He further argued that traditional organizational theory with its emphasis on organizational rationality and efficiency failed to meet the needs of students and faculty in colleges and universities. Thus, there was a need to develop a simple, comprehensive, and conceptual framework for analyzing and understanding a university administration as a whole. Social systems theory was an alternative way of thinking to provide a conceptual perspective, to integrate the behavioral elements of university administration, and to make meaningful to the institution as a whole (Andes, 1970; Banathy, 1973).

Social systems model. The social systems perspective was "a way of looking at ourselves, at the environment we live in, and at the entities that surround us or that we are part of" (Banathy, 1973, p.1). Higher education has been a part of the synthetic, man-made, living, social system that could be studied and analyzed by using social systems concepts and principles. There were three ways of building social systems models on the basis of educational organization settings: (1) a systems-environment model or the systems-context model that examined systems in the context of their environment, emphasizing the relationships between the system and the environment; (2) a spatial structural model that focused on what the system was and its organizational structure, what it looked like, and how it was organized; and (3) a process model that examined the behavior of the system over a period of time to explain how the system operates. Among those three models, the systems-environment model provided a useful framework to examine and solve problems in educational settings (Banathy, p. 4).

The systems-environment model focused on an analysis of the relationships between the system and its environment. It viewed an organization as a social system existing within a given 
environment. Within the boundaries of the environment, the system received input from the environment, transformed the input through the process of operation, and then sent the outcome or the output back into the environment. The input was a collective term referring to everything that the system received from its environment. Input was made up of expectation, demands, and requirements from the environment and could be described through analysis of people, raw materials, information, resources, energies, finances, and so forth (Banathy, 1973; Hoy \& Miskel, 1996). Input was then transformed by the system into output and exported back into the environment. Output was another collective term that was sent back by the system into its environment through a transformational process. Output usually referred to products and services generated by the system, but they also included employee satisfaction and other by products (Hoy \& Miskel, 1996). It was the output that enabled the system to meet the expectations, requirements, and demands of its environment.

System survival depended on its self-regulating adjustment exercised by feedback loops; through feedback loops, the actual state of the output was continuously compared with the expected state of the output, and adjustments could be made on the basis of this information feedback, enabling the system to correct the differences between what is actually produced by the system and what the environment expected it to produce. Thus, the system could control itself through self-adaptive, self-regulating, and self-adjusted actions. System control made the system able to adjust to the environment, influence the environment, and finally accommodate the environment.

Within a larger system, often called a suprasystem, there was a set of subsystems, or peer systems with three kinds of relationships: hierarchical, centralized, and equalitarian (Banathy, 1973). The hierarchical relationship implied that one subsystem was subordinate to others; the 
centralized relationship meant that one subsystem played a central role and other subsystems were related to it and arranged around it. In an equalitarian relationship, none of the subsystems had a dominant or a central role; they were equally related (pp. 7-8).

The following theoretical model was adopted from Hoy and Miskel (1996) to explain the structure and process of a social system (see Figure 2.2).

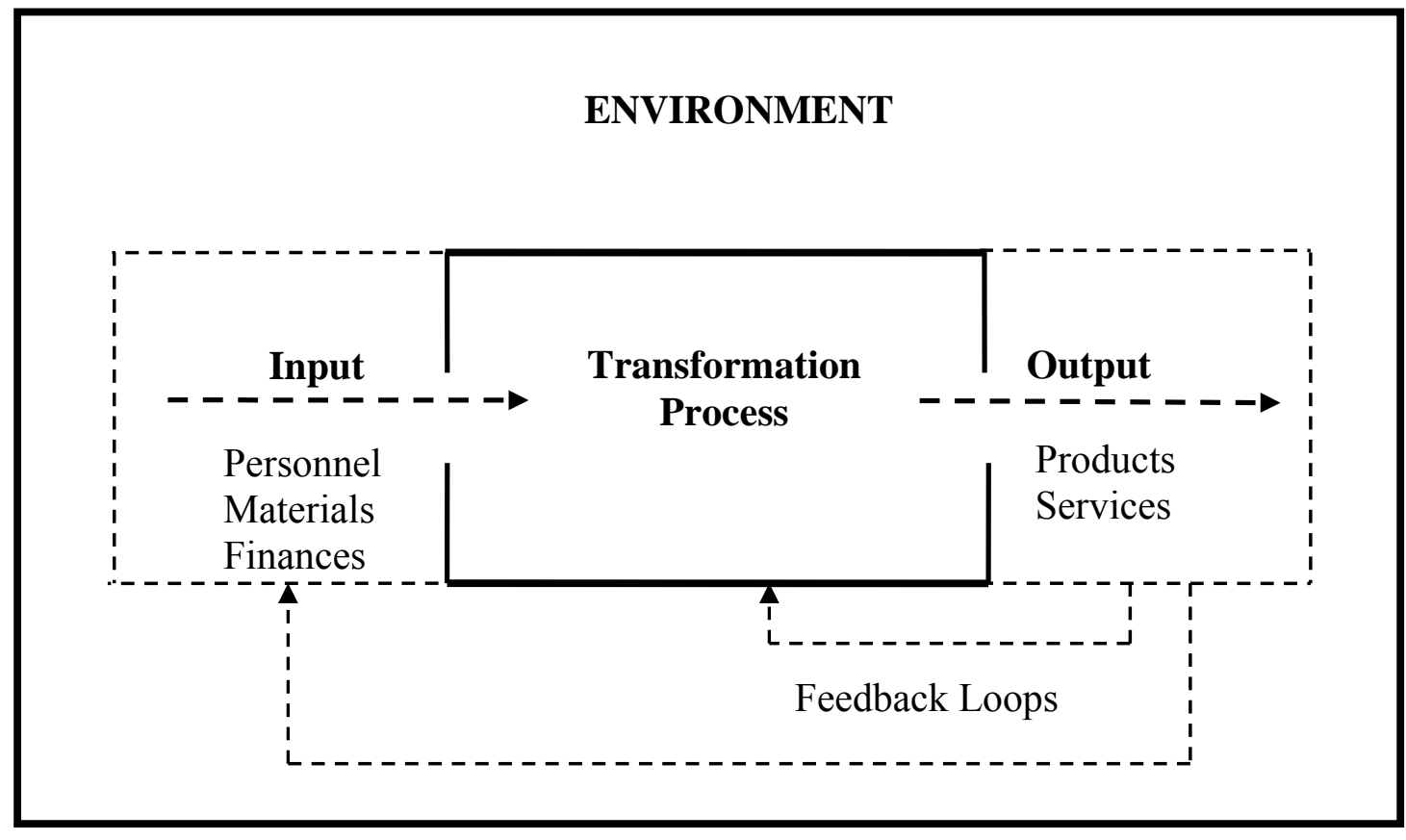

Figure 2.2 Systems-Environment Model (Hoy \& Miskel, 1996)

Modified social systems model. A university has been considered as a part of the educational suprasystems within the state and the nation that supported the university with direction, information, material, resources, finances, values, and other functional necessities. Scott and Blau (1962) argued that a university was an open social system where students were the prime beneficiary, and a mainly administrative problem was the conflict between the professional services to the students and the administrative procedures. Andes (1970) further elicited the relationship between the university and its suprasystems: 
In a university, the interaction is between the participants who comprise the university and is found both in the learning process and in formal and informal interaction of the participants of the university. These are more manifest in the subsystem. The university exchanges energy and information with its environment. The environment is everything outside of university boundary. Some of the inputs from the environment come from state government, community, research groups, foundations, professional organizations and associations, public, and new faculty, administrators, students, service personnel. Some of the outputs are graduates, dropouts, research results, information and services, and public perceptions of the university based on news media. (p. 25)

Parsons (1965) categorized the subsystems of a university into three levels: institutional level, managerial level, and technical level. Andes (1970) further explained the relationships among these three levels:

1. The institutional system formed the outer segment of the university through the board of trustees;

2. The managerial system within the university included two subsystems: administrative and service. The administrative subsystem included the president, VP, deans, business managers, and other administrative personnel who administer the internal affairs of the university and mediate the university with its environment, as well as provided resources needed by the faculty and students in the technical subsystem. The service subsystem included housing, police, food services, and the other sections that provided the facilities and equipment for the technical subsystems; and 
3. The technical subsystem consisted of faculty and students who were responsible for overall functions of the university in learning, teaching, research, and service. The boundaries among these subsystems were overlapped with each other. (p. 31)

Getzel, Liphman, and Campbell (1968) suggested that the concept of the social system was useful and applicable when analyzing administrative behavior through the operational process regardless of the level or size of the organization. For general analytic purposes, the social systems could be analyzed at the institutional level and the individual level. The institution with its roles and expectations constituted the normative dimension of activities in a social system; individual personality and disposition constituted the personal dimension of activities in a social system. To understand the nature of social behaviors in an organization, it was necessary to understand the interactions among these elements first (pp. 55-57).

On the basis of the systems-environment model (Hoy \& Miskel, 1996), a modified social systems-environmental model (see Figure 2.3) was developed and applied to this study. Because this study measured the institutional efforts on internationalization through the lens of study abroad programs coordinated by the centralized OIPs at U.S. research universities, the university would be considered as a system, or an environment; the OIP in each institution was the subsystem with typically centralized or decentralized relationships with their peer systems, such as schools, colleges, and departments. 


\section{U.S. Research Universities (Environment)}

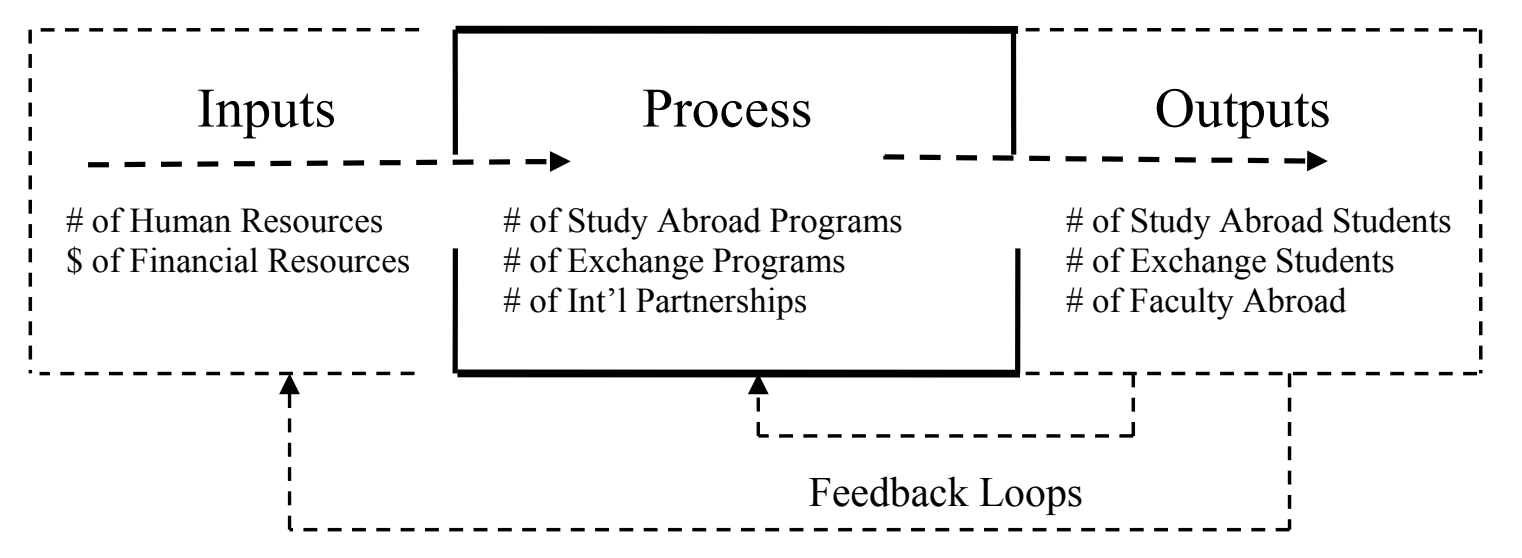

Figure 2.3 Modified Social Systems-Environment Model

An institution has established its mission with international education as the specific goal-producing "globally educated graduates" with high level of intercultural competence. To fulfill these specific expectations, requirements, and demands, one effective way that most research universities have done was that (1) the central administration provided scarce resources such as its human resources, financial resources, material means, and its facilities to support international programs through its subsystem-the OIP; (2) the OIP transformed these inputs into the process through development, administration, and coordination of international education programs and activities and sent students and faculty studying or working abroad; and (3) finally these globally educated students were produced and results were sent back to the university. Thus, the process of input — process — output should be regularly assessed on the basis of the institutional mission and the strategic planning related to international education. 
A system had the capacity to facilitate the repetitive and cyclic pattern of inputprocess - output through feedback loops. Feedback was the information that enabled the system to correct itself; therefore, adjustment could be made through feedback loops in terms of student learning outcomes in international dimensions. Through its self-regulating, control-based feedback, a university would fulfill institutional expectations through improvement of the input and the operation process, and realize the desired educational outcomes which would ensure the institution survival and success.

Kehm \& Teichler (2007) identified six broad themes that could apply social systems theory to measure institutional efforts on the internationalization of higher education:

1. Mobility of students and faculty including (1) U.S. students studying abroad, (2) the recruitment and the presence of international students, (3) faculty and staff abroad, and (4) related organizational administration and financial issues;

2. Mutual influence of higher education systems;

3. Internationalization of academic core activities in teaching, research, and service;

4. Knowledge transfer;

5. Cooperation and competition; and

6. National policies regarding the international dimensions in higher education institutions. (p. 265)

Accordingly, variables in this study were identified based on the input — process — output for study abroad programs administered by the centralized OIPs. The input variables addressed the institutional commitment to international education by investing human resources and financial resources to study abroad programs through the OIP (e.g., the number of professional and support staff working for study abroad programs, and the dollar amount of the annual budget 
allocated to study abroad programs through the OIP). The process variables consisted of international education programs and activities established and coordinated by the OIP in general (e.g., number of study abroad programs, number of exchange programs, and number of international partnerships). The output variables included the desired outcomes from the study abroad programs (e.g., number of study abroad students, number of international exchange students, and number of faculty abroad for teaching, research and service) (see Table 1.1). In conclusion, the social systems perspective was concerned with both the structure of an organization and the process in operation. The model was open, dynamic, and flexible and could be used in this study to assess the relationships among the university, its subsystem (the Office of International Programs), and the study abroad programs under the supervision of the OIP. It also provided for central administrators an overall understanding of the process of internationalization of higher education through the lens of study abroad programs and helped them in decisionmaking regarding internationalization of higher education institutions.

\section{Summary}

This chapter provided an overview of the development of internationalization of higher education in the United States since World War II, the definitions of internationalization of higher education, the organizational leadership and administrative structure of international programs, and studies of indicators relating to assess institutional efforts on internationalization of higher education institutions. In addition, it outlined a social systems theory and developed a modified systems-environment model to guide the study. 
Chapter Three

Research Methodology

\section{Introduction}

This study focused on the measurement of institutional efforts on internationalization of higher education through the lens of study abroad programs coordinated by the centralized Offices of International Programs (OIPs) at U.S. research universities. It was based on a modified theoretical framework of a social systems theory in terms of input—process—output.

This chapter describes the research methodology used in this study. The first section is the research design; the second part explains the population and the sample obtained from the web survey (e-Survey); the third section consists of data sources with detailed descriptions of research variables; the fourth section describes the instrument used in the web survey; the fifth part details the procedure of data cleaning, including missing value analysis, data transformation, and the diagnostics of multicollinearity; the sixth section provides the method of data analysis and assessment of validity and generalization of established models; and finally, the eighth section ends with a summary of this chapter.

\section{Research Design}

The literature on internationalization of higher education included few empirical studies that measured institutional efforts on internationalization of higher education at U.S. research universities. Few studies addressed (1) what kinds of variables were significantly related to the comprehensive internationalization of higher education through study abroad programs coordinated by the centralized OIP; (2) how these variables were correlated with each other; and (3) what kinds of variables were best to measure and assess the status of internationalization through study abroad programs at U.S. colleges and universities. 
This study developed three multiple regression models to explore if there were relationships existing between institutional input, process, and output of study abroad programs based on the modified social system model. Institutional input and process variables served as independent/predictor variables, and the output variables served as the dependent/outcome variables. Thus, standard multiple regression analysis was used to establish the regression models and assess how well these five independent variables predicted each of the dependent variables.

\section{Population}

According to Tabachnick and Fidell (1996), there were two basic principles used to follow when sampling institutions. First, the sampling required a relatively large number from represented institutions to insure the validity and reliability of the study; second, the sampled institutions should adequately represent the population so that the generalization of the results of the study could be stated. The population of this study included executive directors of Offices of International Programs at research universities in the United States because almost all research universities (97\%) have an office to coordinate international programs and activities on campus (Siaya \& Hayward, 2003).

The selective information, such as the names of U.S. research universities, Offices of International Programs, executive directors of the OIPs and their email addresses, was gathered from the following sources:

(1) 2005 Carnegie Groupings of Research Universities (Chronicle of Higher Education, 2008);

(2) 2009 Higher Education Directory (Burke, 2009); and

(3) Each research institution's website. 
The total population consisted of 282 U.S. research universities, which constituted 6.4 percent of the total number of institutions and 27.9 percent of the total student enrollment in higher education in the United States. According to the 2005 Carnegie Classification of Higher Education Institutions, there were three subgroups among the research institutions: very high research universities, high research universities, and doctoral research universities. Among these research universities, 96 (or 34 percent) research universities were institutions with very high research activity; 103 (or 36.5 percent) research universities were institutions with high research activity; and 83 (or 29.3 percent) research universities were doctoral research universities. Moreover, among these sampled institutions, 58.9 percent were public institutions and 41.1 percent were private institutions.

On the basis of web searching, 24 institutions were excluded from the population in this study because nine institutions were identified as graduate schools, three institutions offered only online education, and 12 institutions lacked information relating to the administrative unit of study abroad programs on their institutional websites. Thus, the total of 258 U.S. research universities was sampled.

The survey questionnaire was emailed directly to each executive who directed the OIP at each research institution. For those institutions lacking of information of study abroad programs, or those with multiple units managing study abroad programs, the survey questionnaire was sent directly to the provost or assistant vice president of academic affairs who was asked to send the survey to the appropriate person.

\section{Data Sources}

Establishment and verification of predictor variables correlating to internationalization of higher education through the lens of study abroad programs coordinated by the centralized OIP 
was critical. In this study, data were obtained from research universities through a web survey. A total of 15 questions were designed to obtain the data relating to institutional input to study abroad programs, the process of administration and coordination of study abroad programs, and the output of study abroad programs.

Independent variables included institutional input variables and process variables. The input variables referred to human resources (HR) and financial resources (FR) variables that were provided to support study abroad programs. Human resources variables consisted of three categories: (1) the number of full-time equivalent (FTE) professional staff; (2) the number of FTE support staff; and (3) the number of graduate assistants (FTE) employed by the OIP. Financial resources included the dollar amount of the annual budget managed by the centralized OIP and used for study abroad programs. In addition, the process variables included three categories: (1) the number of study abroad programs (NSAProg), (2) the number of international exchange programs (NEXProg), and (3) the number of international partnerships (NPartner) (see Table 1.1).

The dependent variables were the output of the study abroad programs in terms of the number of study abroad students (NSAStu), the number of exchange students (NEXStu), and the number of faculty abroad (NFac) (see Table 1.1).

\section{Instrument}

The survey questionnaire was designed by the researcher based on the related literature review. The content and the format of the questionnaire were guided by the Mail and Internet Survey: Tailored Design Method (Dillman, 2000) and International Handbook of Survey Methodology (de Leeuw, Hox, \& Dillman, 2008). There were two formats of questionnaires: the PDF filling-in file and the webpage-based file. 
The content of the questionnaire covered the general information and major responsibility of OIPs regarding administration and coordination of study abroad programs through centralized OIPs at U.S. research universities. The questionnaire consisted of four sections.

Section one included five questions dedicated to gaining a complete picture of the administrative structure of international programs, the scope of responsibility of the OIPs, and the report line of the executive who directed the OIP.

The second part included six questions addressing the information relating to institutional input to study abroad programs, the process of administration and coordination of study abroad programs through the centralized OIP, and the outcome of study abroad programs. All data collected from this section were used in the multiple regression analysis to build regression models. In addition, the results of findings based on established regression models were the key evidence to answer three research questions in the study.

The third section solicited information regarding funding sources of the annual budget managed by the OIP and used for study abroad programs, such as the dollar amount of the annual budget allocated from central funds to the OIP, the dollar amount of fees the OIP charged for student services, and money generated from grants and contracts, as well as gifts for study abroad programs.

The last section consisted of three questions to address (1) the dollar amount of scholarships the OIP used to promote students study abroad and faculty abroad for teaching, research, and service; (2) the number of extra-curricular programs coordinated by the OIP to promote students study abroad; and (3) the incentives and policies related to encourage faculty abroad (see Appendix C). 
To test the reliability and the content validity of the survey questions, a full draft of the research questionnaire including both PDF fill-in format and the web survey format, three cover letters (e.g., pre-notice cover letter, formal cover letter, and the thank-you/reminder cover letter) were emailed to a group of experts who were executives of the OIPs or research experts at U.S. research universities (see Appendix A). Campanelli (2003) strongly suggested using a panel of three to four experts plus the questionnaire designer as a focus group to review the survey questions and discussion among these experts should be informal and free flowing. In this study, a panel of experts included all five dissertation committee members, three executive directors at research universities, and the researcher.

The selected experts examined the content of the survey questionnaire and considered the following issues: (1) whether the questionnaire covered major functions of international education programs and activities administered by the OIP at U.S. research universities; (2) whether the questions were accessible for executives of OIPs to get the data; and (3) whether questions were misinterpreted or ambiguous to understand. Suggestions and feedback were considered and included in the final draft. Finally, the revised cover letters and the questionnaire were sent to the each executive director of the OIP individually through the email.

To address the construct validity of the survey, Pearson's correlation was undertaken to test correlation among independent variables before building multiple regression models. Once the data were collected, a correlation matrix was produced to see whether the independent variables were highly correlated with each other because highly correlated variables $(r>.90)$ would cause multicollinearity and could not meet the pre-requirement of multiple regression analysis (Tabachnick \& Fidell, 2001, 2006). Field (2005) further suggested testing the multicollinearity and singularity based on values of VIF and Tolerance (p. 196). 


\section{Data Collection}

Data for this study were collected through the electronic survey (e-Survey) from executives who directed the centralized OIPs at U.S. research universities. According to Dillman (2000), the e-Survey conducted through the Internet has become the dominant mode in the United States, with fast speed and extremely low cost. The mixed-mode surveys became powerful when combining multiple tools through mail, telephone interview, email, and Internet. Anderson \& Kanuka (2003) further suggested that e-Survey generally could save one-tenth the cost compared to equivalent the mailing survey; and the response rate was faster and could save a plenty of time. For instance, on average, 50 percent of responses from the e-Survey came in within 24-48 hours, and two-thirds came in within 72 hours (p. 148).

In this study, a mixed mode of e-Survey (a web-survey through emails) was designed. The researcher gathered all personal contact information of OIP executives from their institutional websites, including name, office phone number, mailing address, and email address; at the same time, an official website for input and output of survey data was established by a professional computer programmer. Through the specific website, the executive who took the survey could access the following information: (1) approved cover letters by WVU IRB; (2) a survey with PDF fill-in-file format; and (3) the webpage-based questionnaire. When the survey was finished, data were automatically saved into the database and transformed into an Excel file.

The survey was delivered through email in three steps. First, on April 15, 2009, a brief pre-notice email was sent to each executive director, informing the respondents that an important survey was going to be conducted in the following six weeks and assistance in answering the questions would be greatly appreciated. 
Second, on April 20, 2009, five days after the pre-notice email, a formal email was sent to each executive director and the following documents were attached:

(1) A web link for the survey;

(2) A cover letter with detailed directions on how to finish the survey;

(3) An approved IRB; and

(4) A PDF questionnaire with fill-in format.

On April 28, 2009, a thank-you or reminder email was sent out to all respondents; meanwhile, the copy of the survey questionnaire and the web link were also attached for encouraging non-respondents to implement the survey.

A total of 230 of emails were successfully sent out, which consisted of 81.6 percent of the population. The reasons for 52 samples not responding included the following reasons: (1) some research institutions did not have study abroad programs at all, such as those institutions offering only graduate programs and some Christian universities; (2) study abroad programs in some institutions were administered through decentralized function, which made it harder to respond to this survey; and (3) a lot directors were out of the office for business trips. Finally, 104 of 230 (45.2\%) respondents finished the web survey questionnaire; among them, 93 (or $40.4 \%$ ) respondents' answers were identified as valid cases and used in this study.

To assess whether the received sample size met the pre-requirement for conducting multiple regression analysis, the formula of $N \geq 50+8 m$, ( $m$ is the number of independent variables or predictors) was used on the basis of achievement of Cohen's medium-size relationships between predictors and the dependent variable $(\alpha=.05, \beta=.20$, power $=.80)$ (Green, 1991). In this study, because there were five predictors, the required sample cases 
needed to be at least 90 . A total of 93 valid cases obtained from the web survey, thus, the number of cases met the basic requirement to predict the significance of multiple regression models.

\section{Data Cleaning}

Before conducting the multiple regression analysis, several steps of data cleaning recommended by Tabachnick and Fidell (2001) and Field (2005) were further considered.

Missing data analysis. First of all, all independent variables and dependent variables were entered into the SPSS (Statistical Package for the Social Sciences, $15^{\text {th }}$ edition) and screened. The purpose was to see whether the missing data exceeded 5 percent. For variables with missing data more than 5 percent, SPSS missing value analysis (MVA) was used to diagnose if data were missing randomly, and the expectation maximization (EM) method was used to fix this problem.

Table 3.1 below presented the number of valid data and the percentage of missing data obtained from the e-Survey. It indicated that (1) four out of eight variables had missing data in excess of 5 percent; (2) among them, variables of financial resources (FR) and the number of faculty abroad (NFac) had the highest percentage of missing data $(9.7 \%)$, followed by the number of partnerships (NPartner) (7.5\%) and the number of exchange students (NEXStu) $(6.5 \%)$. 
Table 3.1

Missing Data Analysis $(N=93)$

Independent Variables

Valid Missing \% of Missing

Human Resources (HR)

93

0

0

Financial Resources (FR)

84

9

$9.7 \%$

Number of Study Abroad Programs (NSAProg)

93

0

0

Number of Exchange Programs (NEXProg)

93

0

0

Number of Partnerships (NPartner)

86

7

$7.5 \%$

Dependent Variables

Valid Missing \% of Missing

Number of Study Abroad Students (NSAStu)

93

0

0

Number of Exchange Students (NEXStu)

87

6

$6.5 \%$

Number of Faculty Abroad (NFac)

84

9

$9.7 \%$

Table 3.2

Missing Value Analysis $(N=93)$

\begin{tabular}{|r|c|c|r|r|r|r|r|r|}
\hline Variables & HR & FR & NSAProg & NEXProg & NPartner & NSAStu & NEXStu & NFac \\
\hline $\begin{array}{r}\text { EM } \\
\text { Means }\end{array}$ & 6.35 & 1027.14 & 87.65 & 24.44 & 27.45 & 601.24 & 40.93 & 30.08 \\
\hline
\end{tabular}

Note. Little's MCAR test: $\chi^{2}=71.649, D F=58, p=.107$. Significant levels: ${ }^{*} p<.05 ; * * p$ $<.01 ; * * * p<.001$.

In addition, Little's MCAR test was used to examine whether data were randomly and unsystematically missing (see Table 3.2). The result showed that $\chi^{2}(58)=71.649(p=.107)$ was 
not statistically significant at $\alpha$-level of .05 , which indicated that data were randomly missing among the 93 cases and the Expectation Maximization (EM) method was applied to fix the problem. Finally, a new set of EM data $(N=93)$ without any missing value was established for multiple regression analysis.

Normality. Normality was not fatal to analysis of the linear relationships, but it could weaken the analysis and results. Therefore, histogram plots of all variables were explored by using both the original data and the EM data. The results showed that all variables were positively skewed and distribution of variables in the original data and the EM data were the same (see Appendix D). Further, the evidence of non-normality was found through checking the level of skewness and the level of kurtosis based on frequency statistics. The level of skewness (skewness/standardized error of skewness) and the levels of kurtosis (kurtosis/standardized error of kurtosis) of each variable based on original data were far greater than standardized $z$-score 3.29, which indicated that variables were highly skewed (Appendix D \& E).

Data transformation. For ungrouped data, Tabachnick and Fidell (2001) and Field (2005) strongly recommended data transformation when variables did not distributed normally. Without data transformation, the skewed variables would weaken the analysis and the results. Thus, the EM data were further transformed by using the logarithm method. After data transformation, absolute values of levels of skewness and levels of kurtosis were far below 3.29; among them, most absolute values were close to 1 . Finally, after missing value analysis and data transformation, distribution of all independent variables and dependent variables became roughly normal (see Appendix D \& E).

Multicollinearity. Accordingly, multicollinearity occurred when highly relationships existed between predictor variables and weakened the construct validity of the survey. The rule 
of thumb was that correlation coefficients between predictors should not be higher than 90 . Violation of this rule would cause an increase of type II error and make the regression model weak in predicting the outcome. In this study, correlation matrixes before and after MVA and data transformation were both explored to show relationships between any of two independent variables. As shown in Table 3.3 and Table 3.4, the highest correlation coefficients before and after MVA and data transformation were .80 and .82 , respectively, which were smaller than .90 , and met the pre-requirement of multiple regression analysis.

Table 3.3

Diagnostics of Multicollinearity for Untransformed Data $(N=93)$

\begin{tabular}{lllrrrr}
\hline & & 1 & 2 & 3 & 4 & 5 \\
\hline 1 & HR & & & & \\
2 & FR & $.22 *$ & & & & \\
3 & NSAProg & $.50^{* * *}$ & .11 & & & \\
4 & NEXProg & .16 & .12 & $.52^{* * *}$ & \\
5 & NPartner & $.32^{* *}$ & -.05 & $.48^{* * *}$ & $.32^{* * *}$ \\
\hline
\end{tabular}

Note. Significant Levels: $* p<.05 ; * * p<.01$; *** $p<.001$ (one-tailed). 
Table 3.4

Diagnostics of Multicollinearity for Transformed Data $(N=93)$

\begin{tabular}{lllllll}
\hline & & 1 & 2 & 3 & 4 & 5 \\
\hline 1 & LogHR & & & & \\
2 & LogFR & $.42 * * *$ & & & & \\
3 & LogNSAProg & $.60 * * *$ & $.28 * *$ & & & \\
4 & LogNEXProg & $.37 * * *$ & .17 & $.63 * * *$ & \\
5 & LogNPartner & $.52 * * *$ & .12 & $.64 * * *$ & $.77 * * *$ \\
\hline
\end{tabular}

Note. Significant Levels: ${ }^{*} p<.05 ; * * p<.01 ; * * * p<.001$ (one-tailed).

Outliers. When assessing standard deviation of residuals and the histogram plots of standard residuals, it was found that:

1. With LogNSAStu served as the outcome variable, all standard residuals with absolute values were lower than 3.29, which indicated that no outlier existed in the dataset;

2. With LogNEXStu served as the outcome variable, the case number 32 had the standard residual with absolute value greater than 3.29 , which presented that this case was an outlier. Thus, case number 32 was deleted when conducting the analysis of regression model. As a result, a total of 92 cases were used for analysis of the research question two (see Appendix J).

3. With LogNFac served as the outcome variable, it was found that case number 6 had the standard residual with an absolute value greater than 3.29 and deleted; the second run appeared that the case number 87 was an outlier with the standard residual -3.30 and deleted; the third run presented that the case number 75 was an outlier with the standard residual -3.33 and deleted. After deleting these three cases, no more outlier 
existed in the dataset. Thus, a total of 90 cases were used in analysis of the research question three (see Appendix J).

\section{Data Analysis}

The standard multiple regression analysis was used to explain each of three research questions. Multiple regression analysis was a flexible tool to assess relationships between a set of independent variables to a dependent variable, even though these independent variables are somehow correlated with each other $(r<.90)$; in addition, multiple regression analysis could clearly demonstrated the contribution of each predictor to the outcome variable (Tabachnick $\&$ Fidell, 2001, 2006; Field, 2005).

In this study, the standard multiple regression analysis was conducted to explore whether there were relationships existing between the independent variables (human resources, financial resources, the number of study abroad programs, the number of exchange programs, and the number of international partnerships) and each of dependent variables (the number of study abroad students, the number of exchange students, and the number of faculty abroad). The procedure of using SPSS to conduct the standard multiple regression analysis was guided by Andy Field's Discovery Statistics Using SPSS (2005).

Finally, each of research questions was readdressed and multiple regression models were assessed based on the following guideline: (1) whether the regression model was statistically significant; (2) whether each of independent variables was statistically significant to predict the dependent variable; and (3) the contribution of each independent variable to the model. Finally, a multiple regression model was established and findings were reported based on statistical criteria, including $R, R^{2}$, adjusted $R^{2}, F$-test, unstandardized coefficients $(B)$, standardized coefficients $(\beta)$, and $t$-test (see Table 3.5). 
Table 3.5

Research Questions and Multiple Regression Models

\begin{tabular}{|l|c|}
\hline \multicolumn{1}{|c|}{ Research Questions } & Multiple Regression Models \\
\hline $\begin{array}{l}\text { Q1. Do the institutional input variables and the } \\
\text { process variables have relationships with the } \\
\text { number of undergraduate study abroad students? }\end{array}$ & $\begin{array}{l}\text { Model 1. } N S A S t u=b_{0}+B_{1} \mathrm{HR}+B_{2} \mathrm{FR}+B_{3} \mathrm{NSAProg}+B_{4} \mathrm{NEXProg}+ \\
B_{5} \mathrm{NPartner}\end{array}$ \\
\hline $\begin{array}{l}\text { Q2. Do the institutional input variables and the } \\
\text { process variables have relationships with the } \\
\text { number of international exchange students? }\end{array}$ & $\begin{array}{c}\text { Model 2. } N E X S t u=b_{0}+B_{1} \mathrm{HR}+B_{2} \mathrm{FR}+B_{3} \mathrm{NSAProg}+B_{4} \mathrm{NEXProg}+ \\
B_{5} \mathrm{NPartner}\end{array}$ \\
\hline $\begin{array}{l}\text { Q3. Do the institutional input variables and the } \\
\text { process variables have relationships with the } \\
\text { number of faculty abroad? }\end{array}$ & $\begin{array}{c}\text { Model 3. } N F a c=b_{0}+B_{1} \mathrm{HR}+B_{2} \mathrm{FR}+B_{3} \mathrm{NSAProg}+B_{4} \mathrm{NEXProg}+ \\
B_{5} \mathrm{NPartner}\end{array}$ \\
\hline
\end{tabular}

Note. 1 . These three models are based on the general equation of multiple regression formula: $Y_{1}=b_{0}+b_{1} \mathrm{X}_{1}+b_{2} \mathrm{X}_{2}+\cdots+b \mathrm{nXn}$;

2. Predictors: HR (Human Resources); FR (Financial Resources); NSAProg (Number of Study Abroad Programs);

NEXProg (Number of Exchange Programs); NPartner (Number of Partnerships); Dependent Variables: NSAStu

(Number of Study Abroad Students); NEXStu (Number of Exchange Students); NFac (Number of Faculty Abroad). 


\section{Assessing Validity and Generalization of Multiple Regression Models}

For assessing whether each of multiple regression models fitted the observed data well, diagnostic statistics of residuals and influence cases were further examined based on values of standardized residuals, Cook’s distance, centered leverage, Mahalanobis distances, standardized DFBeta, and covariance ratio (CVR).

For assessing the generalization of regression models, assumptions of multiple regression analysis and cross-validation were further examined. Statistical diagnosis consisted of variable types, sample size, values of variance inflation factors (VIF), proportion of variance and eigenvalue, distribution of standardized residual, Durbin-Waston test, and Stein's adjusted $R^{2}$. Finally, an actual example was given to show how to use the model if generalization of the model to the whole population was approved to be true.

\section{Summary}

This study is to assess the institutional efforts on internationalization of higher education through study abroad programs coordinated by the centralized Offices of International Programs at U.S. research universities. The theoretical framework is based on an open social systems perspective of input - process - output. Data are obtained through the questionnaire based on the self-administered Internet survey.

Moreover, data cleaning is conducted and all variables were assessed based on prerequirement of performing multiple regression analysis. Since four variables have missing data in excess of 5 percent, data are further reestablished though EM method and the logarithmic transformation. Moreover, outliers are assessed and 90 to 93 valid cases are used in this study.

Finally, standard multiple regression analysis is undertaken to assess whether multiple regression models are significant and the contribution of each significant predictor variable to the 
outcome variable. Meanwhile, the validity and generalization of three reestablished regression models are evaluated. 


\section{Chapter Four}

\section{Findings}

\section{Introduction}

The purpose of this study assessed whether relationships existed among institutional input to study abroad programs, the process of administration and coordination of study abroad programs through the centralized Offices of International Programs (OIPs), and the output of these programs at U.S. research universities.

The population included 282 research universities, but only 230 emails were successfully sent out. Among the 230 sampled institutions, 104 (or $45.2 \%$ ) cases were received. Because 11 cases lacked important information related to financial input to study abroad programs and were finally deleted from the dataset. As a result, 93 of $230(40.4 \%)$ cases were assessed as valid data and actually used in this study.

Three multiple regression models are established to present each of research questions. The remained of this chapter describes the results of findings obtained from the multiple regression analysis. It is organized into seven sections based on each of research questions: (1) the first section describes the finding from descriptive statistics based on analysis of frequency, means, and standard deviations; (2) in the second part, Pearson's correlation coefficients are produced to address relationships between each of predictor variables and the dependent variable; (3) in the third section, three multiple regression models are established on the basis of each of research questions; within this part, the evaluation were further conducted to assess the significance of the model, the significance and contribution of each predictor to the outcome variable; (4) the fourth part is to assess the validity of three established models; (5) the firth part 
is to assess the generalization of three established models to a large population; and (6) the sixth part is a summary of this chapter.

Independent variable (predictor variables) included human resources (HR), financial resources (FR), the number of study abroad programs (NSAProg), the number of exchange programs (NEXProg), and the number of international partnerships (NPartner); dependent variables (outcome variables) consisted of the number of study abroad students (NSAStu), the number of exchange students (NEXStu), and the number of faculty abroad (NFac) (Appendix B). Descriptive Statistics

Independent variables (predictor variables). As shown in Table 4.1, the means of independent variables were HR (6.35), FR (947.21), NSAProg (87.65), NEXProg (24.44), and NPartner (29.20), respectively; standard deviations of independent variables were HR (5.93), FR (1433.82), NSAProg (99.37), NEXProg (37.08), and NPartner (48.80), with the FR variable biggest and the HR variable smallest.

Table 4.1

Means and Standard Deviations of Independent Variables $(N=93)$

\begin{tabular}{lccc}
\hline $\begin{array}{c}\text { Independent } \\
\text { Variables }\end{array}$ & Means & $\begin{array}{c}\text { Standard } \\
\text { Deviations }\end{array}$ & $\begin{array}{c}\text { Sample } \\
\text { Size }\end{array}$ \\
\hline HR & 6.35 & 5.93 & 93 \\
FR & 947.21 & 1433.82 & 84 \\
NSAProg & 87.65 & 99.37 & 93 \\
NEXProg & 24.44 & 37.08 & 93 \\
NPartner & 29.20 & 48.80 & 86 \\
\hline
\end{tabular}

Note. Results were produced based on untransformed data. 
The findings based on Table 4.1 and other results from the Survey indicated that, in academic year of 2007-08:

1. An average of 6.35 FTE staff, such as professional staff, support staff, and graduate assistants, worked for study abroad programs at research universities; among them, 62.3 percent were professional practitioners, such as study abroad program directors, coordinators, and advisors; 22.1 percent were support staff (e.g., the secretary, accountant, etc.); and 15.6 percent were graduate assistants.

2. An average of $\$ 947.21$ thousand dollars of the annual budget was used for study abroad programs at research universities; among them, more than half of the annual budget were fees generated from students who participated in study abroad programs; further, nearly 40 percent of the annual budget for study abroad programs were allocated from the central administration; moreover, money from gifts and donations consisted of 6.4 percent, and slightly more than 1 percent of budget came from grants and contracts related to international education.

3. An average of 87.65 study abroad programs was administered and coordinated by the OIPs (e.g., study abroad for credit, internship abroad, and service learning abroad) at research universities;

4. An average of 24.44 exchange programs was administered and coordinated by OIPs at research universities.

5. An average of 29.20 international partnerships was established by the OIPs and has been active in recent three years at research universities.

Dependent variables (outcome variables). SPSS produced the means and standard deviations for dependent variables. As shown in Table 4.2, means of NSAStu, NEXStu, and 
NFac were 601.24, 42.51, and 32.11, respectively; and standard deviations of these three dependent variables were $609.50,68.73$, and 40.69, respectively.

Table 4.2

Means and Standard Deviations of Dependent Variables $(N=93)$

\begin{tabular}{lccc}
\hline $\begin{array}{c}\text { Dependent } \\
\text { Variables }\end{array}$ & Means & $\begin{array}{c}\text { Standard } \\
\text { Deviations }\end{array}$ & $\begin{array}{c}\text { Sample } \\
\text { Size }\end{array}$ \\
\hline NSAStu & 601.24 & 609.50 & 93 \\
NEXStu & 42.51 & 68.73 & 87 \\
NFac & 32.11 & 40.69 & 84 \\
\hline
\end{tabular}

Note. Results were produced based on untransformed data.

The results from Table 4.2 indicated that, in academic year of 2007-08:

1. An average of 601.24 U.S. students participated in study abroad programs at U.S. research universities;

2. An average of 42.51 international students studied at U.S. research universities through exchange programs administered by the OIPs;

3. An average of 32.11 faculty members at research universities had a chance to go abroad for teaching, research, and service.

\section{Pearson's Correlation Coefficients}

Accordingly, the Pearson's correlation was conducted to assess whether there were significant relationships between independent variables and dependent variables. Thus, Pearson's correlation matrixes for both untransformed and transformed data were explored and significant levels of correlation coefficients were reported at $\alpha$-level of .50 and above (see Table 4.3). 
Table 4.3

Correlation Matrix before Data Transformation $(N=93)$

\begin{tabular}{|c|c|c|c|c|c|c|}
\hline & & 1 & 2 & 3 & 4 & 5 \\
\hline 1 & HR & & & & & \\
\hline 2 & FR & $.38 * * *$ & & & & \\
\hline 3 & NSAProg & $.50 * * *$ & .15 & & & \\
\hline 4 & NEXProg & .16 & .12 & $.52 * * *$ & & \\
\hline 5 & NPartner & $.34 * *$ & -.04 & $.49 * * *$ & $.33 * *$ & \\
\hline 6 & NSAStu & $.80 * * *$ & $.51 * * *$ & $.49 * * *$ & $.22 *$ & $.23^{*}$ \\
\hline 7 & NEXStu & $.19 *$ & -.05 & $.27 * *$ & $.37 * * *$ & $.38 * * *$ \\
\hline 8 & NFac & $.45 * * *$ & -.11 & $.57 * * *$ & $.28 * *$ & $.64 * * *$ \\
\hline
\end{tabular}

Note. Dependent Variables: NSAStu, NEXStu, and NFac. Significant Levels: ${ }^{*} p<.05$;

$* * p<.01 ; * * * p<.001$ (one-tailed). 
Table 4.4

Correlation Matrix after Data Transformation $(N=93)$

\begin{tabular}{|c|c|c|c|c|c|c|}
\hline & & 1 & 2 & 3 & 4 & 5 \\
\hline 1 & LogHR & & & & & \\
\hline 2 & LogFR & $.42 * * *$ & & & & \\
\hline 3 & LogNSAProg & $.60 * * *$ & $.28 * *$ & & & \\
\hline 4 & LogNEXProg & $.37 * * *$ & .17 & $.63 * * *$ & & \\
\hline 5 & LogNPartner & $.52 * * *$ & .12 & $.64 * * *$ & $.77 * * *$ & \\
\hline 6 & LogNSAStu & $.75 * * *$ & $.51 * * *$ & $.60 * * *$ & $.41 * * *$ & $.46 * * *$ \\
\hline 7 & LogNEXStu & $.42 * * *$ & .13 & $.56 * * *$ & $.82 * * *$ & $.74 * * *$ \\
\hline 8 & LogNFac & $.49 * * *$ & $.21 *$ & $.59 * * *$ & $.43 * * *$ & $.52 * * *$ \\
\hline
\end{tabular}

Note. Dependent Variables: LogNSAStu, LogNEXStu, and LogNFac. Significant Levels:

$* p<.05 ; * * p<.01 ; * * * p<.001$ (one-tailed).

As shown in Table 4.4 above, the results of Pearson's correlation for transformed data indicated that:

1. The outcome variable, i.e., (log of) the number of study abroad students (LogNSAStu), was strongly associated with all five predictor variables, with correlation coefficients of .75 (LogNSAStu/LogHR), .60 (LogNSAStu/LogNSAProg), .51 (LogNSAStu/LogFR), .46 (LogNSAStu/LogNPartner), and .41 (LogNSAStu/LogNEXProg), respectively; moreover, all theses Pearson's correlation coefficients were statistically significant at $\alpha$-level of .001. 
2. The outcome variable, i.e., (log of) the number of exchange students (LogNEXStu), was strongly related with four out of five predictor variables, with correlation coefficients of .82 (LogNEXStu/LogNEXProg), .74 (LogNEXStu/LogNPartner), .56 (LogNEXStu/LogNSAProg), and .42 (LogNEXStu/LogHR), respectively; moreover, these correlation coefficients were positive and significant at $\alpha$-level of .50. However, one predictor of LogFR had no significant relationship with LogNEXStu $(r=.13)$, which indicated that the variable of $\operatorname{LogFR}$ was not a good predictor for the dependent variable of LogNEXStu.

3. The outcome variable, i.e., (log of) the number of faculty abroad (LogNFac), was strongly related with all five predictor variables, with correlation coefficients of .59 (LogNFac/LogNSAProg), .52 (LogNFac/LogNPartner), .49 (LogNFac/LogHR), .43 (LogNFac/LogNEXProg), and .21 (LogNFac/LogFR), respectively; and all correlation coefficients were statistically significant.

In summary, the results of Pearson's correlation coefficients showed that the five predictor variables were significantly associated with each of the outcome variables (except $\operatorname{LogFR} / \operatorname{LogNEXStu}$ ) and were used to build multiple regression models.

\section{Multiple Regression Analysis}

The standard multiple regression analysis was undertaken to establish the multiple regression models based on each research question; meanwhile the following issues were addressed: (1) what the regression equation model was; (2) whether the established multiple regression model was statistically significant; (3) whether the independent variables were statistically significant to predict the dependent variable; and (4) the contribution of each independent variable to the dependent variable. In this part, each of research questions was 
restated and analyzed based on results of the multiple regression analysis. Findings were reported by using $R, R^{2}$, adjusted $R^{2}, F$-test, unstandardized coefficients $(B)$, standardized coefficients $(\beta)$, $t$-test, and the like.

Because two independent variables and two dependent variables had missing data in excess of 5 percent and histogram plots of all variables were positively skewed (see Table 3.1), SPSS missing value analysis (see Table 3.2) and data transformation (logarithm) were undertaken to ensure that standard deviations of residuals were normally distributed. As a result, data used in the multiple regression analysis were transformed data.

\section{Research Question One}

The first research question asked: Do the institutional input variables (e.g., human resources and financial resources) and the process variables (e.g., the number of study abroad programs, the number of exchange programs, and the number of international partnerships) have relationships with the number of study abroad students?

The independent variables included (log of) human resources ( $\log H R),(\log$ of $)$ financial resources (LogFR), (log of) the number of study abroad programs (LogNSAProg), ( $\log$ of) the number of exchange programs (LogNEXProg), and (log of) the number of international partnerships (LogNPartner); and the dependent variable was (log of) the number of study abroad students (LogNSAStu).

Equation of multiple regression model 1. The multiple regression model 1 was formulized based on values of the constant and unstandardized coefficients $(B s)$ of five predictors. As shown in Table 4.5 below, the constant was 0.991 ; and the unstandardized coefficients $(B)$ for five predictor variables were listed as $0.86(\log H R), 0.21(\operatorname{LogFR})$, 0.19 (LogNSAProg), 0.06 (LogNEXProg), and -0.01(LogNPartner), respectively. 
Table 4.5

Results of Standard Multiple Regression Model $1(N=93)$

\begin{tabular}{llll}
\hline \multicolumn{1}{c}{ Variables } & $B$ & $S E B$ & $\beta$ \\
\hline Constant & 0.991 & 0.17 & \\
(log of) Human Resources & 0.86 & 0.15 & $.51^{* * *}$ \\
(log of) Financial Resources & 0.21 & 0.06 & $.24^{* *}$ \\
(log of ) Number of Study Abroad Programs & 0.19 & 0.09 & $.20^{*}$ \\
(log of) Number of Exchange Programs & 0.06 & 0.09 & .07 \\
(log of) Number of Partnerships & -0.01 & 0.10 & -.02 \\
\hline
\end{tabular}

Note. Predictors: (Constant), LogHR, LogFR, LogNSAProg, LogNEXProg, LogNPartner.

Dependent Variable: LogNSAStu. Significant Levels: ${ }^{*} p<.05 ; * * p<.01 ; * * * p<.001$.

Because the equation of the multiple regression for the question one was: NSAStu $=b_{0}+$ $b_{1} \mathrm{HR}+b_{2} \mathrm{FR}+b_{3} \mathrm{NSAProg}+b_{4} \mathrm{NEXProg}+b_{5} \mathrm{NPartner}$; thus, the established multiple regression model 1 was formulated as follows:

$$
\begin{aligned}
\operatorname{LogNSAStu}= & 0.991+(0.86 \operatorname{LogHR})+(0.21 \operatorname{LogFR})+(0.19 \operatorname{LogNSAProg})+(0.06 \operatorname{LogNEXProg}) \\
& -(0.01 \operatorname{LogNPartner})
\end{aligned}
$$

(Equation 4.1)

Significance of multiple regression model 1 . Table 4.6 below displayed the summary of the multiple regression model 1 , with $R=.80, R^{2}=.64$, adjusted $R^{2}=.62, F(5,87)=31.332$, $p<.001$. The results indicated that (1) the regression model 1 was statistically significant, and (2) five predictors together accounted for 62.2 percent of variance on the outcome variable of LogNSAStu. 
Table 4.6

Summary of Standard Multiple Regression Model 1( $N=93)$

\begin{tabular}{|c|r|r|r|r|r|r|r|r|}
\hline Model & \multicolumn{1}{|c|}{$\mathrm{R}$} & R Square & $\begin{array}{c}\text { Adjusted R } \\
\text { Square }\end{array}$ & $\begin{array}{c}\text { R Square } \\
\text { Change }\end{array}$ & df1 & df2 & \multicolumn{1}{c|}{ F } & $\begin{array}{c}\text { Durbin- } \\
\text { Watson }\end{array}$ \\
\hline 1 & .802 & .643 & .622 & .643 & 5 & 87 & $31.332 * * *$ & 1.830 \\
\hline
\end{tabular}

Note. Predictors: (Constant), LogHR, LogFR, LogNSAProg, LogNEXProg, LogNPartner. Dependent Variable: LogNSAStu. Significant Levels: ${ }^{*} p<.05 ; * * p<.01 ; * * * p<.001$.

Significance of predictor variables. To assess the significant relationships among predictor variables and the outcome variable, values based on unstandardized coefficients $(B)$, standardized coefficients $(\beta)$, and $t$-tests with significant $\alpha$-level of .05 were examined.

As shown in Table 4.5 above, the values of standardized coefficients $(\beta)$ indicated that three predictors (e.g., LogHR, LogFR, \& LogNSAProg) had strongly significant relationships with the outcome variable (LogNSAStu), and two predictors (e.g., LogNEXProg \& LogNPartner) had non-significant relationships with the outcome variable (LogNSAStu).

According to Cohen's widely accepted guideline for the effect size, it indicates that: (1) $r=.10$ means a small effect that explained only 1 percent of the total variance; (2) $r=.30$ indicates a medium size of effect that accounted for 9 percent of the total variance; and (3) $r=.50$ represents a large effect that accounted for 25 percent of the total variance (Field, 2005). Therefore, the explanation of regression correlations between each of predictor variables and the outcome variable (LogNSAStu) were detailed as follows:

1. The predictor of (log of) human resources had a large size of regression correlation with the outcome variable of (log of) the number of study abroad students, with 
$\beta=.51, t(87)=5.709$, and the correlation coefficient was positively significant at $\alpha$-level of .001;

2. The predictor of ( $\log$ of financial resources had a small size of regression correlation with the outcome variable of (log of) the number of study abroad students, with $\beta=.24, t(87)=3.261$, and the correlation coefficient was positively significant at $\alpha$-level of .01;

3. The predictor of (log of) the number of study abroad programs had a small size of regression correlation with the outcome variable of (log of) the number of study abroad students, with $\beta=.20, t(87)=2.058$, and the correlation coefficient was positively significant at $\alpha$-level of .05.

4. There was no significant regression correlation between the predictor of (log of) the number of exchange programs and the outcome variable of (log of) the number of study abroad students, with $\beta=.07, t(87)=0.624, p=.53$.

5. There was no significant regression correlation between the predictor (log of the number of partnerships and the outcome variable of (log of) the number of study abroad students, with $\beta=-.02, t(87)=-0.153, p=.88$.

However, when examining Pearson's correlation coefficients between predictor variables and the outcome variables, it appeared that both predictors of LogNEXProg and LogNPartner were strongly associated with the outcome variable of LogNSAStu, with Pearson's correlation coefficients of .41 $(p<.001)$ and $.46(p<.001)$, respectively. Because they were not significantly correlated with LogNSAStu in the regression model, the post hoc evaluation was conducted to assess whether these two predictors should be omitted from the regression model. 
Had the researcher measured the bivariate regression correlation between the predictor of LogNEXProg and the outcome variable of LogNSAStu, the findings indicated that, with LogNEXProg served as the predictor variable and LogNSAStu served as the outcome variable:

(1) the regression model was statistically significant $(R=.41, F(1,91)=18.212, p<.001)$;

(2) the predictor of LogNEXProg was significant associated with the outcome variable of LogNSAStu, with $B=0.34, t(91)=4.268, p<.001$; and (3) the predictor of LogNEXProg itself explained 16 percent of variance in the outcome variable of LogNSAStu (adjusted $R^{2}=.16$ ). Thus, it appeared that the regression correlation between LogNEXProg and LogNSAStu seemed to be mediated by the relationships between LogNSAStu and other predictor variables in the regression model. As a result, the predictor of LogNEXProg remained in the regression model 1.

Another bivariate correlation was conducted to measure the relationship between the predictor variable of LogNPartner and the outcome variable of LogNSAStu. The results showed that, with LogNPartner served as the predictor variable and LogNSAStu served as the outcome variable: (1) the regression model was statistically significant, with $R=.46, F(1,91)=24.207$, $p<.001 ;(2)$ the predictor of LogNPartner was strongly associated with the outcome variable (LogNSAStu), with $B=0.39, t(92)=4.920, p<.001$; and (3) the predictor of LogNPartner itself explained 20 percent of variance in the outcome variable of LogNSAStu (adjusted $R^{2}=.20$ ). Consequently, the result represented that the regression correlation between LogNPartner and LogNSAStu seemed to be mediated by the relationships between LogNSAStu and other predictor variables in the dataset. As a result, the predictor of LogNPartner remained in the regression model 1. 
Contribution of predictor variables. To assess the contribution of each predictor to the outcome variable of LogNSAStu, Pearson's correlation coefficients $(R), R^{2}$, adjusted $R^{2}$, part correlation coefficients, and squared semipartial correlation coefficients $\left(s r^{2}\right)$ were employed.

As shown in Table 4.6, $R=.80$, adjusted $R^{2}=.62$, which indicated that all five predictor variables together accounted for 62 percent of variance in the outcome variable (LogNSAStu).

Field (2005) stated that the part correlation represents the unique relationship that each predictor has with the outcome by controlling the effect of other independent variables (p.194). Moreover, Tabachnick and Fidell (2001) recommended using squared semipartial correlation $\left(s r^{2}\right)$ to express the amount of the observed $R^{2}$ reducing whether the significant predictor is removed from the regression model.

Table 4.7

Summary of Part and Partial Correlation Coefficients $(N=93)$

\begin{tabular}{lccc}
\hline & \multicolumn{3}{c}{ Correlation } \\
\cline { 2 - 4 } Variables & Partial & Part & $\mathrm{sr}^{2}$ \\
\hline \multicolumn{1}{c}{$(\log$ of) Human Resources } & .522 & .366 & $.134^{* * *}$ \\
$(\log$ of) Financial Resources & .330 & .209 & $.044^{* *}$ \\
$(\log$ of $)$ Number of Study Abroad Programs & .215 & .132 & $.017^{*}$ \\
$(\log$ of $)$ Number of Exchange Programs & .067 & .040 & \\
$(\log$ of $)$ Number of Partnerships & -.016 & -.010 & \\
\hline
\end{tabular}

Note. Dependent Variable: (log of) the number of study abroad students. Significant Levels:

$* p<.05 ; * * p<.01 ; * * * p<.001$. 
As shown in Table 4.7, the significant predictor variable with the greatest part correlation coefficient was LogHR (0.366), followed by LogFR (0.209), and LogNSAProg (0.132), respectively. Squared semipartial correlation $\left(s r^{2}\right)$ for three significant predictors were .134, .044, and .017, respectively. The results indicated that: (1) the significant predictor of LogHR itself contributed to 13.4 percent of variance to the observed $R^{2}$; (2) the significant predictor of $\operatorname{LogFR}$ itself contributed 4.4 percent of variance to the observed $R^{2}$ individually; and (3) the significant predictor of LogNSAProg itself contributed 1.7 percent of variance to the observed $R^{2}$.

In addition, given the sum of significant $s r^{2}=.195$, and the observed $R^{2}=.643$, the difference between the observed $R^{2}$ and the significant $s r^{2}$ was .448 , representing that all five predictors jointly contributed 44.8 percent of variance of the observed $R^{2}$.

In summary, all five predictor variables (e.g., LogHR, LogFR, LogNSAProg, LogNEXProg, \& LogNPartner) were significantly correlated with the outcome variable of LogNSAStu in Pearson's correlation coefficients. Moreover, three predictor variables (e.g., LogHR, LogFR, \& LogNSAProg) were significantly correlated with the outcome variable of LogNSAStu in the regression model 1; among them, the most significant predictor variable was LogHR, followed by LogFR and LogNSAProg, respectively. Assessing Validity of Multiple Regression Model 1

To assess whether the regression model 1 fits the observed data, diagnostics of residuals and influence cases were undertaken and results of standardized residuals, Cook's distance, centered leverage, Mahalanobis distances, standardized DFBeta, and the covariance ratio (CVR) were analyzed and reported.

Diagnostics of residuals. Field (2005) provides a general guideline to assess outliers through standard residuals: (1) whether standard residuals with an absolute value greater than 
3.29 , the cases should be caused for concern; (2) whether more than 1 percent of cases had standard residuals with an absolute value greater than 2.58 , the model was fairly poor fit of the sampled data; and (3) whether more than 5 percent of cases had standard residuals with an absolute value greater than 1.96, then the model poorly represented the actual data (p. 194). As shown in Table 4.8 below, only three (or 3.2\%) cases had standard residuals with absolute values in excess of two and none of them were greater than 3.29. Consequently, the evidence indicated that the regression model 1 was fairly accurate to represent the actual sample. Table 4.8

Casewise Diagnostics for the Multiple Regression Model $1(N=93)$

\begin{tabular}{ccccc}
\hline $\begin{array}{c}\text { Case } \\
\text { Number }\end{array}$ & Std. Residual & LogNSAStu & Predicted Value & Residual \\
\hline 85 & -3.201 & 1 & 2.08 & -1.038 \\
29 & -2.966 & 2 & 1.92 & -.962 \\
49 & -2.319 & 1 & 2.31 & -0.752 \\
\hline
\end{tabular}

Note. Dependent Variable: LogNSAStu.

Diagnostics of influential cases. To assess whether the regression model 1 is stable across the sample, it is critical to examine whether certain cases exert undue influence on the parameters of the regression model. Therefore, Cook's distance, centered leverage, Mahalanobis distances, standardized DFBeta, and the covariance ratio (CVR) were examined and reported. The results of findings showed as follows:

1. All cases with values of Cook's distance were lower than 1 that indicated that no more cases had the overall undue influence on the regression model 1.

2. The average leverage value was defined as $(k+1) / n$. The values of centered leverage showed that all cases were located within the boundary of three times the average 
leverage (0.195), indicating that none of cases had undue influence on the regression model 1.

3. With five variables served as predictors, the values of Mahalanobis distance should not be greater than $20.515\left(x^{2}(5)=20.515, \alpha<.001\right)$ (Tabachnick \& Fidell, 2001, p. 157). None of cases had Mahalanobis distance in excess of 20.515; thus, no outliers were identified.

4. The standardized DFBeta was examined to see the difference between a parameter estimated using all cases and estimated when one case was excluded. The results showed that values of the standardized DFBeta of all cases were below 1. It concluded that all cases had no substantial influence on parameters of the regression model 1 .

5. Covariance ratio (CVR). The final measure is the CVR that addresses whether a case influenced the variance of the regression parameters. Field (2005) suggests that when CVR is close to 1 , the case has very little influence on the variances of the model parameter. In addition, Belsey, Kuh \& Welsch (1980) recommend that: (1) if $\mathrm{CVR}_{i}>1+[3(\mathrm{k}+1) / \mathrm{n}]$, deleting the $i$ th case can damage the precision of some of the model's parameters; and (2) if $\mathrm{CVR}_{i}<1-[3(\mathrm{k}+1) / \mathrm{n}]$, deleting the $i$ th case can improve the precision of some of the model's parameters. Based on Belsey, Kuh \& Welsch's (1980) formula, the value of each CVR should be greater than 0.81 and lower than 1.19. After examining the CVR values based on values of the case summary, it was found that two (or $2 \%$ ) cases had CVR lower than 0.81 that should cause for concern. However, given Cook's distance of these two cases far below 1, there was no real need to delete these two cases from the dataset. 
All above, on the basis of the casewise diagnostic and the case summary of the regression model 1 , it is concluded that the multiple regression model 1 is established based on the observed sample and it is reliable and stable across the sample.

\section{Assessing Generalization of Multiple Regression Model 1}

The generalization of a regression model is to assess whether the regression model is reliable to a large population. Under this condition, assumptions of multiple regression analysis and cross-validation of the multiple regression model are examined and reported.

Assumptions of multiple regression analysis. The check-list of assumption of multiple regression analysis included variable types, multicollinearity, normality, linearity, and homoscedasticity of residuals, and the independent errors. The results were detailed as follows:

1. Variable types. All predictor variables and dependent variables were quantitative and continuous; and no zero variance was found in analysis of variance for both untransformed and transformed data.

2. Multicollinearity. Multicollinearity increases type II error and makes it difficult to assess the individual importance of a predictor; further, multicollinearity increases regression coefficients and causes the multiple regression model unstable. As shown in Table 4-3 and Table 4-4, no more Pearson's correlation coefficient was found greater than .90. In addition, the results of variance inflation factors (VIF) and tolerance statistics showed that the largest VIF was 3.09, which was far below 10 and the values of tolerance were all greater than 0.2 . Moreover, it was found that the large proportion of variance had eigenvalue below 0.093. Consequently, all evidences indicated that the multicollinearity was not problematic in the regression model 1. 
3. Normality, linearity, and homoscedasticity of Residuals. The results of histogram plots of standard residuals and partial plots of each predictor variable against the residual of the outcome variable indicated that the normality, linearity, and homoscedasticity were roughly met (see Appendix M).

4. Independent errors. As shown in Table 4-6, Durbin-Waston test for the regression model 1 was 1.830 that was very close to 2 . This value indicated that residuals were independent and did not cause for concern.

Cross-validation. The analysis of the cross-validation provides another way to assess whether the regression model accurately predicts the outcome in a different sample. In other words, the cross-validity is used to assess whether the regression model can be generalized to predict the same outcome variable with the same predictors in a large population.

According to Stein's formula, (Field, 2005, p. 172), Stein's adjusted $R^{2}=.596$, which indicated that the five predictors together accounted for 59.6 percent of variance in the outcome variable of the number of study abroad students. In addition, the difference between observed $R^{2}$ and Stein's adjusted $R^{2}$ was .047 that was lower than .05 , indicating that the cross-validity of this regression model 1 was good.

Sample size. Green (1991) provides two rules of thumb for the minimum acceptable sample size when conducting multiple regression analysis: (1) to test the overall significance of the multiple regression model, the minimum sample size of $50+8 \mathrm{k}$ is required; and (2) to test the significance of individual predictor, the minimum sample size of $104+\mathrm{k}$ is needed. Moreover, Miles and Shevlin (2001) designed a diagram to detect the sample size based on Cohen's benchmark level of power (.80). With five predictors, the required sample size is around 90 if the medium effect size is achieved (Field, 2005, p. 173). 
With five predictors and 93 cases, the regression model 1 met the minimum requirement $(N=90)$ of sample size to assess the overall significance of the regression model. However, the minimum requirement of assessing the significance of individual predictor was not achieved $(N=109)$, even though the observed cases were very close.

In summary, the regression model 1 is accurate to predict the sample data and could be roughly generalized to the population. Therefore, the five predictors together (e.g., human resources, financial resources, the number of study abroad programs, the number of exchange programs, and the number of partnerships) can be applied to estimate the outcome variable of the number of study abroad students. In addition, each of significant predictors (e.g., human resources, financial resources, the number of study abroad programs) can be used to estimate the outcome variable.

Research Question Two

The second research question asked: Do the institutional input variables (e.g., human resources and financial resources) and the process variables (e.g., the number of study abroad programs, the number of exchange programs, and the number of international partnerships) have relationships with the number of international exchange students?

The independent variables included (log of) human resources ( $\log H R),(\log$ of $)$ financial resources (LogFR), (log of) the number of study abroad programs (LogNSAProg), $(\log$ of) the number of exchange programs (LogNEXProg), and (log of) the number of partnerships (LogNPartner); and the dependent variable was (log of) the number of exchange students (LogNEXStu). Because one outlier in the dataset was found and deleted, 92 valid cases were used in the regression analysis for the research question two. 
Equation of multiple regression model 2. The multiple regression model 2 was

formulized based on values of the constant and unstandardized coefficients $(B)$ of five predictors. As shown in Table 4.9 below, the constant was 0.259 ; and the unstandardized coefficients $(B)$ of five predictors were 0.25 (LogHR), -0.06 (LogFR), -0.08 (LogNSAProg), 0.73 (LogNEXProg), and 0.30 (LogNPartner), respectively.

Table 4.9

Results of Multiple Regression Model $2(N=92)$

\begin{tabular}{lccc}
\hline \multicolumn{1}{c}{ Variables } & $B$ & SE B & $\beta$ \\
\hline Constant & 0.259 & 0.18 & \\
$(\log$ of) Human Resources & 0.25 & 0.16 & .11 \\
$(\log$ of) Financial Resources & -0.06 & 0.07 & -.05 \\
$(\log$ of $)$ Number of Study Abroad Programs & -0.08 & 0.10 & -.06 \\
$(\log$ of $)$ Number of Exchange Programs & 0.73 & 0.10 & $.66^{* * *}$ \\
$(\log$ of $)$ Number of Partnerships & 0.30 & 0.10 & $.26^{*}$ \\
\hline
\end{tabular}

Note. Predictors: (Constant), LogHR, LogFR, LogNSAProg, LogNEXProg, LogNPartner. Dependent Variable: LogNEXStu. Significant Levels: ${ }^{*} p<.05 ; * * p<.01 ; * * * p<.001$.

Because the formula of the regression model used for the research question two was:

$N E X S t u=b_{0}+b_{1} \mathrm{HR}+b_{2} \mathrm{FR}+b_{3} \mathrm{NSAProg}+b_{4} \mathrm{NEXProg}+b_{5}$ NPartner, the multiple regression model 2 was established as the following:

$$
\begin{aligned}
\operatorname{LogNEXStu}= & 0.259+(0.25 \mathrm{LogHR})-(0.06 \operatorname{LogFR})-(0.08 \operatorname{LogNSAProg})+(0.73 \operatorname{LogNEXProg}) \\
& +(0.30 \operatorname{LogNPartner})
\end{aligned}
$$

(Equation 4.2)

Significance of multiple regression model 2. Table 4.10 below displayed the summary of the regression model 2. With all five independent variables (e.g., LogHR, LogFR, LogNSAProg, 
LogNEXProg, \& LogNPartner) served as predictor variables and the dependent variable of LogNEXStu served as the outcome variable, $R=.88, F(5,86)=56.551, p<.001$, the results indicated that the regression model 2 was statistically significant.

Table 4.10

Summary of Standard Multiple Regression Model $2(N=92)$

\begin{tabular}{|c|r|r|r|r|r|r|r|r|}
\hline Model & R & R Square & $\begin{array}{c}\text { Adjusted R } \\
\text { Square }\end{array}$ & $\begin{array}{c}\text { R Square } \\
\text { Change }\end{array}$ & df1 & df2 & F & Sig. \\
\hline & & & & & & & & \\
2 & .876 & .767 & .753 & .767 & 5 & 86 & 56.551 & .000 \\
\hline
\end{tabular}

Note. Predictors: (Constant), LogHR, LogFR, LogNSAProg, LogNEXProg, LogNPartner. Dependent Variable: LogNEXStu. Significant Levels: ${ }^{*} p<.05 ;{ }^{* *} p<.01 ; * * *<.001$.

Significance of predictor variables. To assess whether there are significant relationships among predictor variables and the outcome variable, values based on unstandardized coefficients $b$-value (B), standardized coefficients $\beta$, and $t$-tests at significant $\alpha$-level of .05 are examined and reported.

As shown in Table 4.9 above, the results indicated that two out of five predictors (e.g., $\operatorname{LogNEXProg} \& \operatorname{LogNPartner}$ ) significantly correlated with the outcome variable of LogNEXStu; and other three predictors (e.g., $\log H R, \operatorname{LogFR}, \& \operatorname{LogNSAProg}$ ) had no significant relationships with the outcome variable of LogNEXStu.

According to Cohen's widely accepted guideline for the effect size ( $r=.10$, small effect; $r=.30$, medium effect; $\& r=.50$, large effect) (Field, 2005), the regression correlations between each predictor and the outcome variable of LogNEXStu were illustrated as the following:

1. The predictor of (log of) human resources had a small size of regression correlation with the outcome variable of (log of) number of exchange students, with $B=0.25$, 
$\beta=.11$; however, the relationship was not statistically significant, with $t(86)=1.518$, $p=.13$.

2. No significant relationship was found between the predictor of (log of) financial resources and the outcome variable of (log of) the number of exchange students, with $B=-0.06, \beta=-.05, t(86)=-0.904, p=.37$

3. No significant relationship was found between the predictor of (log of) the number of study abroad programs and the outcome variable of (log of) the number of exchange students, with $B=-0.08, \beta=-.06, t(86)=-0.806, p=.42$.

4. The predictor of (log of) the number of exchange programs had a large significant relationship with the outcome variable of (log of) the number of exchange students, with $B=0.73, \beta=.66, t(86)=7.554, p<.001$.

5. The predictor (log of) the number of partnerships had a medium size of relationship with the outcome variable of (log of) the number of exchange students, with $B=0.30$, $\beta=.26, t(86)=2.895, p<.01$.

In addition, as shown in Table 4.4, when examining the Pearson's correlation coefficients of these three non-significant predictors (e.g., LogHR, LogFR, and LogNSAProg), the findings indicated that: (1) the predictor of LogFR was not significantly related to the outcome variable of LogNEXStu and was deleted from the regression model 2; (2) the other two predictor variables (e.g., LogHR \& LogNSAProg) were strongly associated with the outcome variable of LogNEXStu, with Pearson's correlation coefficients of .43 $(p<.001)$ and $.58(p<.001)$, respectively. Because these two variables (e.g., LogHR \& LogNSAProg) did not significantly relate to the outcome variable of LogNEXStu in the regression model 2 (see Table 4.9), the post 
hoc evaluation was further conducted to assess whether they should be omitted from the regression model 2.

Based on the analysis of bivariate regression correlations between each of predictor variables (e.g., LogHR \& LogNSAProg) and the outcome variable of LogNEXStu, the findings indicated that:

1. With LogHR served as the only predictor in the regression model: (1) the regression model was statistically significant, with $R=.43, F(1,90)=20.454, p<.001$; (2) the predictor of LogHR had strongly significant relationship with the outcome variable of LogNEXStu, with $B=0.96, \beta=.43, t(90)=4.523, p<.001$; and (3) the predictor of LogHR itself explained 17.6 percent of variance in the outcome variable of LogNEXStu (adjusted $R^{2}=.176$ ). Thus, it was concluded that the regression correlation between LogHR and LogNEXStu seemed to be mediated by relationships between LogNEXStu and other predictor variables in the dataset. As a result, the predictor of LogHR remained in the regression model 2.

2. With LogNSAProg served as the only predictor in the regression model: (1) the regression model was statistically significant, with $R=.57, F(1,90)=42.732$, $p<.001 ;$ (2) the predictor of LogNSAProg had strongly significant relationship with the outcome variable of $\operatorname{LogNEXStu}$, with $B=0.74, \beta=.57, t(90)=6.573, p<.001$; and (3) the predictor of LogNSAProg itself explained 31.4 percent of variance in the outcome variable of LogNEXStu (adjusted $R^{2}=.314$ ). Thus, it was concluded that the regression correlation between LogNSAProg and LogNEXStu seemed to be mediated by relationships between LogNEXStu and other predictor variables in the dataset. As a result, the predictor of LogNSAProg remained in the regression model 2. 
Consequently, the regression model 2 was re-operated based on four predictor variables (e.g., LogHR, LogNSAProg, LogNEXProg, \& LogNPartner). As shown in Table 4.11 below, the results showed that: (1) the new regression model 2 was statistically significant, with $R=.87$, $F(4,87)=70.633, p<.001 ;(2)$ four predictor variables together accounted for 75 percent variance in the outcome variable of LogNEXStu, with adjusted $R^{2}=.754$; and (3) only two predictors (e.g., LogNEXProg \& LogNPartner) in the regression model 2 were significantly associated with the outcome variable of LogNEXStu.

Table 4.11

Summary of the Multiple Regression Model $2(N=92)$

\begin{tabular}{|c|r|r|r|r|r|r|r|r|}
\hline Model & \multicolumn{1}{c|}{$\mathrm{R}$} & R Square & $\begin{array}{c}\text { Adjusted R } \\
\text { Square }\end{array}$ & $\begin{array}{c}\text { R Square } \\
\text { Change }\end{array}$ & df1 & df2 & F & $\begin{array}{c}\text { Durbin- } \\
\text { Watson }\end{array}$ \\
\hline 2 & .874 & .765 & .754 & .765 & 4 & 87 & $70.633^{* * *}$ & 1.974 \\
\hline
\end{tabular}

Note. Predictors: (Constant), LogHR, LogNSAProg, LogNEXProg, LogNPartner. Dependent Variable: LogNEXStu. Significant Levels: $* p<.05 ; * * p<.01 ; * * * p<.001$.

Table 4.12

Results of Standard Multiple Regression Model $2(N=92)$

\begin{tabular}{lccc}
\hline \multicolumn{1}{c}{ Variables } & $B$ & $S E B$ & $\beta$ \\
\hline Constant & 0.139 & 0.12 & \\
(log of) Human Resources & 0.19 & 0.15 & .09 \\
(log of ) Number of Study Abroad Programs & -0.09 & 0.10 & -.07 \\
(log of ) Number of Exchange Programs & 0.71 & 0.10 & $.65^{* * *}$ \\
(log of) Number of Partnerships & 0.32 & 0.10 & $.28^{* *}$ \\
\hline
\end{tabular}

Note. Predictors: (Constant), LogHR, LogNSAProg, LogNEXProg, LogNPartner.

Dependent Variable: LogNEXStu. Significant Levels: ${ }^{*} p<.05 ; * * p<.01 ; * * * p<.001$. 
In addition, as shown in Table 4.12 above, the results of standard multiple regression analysis based on four predictor variables showed that the constant was 0.139 ; and the unstandardized coefficients $(B)$ were 0.19 (LogHR), -0.09 (LogNSAProg), 0.71 (LogNEXProg), and 0.32 (LogNPartner), respectively. As a result, the final equation of the regression model 2 was formulized as the following:

$$
\begin{aligned}
\operatorname{LogNEXStu}= & 0.139+(0.19 \operatorname{LogHR})+(0.71 \log N E X P r o g)+(0.32 \operatorname{LogNPartner}) \\
& -(0.09 \operatorname{LogNSAProg})
\end{aligned}
$$

(Equation 4.3)

Contribution of predictor variables. To assess the contribution of each predictor to the outcome variable of LogNEXStu, Pearson's correlation coefficients $(R), R^{2}$, adjusted $R^{2}$, part correlation coefficients, and squared semipartial correlation coefficients $\left(s r^{2}\right)$ were employed (see Table 4.13).

Table 4.13

Summary of Part and Partial Correlation Coefficients $(N=92)$

\begin{tabular}{lccc}
\hline & \multicolumn{3}{c}{ Correlation } \\
\cline { 2 - 4 } Variables & Partial & Part & $\mathrm{sr}^{2}$ \\
\hline (log of) Human Resources & .136 & .066 & \\
$(\log$ of $)$ Number of Study Abroad Programs & -.093 & -.045 & $.153^{* * *}$ \\
$(\log$ of $)$ Number of Exchange Programs & .627 & .391 & $.027 * *$ \\
\hline
\end{tabular}

Note. Dependent Variable: (log of) the number of exchange students. Significant Levels:

$* p<.05 ; * * p<.01 ; * * * p<.001$. 
As shown in Table 4.13, the greatest part correlation was $\operatorname{LogNEXProg}(0.391)$, followed by LogNPartner (0.164). The results indicated that the predictor of LogNEXProg itself contributed 39.1 percent of variance to the observed $R^{2}$ and the predictor of LogNPartner itself contributed 16.4 percent of variance to the observed $R^{2}$.

In addition, given the sum of significant $s r^{2}=.18$, and observed $R^{2}=.765$, the difference between the observed $R^{2}$ and the sum of significant $s r^{2}$ was 0.59 , representing that all four predictors jointly contributed 59 percent of variance to the observed $R^{2}$.

In summary, four predictor variables (e.g., LogHR, LogNSAProg, LogNEXProg, \& LogNPartner) were significantly correlated with the outcome variable of LogNEXStu in Pearson's correlation coefficients. Moreover, two predictor variables (e.g., LogNEXProg \& LogNPartner) were significantly correlated with the outcome variable of LogNEXStu in the regression model 2; among them, the most significant predictor variable to the outcome variable of LogNEXStu was LogNEXProg, followed by LogNPartner. Assessing Validity of Multiple Regression Model 2

To assess whether the regression model 2 (Equation 4.3) fits the observed data, analysis of residuals and influence cases were examined based on results of standard residuals, Cook's distance, leverage, Mahalanobis distances, standardized DFBeta, and the covariance ratio (CVR). Diagnostics of residuals. As shown in Table 4.14 below, six (6.5\%) cases had standard residuals with an absolute value in excess of $2(6.5 \%)$; but none of them was greater than 3.29 . In addition, even though 6.5 percent cases had standard residuals with an absolute value greater than 2; the percentage was close to 5 percent; moreover, the histogram of standard residuals distributed normally and did not cause concern. Consequently, with 92 valid cases and four predictors, the regression model 2 was roughly accurate to represent the actual sample. 
Table 4.14

Casewise Diagnostics of Multiple Regression Model 2 ( $N=92)$

\begin{tabular}{ccccc}
\hline $\begin{array}{c}\text { Case } \\
\text { Number }\end{array}$ & Std. Residual & LogNEXStu & Predicted Value & Residual \\
\hline 13 & -2.029 & 1 & 1.79 & -.713 \\
41 & 2.367 & 1 & .21 & .832 \\
50 & 2.009 & 2 & 1.32 & .706 \\
53 & -2.912 & 1 & 1.80 & -1.023 \\
80 & -2.115 & 0 & .74 & -.743 \\
86 & 2.803 & 3 & 1.71 & .985 \\
\hline
\end{tabular}

Note. Dependent Variable: (log of) the number of exchange students (LogNEXStu).

Diagnostics of influential cases. To assess whether the regression model is stable across the sample, Cook's distance, centered leverage, Mahalanobis distances, standardized DFBeta, and the covariance ratio (CVR) are examined to see whether undue influence on the parameters of the regression model exists. The results showed that:

1. The values of Cook's distance of all cases were lower than 1 , indicating that no more cases had the overall undue influence on the regression model 2.

2. It was found that all cases located within the boundary of three times of the average leverage $0.163(3(\mathrm{k}+1) / \mathrm{n})$, indicating that none of cases had undue influence on the regression model 2 .

3. With a small sample and four predictor variables, the values of Mahalanobis distance should not be greater than $18.47\left(x^{2}(4)=18.47, p<.001\right)$. The results showed that no more outliers existed in the dataset.

4. The standardized DFBeta was further examined to see whether the difference between a parameter estimated using all cases and estimated when one case was excluded. The results showed that values of the standardized DFBeta for all cases 
were below 1, indicating that all cases had no substantial influence on parameters of the regression model 2.

5. Covariance ratio (CVR). Based on the formula provided by Belsey, Kuh \& Welsch (1980), CVR in regression model 2 should be lower than 1.16 and greater than 0.84 . Two case were caused for concern, with CVR of 0.783 (case number 41 ) and 0.668 (case number 86), respectively. However, given Cook's distances of these two cases were far below 1, there was no need to delete them from the dataset.

All above, On the basis of the casewise diagnostic and the case summary for the regression model 2 , it was concluded that the multiple regression model 2 was established fairly based on the observed sample and roughly stable.

\section{Assessing Generalization of Multiple Regression Model 2}

The generalization of a regression model is to assess whether the regression model is reliable to a large population. Under this condition, assumptions of multiple regression analysis and the cross-validation of the multiple regression model are examined and reported.

Assumptions of multiple regression analysis. The check-list of assumptions of multiple regression analysis includes variable types, multicollinearity, normality, linearity, and homoscedasticity of residuals, and the independent errors.

1. Variable types. All predictor variables and the outcome variable were quantitative, continuous and unbounded; and no zero variance was found in analysis of variance for both untransformed and transformed data;

2. Multicollinearity. No more Pearson's correlation coefficient was greater than .90 (see Table 4.4). In addition, the collinearity diagnostics based on results of variance inflation factors (VIF) and tolerance statistics showed that the largest VIF was 2.94, 
which was far below 10; the values of tolerance were all greater than 0.2. Moreover, the large proportion of variance had eigenvalue below 0.088 . Thus, all evidences indicated that the multicollinearity was not problematic in the regression model 2.

5. Normality, linearity, and homoscedasticity of residuals. The histogram plots of standard residuals and partial plots of each of predictors against the residual of the outcome variable indicated that the normality, linearity, and homoscedasticity were roughly met.

6. Independent errors. Durbin-Waston test for the regression model 2 was 1.974 , which was close to 2 . This value indicated that residuals were independent and did not cause for concern.

Cross-validation. The analysis of the cross-validation is to assess whether the regression model accurately predicts the outcome variable in a different sample. Accordingly, Stein's adjusted $R^{2}=.734$, indicating that the four predictors together accounted for 73.4 percent of variance in the outcome variable of the number of exchange students. Given the observed $R^{2}=.765$, the difference between observed $R^{2}$ and Stein's adjusted $R^{2}$ was .031 . The difference $(3.1 \%)$ was smaller than 5 percent, indicating that the cross-validity of the regression model 2 was good.

Sample size. According to Green's (1991) formula for the minimum requirement of the sample size for conducting multiple regression analysis, with four predictors in the regression model 2 , at least $82(8 \mathrm{k}+50)$ cases are needed to assess the overall significance of the regression model and $108(104+\mathrm{k})$ cases are needed to assess the significance of individual predictor (Field, 2005, p. 173). Because 92 valid cases were used in analysis of regression model 2, the minimum requirement $(N=82)$ of sample size was achieved to assess the significance of the regression 
model. However, for assessing the significance of individual predictor, at least 16 more cases were needed in the dataset.

In summary, the multiple regression model 2 (Equation 4.3) fairly fits the sample data and can be roughly generalized to the large population. In addition, the four predictors (e.g., human resources, the number of study abroad programs, the number of exchange programs and the number of partnerships) together can be applied to estimate the outcome variable of the number of exchange students.

\section{Research Question Three}

The third research question asked: Do the institutional input variables (e.g., human resources and financial resources) and the process variables (e.g., the number of study abroad programs, the number of exchange programs, and the number of international partnerships) have relationships with the number of faculty abroad?

The independent variables included (log of) human resources $(\log H R),(\log$ of $)$ financial resources (LogFR), (log of) the number of study abroad programs (LogNSAProg), $(\log$ of) the number of exchange programs (LogNEXProg), and (log of) the number of partnerships (LogNPartner); and the dependent variable was (log of) the number of faculty abroad (LogNFac). When screening data, three outliers were found and deleted from the dataset; thus, 90 cases were used in analysis of the regression model 3.

Equation of multiple regression model 3. The multiple regression model 3 was

formulized based on values of the constant and unstandardized coefficients $(B)$ of five predictors. As shown in Table 4.15 below, the constant was 0.252 ; and the unstandardized coefficients $(B)$ of five predictors were 0.38 (LogHR), -0.06 ( $\operatorname{LogFR}), 0.50$ (LogNSAProg), -0.08 (LogNEXProg), and $0.14(\operatorname{LogNFac})$, respectively. 
Table 4.15

Results of Standard Multiple Regression Analysis for the Regression Model $3(N=90)$

\begin{tabular}{lccc}
\hline \multicolumn{1}{c}{ Variables } & $B$ & $S E B$ & $\beta$ \\
\hline Constant & 0.252 & 0.18 & \\
(log of) Human Resources & 0.38 & 0.17 & $.23^{*}$ \\
(log of) Financial Resources & -0.06 & -0.07 & -.07 \\
$(\log$ of $)$ Number of Study Abroad Programs & 0.50 & 0.11 & $.54^{* * *}$ \\
$(\log$ of $)$ Number of Exchange Programs & -0.08 & 0.10 & -.10 \\
$(\log$ of $)$ Number of Partnerships & 0.14 & 0.10 & .17 \\
\hline
\end{tabular}

Note. Predictors: (Constant), LogHR, LogFR, LogNSAProg, LogNEXProg, LogNPartner.

Dependent Variable: LogNFac. Significant Levels: $* p<.05 ; * * p<.01 ; * * * p<.001$.

Because the formula of the multiple regression model 3 was: $N F a c=b_{0}+b_{1} \mathrm{HR}+b_{2} \mathrm{FR}+$ $b_{3}$ NSAProg $+b_{4}$ NEXProg $+b_{5}$ NPartner, the multiple regression model 3 was established as the following:

$$
\begin{aligned}
\operatorname{LogNFac}= & 0.252+(0.38 \log H R)-(0.06 \operatorname{LogFR})+(0.50 \operatorname{LogNSAProg})-(0.08 \operatorname{LogNEXProg}) \\
& +(0.14 \operatorname{LogNPartner})
\end{aligned}
$$

(Equation 4.4)

Table 4.16

Summary of the Multiple Regression Model $3(N=90)$

\begin{tabular}{|c|r|r|r|r|r|r|r|r|}
\hline Model & \multicolumn{1}{|c|}{$\mathrm{R}$} & R Square & $\begin{array}{c}\text { Adjusted R } \\
\text { Square }\end{array}$ & $\begin{array}{c}\text { R Square } \\
\text { Change }\end{array}$ & df1 & df2 & F & Sig. \\
\hline & & & & & & & & \\
3 & .744 & .554 & .527 & .554 & 5 & 84 & 20.874 & .000 \\
\hline
\end{tabular}

Note. Predictors: (Constant), LogHR, LogFR, LogNSAProg, LogNEXProg, LogNPartner.

Dependent Variable: LogNFac. Significant Levels: ${ }^{*} p<.05 ; * * p<.01 ; * * * p<.001$. 
Significance of multiple regression model 3 . Table 4.16 above displayed the summary of the multiple regression model 3, with $R=.74, F(5,84)=20.847, p<.001$. The results indicated that the regression model 3 was statistically significant at $\alpha-$ level of .001 .

Significance of predictor variables. To assess whether there are significant relationships among predictor variables and the outcome variable, values based on unstandardized coefficients $b$-value (B), standardized coefficients $\beta$, and $t$-tests at significant $\alpha$-level of .05 are examined and reported.

As shown in Table 4.15 above, two out of five predictor variables (e.g., LogNSAProg \& LogHR) had significant relationships with the outcome variable of LogNFac; and another three out of five predictors (e.g., LogFR, $\operatorname{LogNEXProg}, \&$ LogNPartner) were not significantly related with the outcome variable of LogNFac.

According to Cohen's widely accepted guideline for the effect size $(r=.10$, small effect; $r=.30$, medium effect; $r=.50$, large effect), the relationships between each predictor variable and the outcome variable ( $\log N F a c)$ are illustrated as follows:

1. The predictor of (log of) human resources had a small size of relationship with the outcome variable of (log of) number of faculty abroad, with $B=0.38, \beta=.23$; and the relationship was statistically significant, with $t(84)=2.231, p<.05$.

2. No significant relationship was found between the predictor of (log of) financial resources and the outcome variable of (log of) the number of faculty abroad, with $B=-0.06, \beta=-.07, t(84)=-0.885, p=.379$.

3. The predictor of (log of) the number of study abroad programs had a large relationship with the outcome variable of (log of) the number of faculty abroad, with $B=0.50, \beta=.54, t(84)=4.548, p<.001$. 
4. No significant relationship was found between the predictor of (log of) the number of exchange programs and the outcome variable of (log of) the number of faculty abroad, with $B=-0.08, \beta=-.10, t(84)=-0.801, p=.425$.

5. A small size of relationship existed between the predictor (log of) the number of partnerships and the outcome variable of (log of) the number of faculty abroad, with $B=0.14, \beta=.17$, and the relationship was not statistically significant, with $t(84)=1.307, p=.195$.

In addition, when examining the Pearson's correlation coefficients between three predictor variables (e.g., LogFR, LogNEXProg, \& LogNPartner) and the outcome variable of LogNFac, the findings indicated that all the three predictors were significantly associated with the outcome variable of LogNFac, with Pearson's correlation coefficients of .19 $(p<.05), .46$ $(p<.001)$, and $.57(p<.001)$, respectively (see Table 4.4). Because these three predictors were not significantly correlated with LogNFac in the regression model, the post hoc evaluation was conducted to assess whether these three predictors should be omitted from the regression model.

Based on the analysis of bivariate regression correlations between each of the three predictor variables (e.g., LogFR, LogNEXProg, and LogNPartner) and the outcome variable of LogNFac, the results showed that:

1. With LogFR served as the only predictor in the regression model, the results indicated that: (1) the regression model was not statistically significant, with $R=.19$, $F(1,88)=3.341, p=.071$; and (2) the predictor of LogFR was not significantly associated with the outcome variable of LogNFac, with $B=0.16, \beta=.19$, $t(88)=1.828, p=.071$. As a result, the predict variable of LogFR was removed from the regression model 3. 
3. With LogNEXProg served as the only predictor in the regression model, the results indicated that: (1) the regression model was statistically significant, with $R=.46$, $F(1,88)=23.870, p<.001 ;(2)$ the predictor of LogNEXProg was significantly associated with the outcome variable of $\operatorname{LogNFac}$, with $B=0.37, \beta=.46$, $t(88)=4.886, p<.001$; and $(3)$ the predictor of LogNEXProg itself accounted for 20.4 percent of variance in the outcome variable of LogNFac. Therefore, it appeared that the regression correlation between LogNEXProg and LogNFac seemed to be mediated by the relationships between LogNFac and other predictor variables in the regression model 3. Finally, the predictor of LogNEXProg remained in the regression model 3.

4. With LogNPartner served as the only predictor in the regression model, the result showed that: (1) the regression model was statistically significant, with $R=.57$, $F(1,88)=40.823, p<.001 ;(2)$ the predictor of LogNPartner was significantly associated with the regression model, with, $B=0.47, \beta=.57, t(88)=6.544, p<.001$; and (3) the predictor of LogNPartner itself explained 32 percent of variance in the outcome variable of LogNFac. Thus, the results indicated that the regression correlation between LogNPartner and LogNFac seemed to be mediated by the relationships between LogNFac and other predictor variables in the regression model. As a result, the predictor of LogNPartner remained in the regression model 3.

Consequently, the regression model 3 was computerized again based on four predictor variables (e.g., LogHR, LogNSAProg, LogNEXProg, \& LogNPartner). As shown in Table 4.17, the results indicated that: (1) the new regression model 3 was statistically significant, with 
$R=.74, F(4,85)=25.929, p<.001 ;(2)$ four predictor variables together accounted for 52.8 percent of variance in the outcome variable of LogNFac, with adjusted $R^{2}=.528$; and (3) two predictors (e.g., LogNEXProg \& LogNPartner) were significantly associated with LogNFac. Table 4.17

Summary of Standard Multiple Regression Model $3(N=90)$

\begin{tabular}{|c|r|r|r|r|r|r|r|r|}
\hline Model & $\mathrm{R}$ & R Square & $\begin{array}{c}\text { Adjusted R } \\
\text { Square }\end{array}$ & $\begin{array}{c}\text { R Square } \\
\text { Change }\end{array}$ & df1 & df2 & F & $\begin{array}{c}\text { Durbin- } \\
\text { Watson }\end{array}$ \\
\hline 1 & .741 & .550 & .528 & .550 & 4 & 85 & $25.929^{* * *}$ & 2.078 \\
\hline
\end{tabular}

Note. Predictors: (Constant), LogHR, LogNSAProg, LogNEXProg, LogNPartner. Dependent Variable: LogNFac. Significant Levels: ${ }^{*} p<.05 ; * * p<.01 ; * * * p<.001$.

Table 4.18

Results of Standard Multiple Regression Model $3(N=90)$

\begin{tabular}{lccc}
\hline \multicolumn{1}{c}{ Variables } & $B$ & SE B & $\beta$ \\
\hline Constant & 0.133 & 0.12 & \\
(log of) Human Resources & 0.32 & 0.16 & $.20^{*}$ \\
(log of) Number of Study Abroad Programs & 0.50 & 0.11 & $.53^{* * *}$ \\
(log of) Number of Exchange Programs & -0.09 & 0.10 & -.11 \\
(log of) Number of Partnerships & 0.16 & 0.10 & .19 \\
\hline
\end{tabular}

Note. Predictors: (Constant), LogHR, LogNSAProg, LogNEXProg, LogNPartner.

Dependent Variable: LogNFac. Significant Levels: ${ }^{*} p<.05 ;{ }^{* *} p<.01 ; * * * p<.001$.

As shown in Table 4.18 above, the constant was 0.133 ; and the unstandardized coefficients $(B)$ of four predictor variables were 0.32 (LogHR), 0.50 (LogNSAProg), -0.09 (LogNEXProg), and 0.16 (LogNPartner), respectively. As a result, the final equation for the regression model 3 was formulized as the following: 


$$
\begin{aligned}
\operatorname{LogNFac}= & 0.133+(0.32 \operatorname{LogHR})+(0.50 \operatorname{LogNSAProg})+(0.16 \operatorname{LogNPartner}) \\
& -(0.09 \operatorname{LogNEXProg})
\end{aligned}
$$

(Equation 4.5)

Contribution of predictor variables. To assess the contribution of each of predictor variables to the outcome variable of LogNFac, Pearson's correlation coefficients $(R), R^{2}$, adjusted $R^{2}$, part correlation coefficients, and squared semipartial correlation coefficients $\left(s r^{2}\right)$ are examined and reported.

Part correlations and squared semipartial correlations were displayed in Table 4.19 below. The results indicated that the greatest significant part correlation was LogNSAProg (0.329), followed by $\operatorname{LogHR}(0.149)$. In addition, given the sum of two significant $s r^{2}=.130$, and observed $R^{2}=.550$, the difference between the sum of significant $s r^{2}$ and observed $R^{2}$ was 0.42 , indicating that all four predictors jointly accounted for 42 percent of variance in the observed $R^{2}$. Table 4.19

Summary of Part and Partial Correlation Coefficients $(N=90)$

\begin{tabular}{lccc}
\hline & \multicolumn{3}{c}{ Correlation } \\
\cline { 2 - 4 } Variables & Partial & Part & $\mathrm{sr}^{2}$ \\
\hline \multicolumn{1}{c}{$(\log$ of $)$ Human Resources } & .217 & .149 & $.022^{*}$ \\
$(\log$ of $)$ Number of Study Abroad Programs & .440 & .329 & $.108^{* * *}$ \\
$(\log$ of $)$ Number of Exchange Programs & -.101 & -.068 & \\
$(\log$ of $)$ Number of Partnerships & .163 & .111 & \\
\hline
\end{tabular}

Note. Dependent Variable: (log of) the number of faculty abroad. Significant Levels: ${ }^{*} p<.05$; $* * p<.01 ; * * * p<.001$. 
In summary, four variables (e.g., LogHR, LogNSAProg, LogNEXProg, \& LogNPartner) were significantly associated with the outcome variable of LogNFac in Pearson's correlation coefficients; In addition, two predictor variables (LogNEXProg \& LogNPartner) were significantly associated with the outcome variable of LogFac in the regression model 3; among them, the most significant predictor variable to the outcome variable of LogNFac was LogNSAProg, followed by LogHR. Assessing Validity of Multiple Regression Model 3

To assess whether the regression model 3 (Equation 4.5) fits from the sampled data, analysis of residuals and influence cases are examined on the basis of values of standard residuals, Cook's distance, leverage, Mahalanobis distances, standardized DFBeta, and the covariance ratio (CVR).

Diagnostics of residuals. As shown in Table 4.20 below, five cases (or 5.6\%) had standard residuals with an absolute value in excess of 3.29 and none of them was greater than 3.29. The results showed that no more outlier existed in the dataset. Consequently, with 90 valid cases and four predictor variables, the multiple regression model 3 was fairly accurate to represent the actual sample.

Table 4.20

Casewise Diagnostics of the Multiple Regression Model $3(N=90)$

\begin{tabular}{ccccc}
\hline $\begin{array}{c}\text { Case } \\
\text { Number }\end{array}$ & Std. Residual & LogNFac & Predicted Value & Residual \\
\hline 18 & -2.662 & 1 & 1.53 & -0.929 \\
28 & -2.124 & 0 & .74 & -0.741 \\
73 & -3.022 & 0 & 1.05 & -1.054 \\
75 & -2.040 & 0 & .71 & -0.711 \\
83 & -2.346 & 0 & .82 & -0.818 \\
\hline
\end{tabular}

Note. Dependent Variable: the number of faculty abroad (LogNFac). 
Diagnostics of influential cases. To assess whether the regression model was stable across the sample, Cook's distance, centered leverage, Mahalanobis distances, standardized DFBeta, and the covariance ratio (CVR) are examined to see whether undue influence on the parameters of the regression model existed. The results showed that:

1. The values of Cook's distance of all cases were lower than 1 , indicating that no more cases had the overall undue influence on the regression model 3.

2. The average leverage value should locate within $3(\mathrm{k}+1) / \mathrm{n}$. The result showed that one case exceeded the boundary of three times of the average leverage (0.168), indicating that this case might have undue influence on the regression model 3. However, given the value of Cook's distance of this case was far below 1, there was no need to cause for concern.

3. With a smaller sample and four predictors in the regression analysis, the values of Mahalanobis distance were lower than $18.47\left(x^{2}(4)=18.47, p<.001\right)$; thus, no more outliers was found in the dataset.

4. The standardized DFBeta was examined to see the difference between a parameter estimated using all cases and estimated when one case was excluded. The results showed that values of the standardized DFBeta were all below 1, indicating that all cases had no substantial influence on parameters of the regression model 3.

5. Covariance ratio (CVR). According to the formula provided by Belsey, Kuh \& Welsch (1980), CVR in the regression model 3 should be lower than 1.17 and greater than 0.83 . It was found that three cases had the CVR lower than 0.83 . However, given Cook's distances for these cases were far below 1, there was no need to delete them from the dataset. 
All above, On the basis of the casewise diagnostic and the case summary for the regression model 3, it was conclude that the multiple regression model 3 (Equation 4.5) fairly represented the observed sample and roughly stable cross the sample.

\section{Assessing Generalization of Multiple Regression Model 3}

The generalization of a regression model is to assess whether a regression model is reliable to a large population. Under this condition, assumptions of multiple regression analysis and the cross-validation of the multiple regression model are examined and reported.

Assumptions. The check-list of assumption of multiple regression analysis included variable types, multicollinearity, normality, linearity, and homoscedasticity of residuals, and the independent errors.

1. Variable types. All predictor variables and dependent variables were quantitative, continuous and unbounded; and no zero variance was found in analysis of variance for the untransformed and the transformed data;

2. Multicollinearity. As shown in Table 4.4, no more Pearson's correlation coefficient was greater than .90 . In addition, collinearity diagnostics based on values of variance inflation factors (VIF) and tolerance statistics showed that the largest VIF was 2.92, which was far below 10; the values of tolerance were all greater than 0.2. Moreover, the large proportion of variance had the eigenvalue below 0.088 . Thus, multicollinearity was not problematic in the regression model 3.

3. Normality, linearity, and homoscedasticity of residuals. The histogram plots of standard residuals and partial plots of each of predictors against the residual of the outcome variable indicated that the normality, linearity, and homoscedasticity were roughly met. 
4. Independent errors. As shown in Table 4.17, Durbin-Waston test for the regression model 3 was 2.078 , which was close to 2 . This value indicated that residuals were independent and did not cause for concern.

Cross-validation. The analysis of the cross-validation provides another way to assess whether the regression model can accurately predict the outcome in a different sample. According to Stein's formula (Field, 2005, p. 172), Stein's adjusted $R^{2}=.506$, which indicated that the four predictors together accounted for 50.6 percent of variance in the outcome variable of the number of faculty abroad. Further, as shown in Tables 4.17 , the observed $R^{2}=.550$, the difference between observed $R^{2}$ and Stein's adjusted $R^{2}$ was .044 (or $4.4 \%$ ). The difference was lower than 5 percent, indicating that the cross-validity of the regression model 3 was good.

Sample size. According to Green's (1991) formula, with four predictors in the regression model 3, the required minimum sample size should be at least $82(8 \mathrm{k}+50)$ to assess the overall significance of the regression model 3 and $108(104+\mathrm{k})$ to evaluate the individual predictor (Field, 2005, p. 173). In this study, the minimum requirement of the sample size to assess the significance of the regression model 3 was achieved $(N=90)$. However, to assess the significance of each individual predictor, 18 more cases were needed in the dataset.

In summary, the multiple regression model 3 (Equation 4.5) is accurate to predict the sampled data and can be roughly generalized to the population. Therefore, the four predictors (e.g., human resources, the number of study abroad programs, the number of exchange programs, and the number of partnerships) together can be applied to estimate the outcome variable of the number of faculty abroad. 


\section{Summary}

This chapter established three multiple regression models to assess whether significant relationships existed between institutional input to study abroad programs (e.g., human resource, financial resources), the process of OIPs to administer and coordinate study abroad programs (e.g., the number of study abroad programs, the number of exchange programs, \& the number of international partnerships), and the outcome of study abroad programs (e.g., the number of study abroad students, the number of exchange students, \& the number of faculty abroad).

The predictor variables included human resources (HR), financial resources (FR), the number of study abroad programs (NSAProg), the number of exchange programs (NEXProg), and the number of international partnerships (NPartner); and the outcome variables consisted of the number of study abroad students (NSAStu), the number of exchange students (NEXStu), and the number of faculty abroad (NFac).

The results indicated that three established regression models were statistically significant to predict each of outcome variables. They were established based on the sampled data and seemed stable cross the sample. Thus, the three regression models could be fairly used to estimate each of the outcome variables.

The study also found that some predictor variables were significantly associated with the outcome variables in the regression models: (1) three predictor variables (e.g., human resources, financial resources, and the number of study abroad programs) were significant to predict the outcome variable of the number of study abroad students; (2) two predictor variables (e.g., the number of exchange programs and the number of international partnerships) were significant to predict the outcome variable of the number of exchange students; and (3) two predictor variables 
(e.g., the number of study abroad programs and human resources) were significant to predict the outcome variable of the number of faculty abroad. 


\section{Chapter Five}

\section{Discussion}

\section{Summary and Discussions}

This study is to assess institutional efforts on internationalization of higher education through the lens of study abroad programs coordinated by the centralized Offices of International Programs (OIPs) at U.S. research universities. The purpose is to know whether there are relationships among institutional input to study abroad programs (e.g., human resources and financial resources), the process of administration and coordination of study abroad programs (e.g., the number of the study abroad programs, the number of exchange programs, and the number of international partnerships), and the output of these programs (e.g., the number of study abroad students, the number of exchange students, and the number of faculty abroad).

This study is based on an assumption that the more FTE staff, specifically professional staff, worked for study abroad office, the larger dollar amount of the annual budget located to study abroad programs, the more number of study abroad programs and exchange programs coordinated by the OIP, the more international partnerships have been established and kept active, then, the larger number of students would be expected to participate in study abroad programs, the larger number of international students would be expected to attend colleges and universities through exchange programs, and the larger number of faculty members would be expected to go abroad for teaching, research, and service.

The population consists of 282 U.S. research universities with three subgroups, including very high research universities, high research universities, and doctoral research universities. Among these research universities, 34 percent of research universities are institutions with very high research activity; 36.5 percent of research universities are institutions with high research 
activity; and 29.3 percent of research universities are doctoral research universities; moreover, 58.9 percent of research universities are public institutions and 41.1 percent of research universities are private institutions.

Because some institutions do not offer study abroad programs or lack information regarding study abroad programs, only 230 emails were successfully sent out to the executives who directed OIPs at U.S. research universities. Of these sampled institutions, survey questionnaires were received from 104 executives representing a response rate of 45.2 percent. Among the 104 received cases, 93 (or 40.4\%) responses were identified as valid cases and used in the multiple regression analysis.

Independent variables (predictor variables) include human resources (HR), financial resources (FR), the number of study abroad programs (NSAProg), the number of exchange programs (NEXProg), and the number of international partnerships (NPartner); dependent variables (outcome variables) consist of the number of study abroad students (NSAStu), the number of exchange students (NEXStu), and the number of faculty abroad (NFac) (see Appendix B). Because four variables (FR, NPartner, NEXStu, \& NFac) have missing data in excess of 5 percent and histogram plots of all variables are positively skewed (see Table 3.1), data used in multiple regression analysis are reestablished based on the SPSS Expectation Maximization (EM) and transformed by the logarithm. Finally, three multiple regression models are built on the basis of each of research questions. The brief summary of the findings and discussion, conclusions, application, and recommendations are illustrated in the following sections.

Research question one. The research question one asked: Do the institutional input variables (e.g., human resources and financial resources) and the process variables (e.g., the number of study abroad programs, the number of exchange programs, and the number of 
international partnerships) have relationships with the outcome variable of the number of study abroad students?

With five independent variables (e.g., HR, FR, NSAProg, NEXProg, \& NPartner) served as predictor variables, the number of study abroad students (NSAStu) served as the outcome variable, the findings indicated that: (1) in Pearson's correlation coefficients, all five predictor variables were significantly associated with the outcome variable of LogNSAStu; however, in multiple regression model 1, only three out of five predictor variables (HR, FR, NSAProg) were significantly associated with the outcome variable of NSAStu; (2) the most significant predictor to estimate the number of study abroad students was human resources $(\beta=.51)$, followed by financial resources $(\beta=.24)$, and the number of study abroad programs $(\beta=.20)$, respectively; (3) the significant regression model to estimate the number of students studying abroad was: $\operatorname{LogNSAStu}=0.991+(0.86 \log H \mathrm{R})+(0.21 \operatorname{LogFR})+(0.19 \operatorname{LogNSAProg})+(0.06 \operatorname{LogNEXProg})$ $-(0.01 \operatorname{LogNPartner})$.

Human resources. It is interesting to note that the variable of human resources becomes the most significant predictor to estimate the number of students participating in study abroad programs rather than the financial resources and the number of study abroad programs. Although no previous studies have detected whether the number of FTE staff working for study abroad programs is significantly associated with the number of students who participated in study abroad programs, it appears that a properly staffed OIP, especially professional program coordinators and study abroad advisors, plays a critical role to encourage students going abroad.

Siaya and Hayward (2003) observed that more than 90 percent of OIPs at research universities employed staff to work with students who are interested in studying abroad. The finding of this study indicated that an average of 6.35 FTE staff worked for study abroad 
programs and 62.3 percent of staff were professional practitioners (see Appendix L). With more professional staff working for study abroad programs, students may spend more time to work with them for collecting the information about study abroad programs, locating a desired place for cultural immersion, fulfilling the graduation requirement, solving financial issues, and so forth. On the other hand, more staff also meant that study abroad advisors and program coordinators may have more opportunities to reach the targeted students and use a variety of strategies to attract those who are interested in study abroad, such as study abroad fairs, study abroad posters, fliers, and e-letters, classroom visits, study abroad information sessions/tables, and the social networking (e.g., Facebook \& Blog). Thus, a properly staffed OIP may function more effectively to fulfill its mission and goals of internationalization of an institution.

Financial resources. The second important predictor variable to estimate the number of students studying abroad is financial resources in terms of the dollar amount of the annual budget managed by the OIP and used for study abroad programs. Harari (1983) assumed that as much as 90 percent of institutional efforts on institutionalization of an institution could be achieved "without a single nickel from the outside" (Leinwand, 1983, p. 39). It can be done by rearrangement and reallocations of financial resources within the institution. Although the size of the operating budget of an institution was not necessarily a decisive factor in the degree of internationalization of the institution (Harari, 1981), the dollar amount of the operating budget allocated for study abroad programs did have an affect on the degree of internationalization of the institution (Nelson, 1995).

Nelson's (1995) study found that the percentage of the operating budget for study abroad programs allocated from the central funds and the percentage of operating budget supported by 
fees generated from students who participated in study abroad had significant relationships with institutional success in sending students to study abroad at large public institutions, with $\chi^{2}=7.957(p<.05)$ and $\chi^{2}=7.488,(p<.05)$, respectively. Moreover, the major funding source at most public institutions (69\%) was the allocation supported by the central funds, followed by fees generated from students who participated in study abroad; private institutions were more depend on the central funds rather than fees generated from students (p. 152-155).

The findings of this study indicated that the number one funding source was fees generated from students rather than the allocation from the central funds. The results showed that slightly more than 50 percent of the annual budget came from fees generated by students who participated in study abroad programs and 40 percent of the annual budget was allocated from the central funds (see Appendix L). This change may point out a trend that studying abroad may be considered more as individual privilege; as customers in the higher education, students should be responsible for covering the whole expenses by themselves.

Recently, actively seeking external funding to support study abroad programs becomes an effective strategy for the OIPs to dedicate their efforts for advancing internationalization. Green's (2005) study demonstrated that more than 80 percent of institutions actively sought external funds from the federal, state, and private sections for internationalization; moreover, for those successful institutions, 88 percent of institutions obtained funds from private foundations and organizations; 79 percent of institutions received funds from the federal government; and 53 percent of institutions received funds from the state government.

Scholarships and incentives for support of participation in study abroad programs represent symbolic gestures. To encourage students participating in study abroad programs, most institutions are willing to offer a small amount of scholarships and incentives to motivate 
students and faculty abroad. As Siaya and Hayward (2003) observed, 35 percent of colleges and universities earmarked funds to support study abroad program. Comparing with other types of institutions, research universities were twice as likely to provide funds for undergraduates to participate in study abroad programs.

The finding of this study demonstrated that more than two-thirds (78\%) of research universities did offer an average of $\$ 70.52$ thousand dollars of scholarships/incentives for students who participated in studying abroad in academic year of 2007-08; however, 16 out of 71 universities did not offer any incentives to support students studying abroad, consisting of 22.5 percent of responded institutions (see Appendix L). Even though the amount of scholarships or incentives is small, the motivation did encourage more students and faculty applying for study abroad programs. That is one of the best practices that the highly active institutions toward internationalization have advocated and implemented (Green, 2005).

Number of study abroad programs. As the researcher assumed, there would be a strong positive correlation between the number of study abroad programs coordinated by the OIP and the number of students studying abroad. The finding of this study indicated that the number of study abroad programs had only a low relationship with the number of students studying abroad and the value of the regression coefficient was lower than human resources and financial resources.

Harari (1983) observed that colleges and universities with the high level of efforts to internationalize the institution scored higher in the number of study abroad programs. Generally, large institutions play important roles to offer a variety of study abroad programs in different academic fields. Compared with other types of institutions, research universities were the most likely to offer a variety of study abroad programs, such as internships abroad (20\%), 
international service learning (13\%), and field study programs (22\%); and highly active research institutions were more likely than less active institutions to offer a diversity of study abroad programs to satisfy students' needs and interests (Siaya \& Hayward, 2003). Nelson's (1995) study further supported that, large institutions obtained significant relationships with institutional success in sending students studying abroad, with $r=.209(p<.05)$ at large private institutions and $r=.578(p<.05)$ at large public institutions.

Research question two. The question two asked: Do the institutional input variables (e.g., human resources and financial resources) and the process variables (e.g., the number of study abroad programs, the number of exchange programs, and the number of international partnerships) have relationships with the outcome variable of the number of international exchange students?

With four variables (e.g., HR, NSAProg, NEXProg, \& NPartner) served as predictors, the number of international exchange students (NEXStu) served as the outcome variable, the findings indicated that: (1) in Pearson's correlation coefficients, the four variables were significantly related with the outcome variable, however, in the multiple regression model 2 , only two predictor variables (e.g., NEXProg \& NPartner) were significantly associated with the outcome variable of the number of exchange students; (2) the most significant predictor was the number of exchange programs $(\beta=.65)$, followed by the number of international partnerships $(\beta=.28)$; and (3) the significant regression model to estimate the number of exchange students was: $\operatorname{LogNEXStu}=0.139+(0.19 \operatorname{LogHR})+(0.71 \operatorname{LogNEXProg})+(0.32 \operatorname{LogNPartner})$ $-(0.09 \log N S A P r o g)$.

Number of exchange programs and number of international partnerships. Compared to study abroad programs, exchange programs and international partnerships function as another 
side of a coin to promote internationalization of an institution. It is assumed that the more international partnerships were built and kept active, the more exchange programs could be established, then, the more international exchange students could attend U.S. colleges and universities, the more diverse cultures U.S. students could experience and explore, and the better U.S. students would understand the world outside of the United States.

International exchange programs have a long history in American higher education. Most research universities host a small number of exchange programs through their international partners because of several advantages for serving U.S. students' needs. First of all, the tuition and room and board students paid at their own institutions are comparable to the expenses they spend in foreign institutions where they studied abroad. Secondly, the host institutions are wellselected and matched with the home institution based on the academic fit and the institutional culture. Generally, the OIP staffs spend more time to recruit and take care of exchange students, such as interviews, paper works for applying J-1 visa, class registration, airport pick-up, orientation, and the like. Moreover, students who are selected particularly for exchange programs live with local students in residence halls and are assigned with local students through a variety of international programs, such as buddy programs and language partner programs; therefore, they may have more chance to immerse into the foreign culture and feel more satisfied.

It is assured that the mere presence of international students on a campus is not a major contribution toward internationalization. Green's (2005) study confirmed that programs and activities that connected international students with American students were highly correlated with the number of U.S. students studying abroad, such as buddy programs, international residence hall programs, and language partner programs. The results of this study showed that: 
(1) 79.6 percent of research institutions provided international festivals to promote international climate on campus; (2) 40.9 percent of institutions offered international residence hall programs and service; (3) 24.7 percent institutions had language partner programs; and (4) 26.9 percent institutions provided buddy programs to bond American students with international students (see Appendix L). It may explain the true existing value of exchange programs.

It is interesting to note that the number of study abroad programs had a small negative influence on the number of exchange students, even though the value of unstandardized coefficient (B) was very small (-.09). The finding indicated that if the OIP staff paid more attention on promoting U.S. students studying abroad, the number of international students participating in the exchange programs would be slightly decreased, if other predictor variables were held constant. Therefore, the OIP directors should know how to balance these two types of international programs to reach the maximum of organizational effectiveness.

Research question three. The research question three asked: Do the institutional input variables (e.g., human resources and financial resources) and the process variables (e.g., the number of study abroad programs, the number of exchange programs, and the number of international partnerships) have relationships with the outcome variable of the number of faculty abroad?

With four independent variables (e.g., HR, NSAProg, NEXProg, \& NPartner) served as predictors, the number of faculty abroad (NFac) served as the outcome variable, it was found that: (1) in Pearson's correlation coefficients, four predictor variables were significantly associated with the number of faculty abroad; however, in regression model, only two predictor variables (HR \& NSAStu) had significant relationships with the number of faculty abroad; (2) the most significant predictor to estimate the number of faculty abroad was the number of study abroad 
programs $(\beta=.53)$, followed by human resources $(\beta=.20)$; and (3) the significant regression model to estimate the number of faculty abroad was: $\operatorname{LogNFac}=0.133+(0.32 \mathrm{LogHR})$ $+(0.50 \operatorname{LogNSAProg})+(0.16 \operatorname{LogNPartner})-(0.09 \operatorname{LogNEXProg})$.

Number of study abroad programs. Faculty is one of the fundamental elements to promote internationalization of an institution. There are a variety of ways faculty can engage in international education programs and activities on and off-campus. Green (2005) reported that more than 70 percent of faculty traveled abroad for academic purposes. In recent years, faculty has taken a leading role to promote short-term study abroad programs. According to Open Door report (IIE, 2007), faculty-led study abroad programs has increased dramatically and students who attended faculty-led programs became the fastest growing cohort in current decade.

Because the number of study abroad programs was significantly associated with not only the number of students studying abroad, but also the number of faculty abroad, the result may indicate that a significant relationship somehow may exist between the number of faculty abroad and the number of students studying abroad. The Pearson's correlation coefficient also showed a strong and positive relationship between these two outcome variables, with $r=.661(p<.001)$. Typically, faculty-led study abroad programs are led by a faculty member and often combined with an existing class or a program of study taught by the leading faculty; students and faculty generally spend less than eight weeks abroad. This arrangement is easier to fit for students' needs and schedules, specifically for those part-time students or non-traditional students who need to work regularly to pay their tuition and living for participating in higher education.

In recent years, faculty-led study abroad programs become successful to attract more students to participate in study abroad programs. According to Open Door report (IIE, 2007), short-term study abroad programs have become more popular than long-term and slightly more 
than half $(52 \%)$ of U.S. students chose studied abroad through summer programs or spring breaks with less than eight weeks. This result may explain the significant phenomenon in recent decade that the number of study abroad programs strongly associated with the number of faculty abroad.

To encourage faculty to engage in international programs, two-thirds of colleges and universities provided financial support for faculty involving in international activities and the most commonly funded activities was leading undergraduates on a study abroad program (46\%), followed by traveling to international conferences and meeting (40\%), and conducting international study or research (27\%)(Siaya \& Hayward, 2003). This study showed that that $\$ 14.9$ thousand dollars of incentives was offered by research universities to support faculty abroad for teaching, research, and service in academic year of 2007-08; however, 25 out of 55 (or 40\%) respondents did not offer any incentive for faculty working abroad (see Appendix L). Moreover, institutional policies related to faculty development play a critical role to encourage faculty to involve in advancing internationalization. This study confirmed the results conducted by Siaya and Hayward (2003) and Green (2005) that: (1) only 8.6 percent of research universities included international working experience in the policy of faculty promotion and tenure review; (2) 9.7 percent offered other types of supports for faculty abroad, such as awards and recognitions for those faculty members who made contribution on international education; (3) 19.4 percent allowed faculty members taking sabbatical leaves for teaching, research, and service abroad; (4) 39.8 percent provided training and workshops for faculty to develop in international dimensions; and (5) 53.8 percent offered incentives for faculty working abroad (see Appendix L). To enhance the overall efforts of internationalization, research universities still have a long way to go. 
Human resources. The finding of the study indicated that number of FTE staff working for study abroad programs is significantly associated with the number of faculty abroad for teaching, research, and service. Although no previous study identified the similar result, the finding illustrates a meaningful way to increase the number of faculty abroad.

It appears that administrative work of managing faculty-led study abroad programs is time-consuming. Faculty members are experts in academic fields concentrating on teaching and research, not on administration. Professional staffs who help faculty design a study abroad program, manage a trip, operate the budget, and complete all kinds of paper works would release a huge burden for faculty. This arrangement may require additional staff to accomplish the work. Therefore, properly staffed OIPs definitely encourage faculty to fulfill the goal of promoting international education. Moreover, more professional staffs also mean that the OIPs have more opportunities to provide training and workshops for faculty development in international dimension, to seek grants and contracts to support those faculty members who would like to dedicate their efforts to internationalize curriculum and instruction, to lead students studying abroad, to conduct research with their international partners, to attend international conferences and meetings, and to provide public service and consultations to developing countries.

It should realize that administrative works related to study abroad programs can be greatly improved by functioning a centralized OIP. The centralized administrative pattern for international programs may reduce the cost and enhance the organizational effectiveness and efficiency.

\section{Conclusions}

This study has attempted to assess institutional efforts toward internationalization of the institution through the lens of study abroad programs coordinated by the centralized Offices of 
International Programs at U.S. research universities. Several conclusions can be drawn from the study as follows:

First of all, a properly staffed OIP is essential to promote students and faculty abroad. The professional staff may provide a basic information, service, coordination, leadership, and initiatives to encourage students and faculty participating in study abroad programs and further benefit for increasing the number of students and faculty members abroad.

Secondly, establishment of a variety of faculty-led programs to encourage faculty members from different academic fields participating in study abroad programs would increase the number of students studying abroad. Therefore, one of the best practices for enhancing internationalization is to work close with faculty members who would like to dedicate their efforts to advance international education and design a variety of faculty-led study abroad programs in different academic fields to satisfy students' needs. In addition, the OIPs should earmark incentives to support faculty members' participation in study abroad programs, provide training and workshops for faculty development in international dimensions, and recognize and reward those faculty members who have made great contributions to advance internationalization through international programs.

Thirdly, well-selected and well-matched international partnerships and exchange programs would increase the number of international students participating in U.S. colleges and universities through exchange programs. However, the OIP directors should keep in mind that the number of study abroad programs had a small negative influence on the number of exchange students; thus, balancing these two types of programs to fit different students' needs is an art of administration. 
Fourthly, the dollar amount of the annual budget managed by the OIP and used for study abroad programs did enhance institutional success in sending students to study abroad, specifically fees generated from students who studies abroad and the allocation supported from central funds. However, under the current economic recession faced by the states and financial constrains experienced by colleges and universities, increasing the allocation from central funds or charging more special fees from students are not realistic; therefore, seeking external funding from private organizations, federal, and state government may provide an alternative way to continue supporting students and faculty abroad.

\section{Application}

As an OIP director who dedicates to fulfill the institution's mission of internationalization through promoting more students and faculty abroad, several strategies obtained from the findings of this study can be used as a guideline or a benchmark to assess the accomplishment of the OIP.

Theoretically, each significant predictor variable in the regression model could be used to estimate the outcome variable based on its standard deviation and standardized $\beta$-value and the results could be explained only when the effects of other predictor variables are held constant. Thus, the application is for illustration purposes only.

Practically, the OIP directors should realize that a variety of factors have influences on the number of study abroad students. Several limitations in this study could be identified when assessing the individual contribution of significant predictor variables: (1) the sample size of this study $(N=93)$ did not meet the minimum requirement $(N=109)$ to assess the contribution of each significant predictor to the outcome variable; (2) all predictor variables and outcome variables were positively skewed and transformed; and (3) the results could be explained 
significantly only when other predictor variables are held constant. Thus, working on the predictor with the most significant $\beta$-value (or $B$-value) is the best way to guide the practices. Assessing the number of study abroad students. On the basis of the equation of the multiple regression model 1, if an OIP had 5 FTE staff worked for study abroad programs, allocated $\$ 800$ thousand dollars of the annual budget for study abroad programs, offered 50 study abroad programs and 20 exchange programs for students, and established 30 international partnerships with institutions in foreign counties, the expected number of students participating in study abroad programs was 389.

$$
\begin{aligned}
\operatorname{LogNSAStu}= & 0.991+(0.86 \log \mathrm{HR})+(0.21 \log \mathrm{FR})+(0.19 \operatorname{LogNSAProg})+(0.06 \operatorname{LogNEXProg}) \\
& -(0.01 \log N \text { Partner }) \\
= & 0.991+(0.86 \log 5)+(0.21 \log 800)+(0.19 \log 50)+(0.06 \log 20)-(0.01 \log 30) \\
\text { NSAStu } \approx & 389
\end{aligned}
$$

This number can be used as a benchmark to compare with the actual number of students studying abroad at the institution. If the calculated number is pretty close to the actual the number of students studying abroad, it means that the overall efforts made by the OIP are comparable with other peer institutions. If the calculated number is much higher than the actual number, it represents that the overall efforts of sending students studying abroad are better than peer institutions; however, one thing that the OIP director needs to ensure is to examine whether staff works are overloaded. If the calculated number is much less than the actual number, the OIP director needs to carefully assess each individual predictor variable, especially the number of professional staff, the dollar amount of the annual budget used for study abroad programs, and the number of study abroad programs coordinated by the OIP, to ensure that: (1) whether the OIP has sufficient professional staff, such as study abroad advisors and programs coordinators, to 
work with students and faculty who are interested in studying abroad; (2) whether the annual budget allocated from the central funds and fees generated from students are sufficient to fulfill the goals and the strategic plan of international programs implemented by the OIP; (3) whether the OIP needs to seek the financial support from external sources to earmark funds to support students and faculty study or work abroad; and (4) whether the OIP could offer more diverse study abroad programs, specifically faculty-led programs to satisfy students' needs.

In addition, the following part illustrates the process to assess the individual contribution of significant predictor variables and the application is for illustration purposes only.

1. Human resources (standardized $\beta=.51$ ). It indicated that if human resources increased by one standard deviation $(S D=5.93)$, the number of study abroad students would increase by .51 standard deviation. Because the standard deviation for the number of study abroad students was 609.50, thus, it constituted a change of 311 $(.51 \times 609.50)$ in the outcome variable. In other words, for every 6 FTE staff work for the study abroad programs, 311 students would be expected to participate in study abroad programs. This interpretation was true only if the effects of the other four predictors were held constant.

1. Financial resources (standardized $\beta=.24$ ). The standardized $\beta$ value of financial resources indicates that as financial resources increased by one standard deviation $(S D=1433.82)$, the expected number of study abroad students would increase by 0.24 standard deviation. Because the standard deviation for the number of study abroad students was 609.50 , it constituted a change of $146.28(0.24 \times 609.50)$ in the outcome variable - the number of study abroad students. Therefore, for every $\$ 1,433.82$ thousand dollars spent on the study abroad programs, 146 students would 
be expected to participate in study abroad programs. This interpretation was true only if the effects of the other four predictors were held constant.

2. Number of study abroad programs (standardized $\beta=.20$ ). The standardized $\beta$ value of the number of study abroad programs indicates that as the number of study abroad programs increased by one standard deviation $(S D=99.37)$, the number of study abroad students would be expected to increase by 0.20 standard deviation. Because the standard deviation for the number of study abroad students was 609.50 , it constituted a change of $121.90(0.20 \times 609.50)$ in number of study abroad students. Therefore, for every 99 more study abroad programs established, 122 more students would be expected to participate in study abroad programs. This interpretation was true only if the effects of the other predictors were held constant.

Assessing the number of exchange students. On the basis of the equation of the multiple regression model 2 and the same numbers used by the OIP, the expected number of international exchange students can be calculated as:

$$
\begin{aligned}
& \operatorname{LogNEXStu}=0.139+(0.19 \operatorname{LogHR})+(0.71 \log N E X P r o g)+(0.32 \operatorname{LogNPartner}) \\
& \text { - (0.09LogNSAProg) } \\
& =0.139+(0.19 \log 5)+(0.71 \log 20)+(0.32 \log 30)-(0.09 \log 50) \\
& N E X S t u \approx 33
\end{aligned}
$$

This number can be used as a benchmark to compare with the actual number of exchange students at the institution. If the calculated number is much less than the actual number, the OIP director needs to reexamine the two predictor variables, i.e., the number of exchange programs and the number of international partnerships established and have been active in recent three years, to ensure that: (1) whether there are sufficient exchange programs to host international 
exchange students; (2) whether the OIP and related departments provide a variety of international programs and activities to serve the needs of international students; and (3) whether contacts between the institution and international partners are still active.

The following part illustrates the detailed process of assessing each significant predictor variable to estimate the number of exchange students and the application described below is for illustration purposes only.

1. Number of exchange programs (standardized $\beta=.65$ ). The standardized $\beta$-value indicates that as the number of exchange programs increased by one standard deviation $(S D=37.08)$, the number of exchange students would increase by 0.65 standard deviation. Because the standard deviation for the number of exchange students was 68.73 , it constituted a change of $44.7(0.65 \times 68.73)$ in the number of exchange students. Therefore, for every 37 more exchange programs established, 45 international students would be expected to participate in exchange programs. This interpretation was true only if the effects of the other three variables were held constant.

2. Number of partnerships (standardized $\beta=.28$ ). The standardized $\beta$-value indicates that as the number of international partnerships increased by one standard deviation $(S D=48.80)$, the number of exchange students would increase by 0.28 standard deviation. Because the standard deviation for the number of exchange students was 68.73 , it constituted a change of $19.24(0.28 \times 68.73)$ in number of students participating in exchange programs. Therefore, for every 49 international partnerships established, 19 international students would be expected to participate in exchange 
programs. This interpretation was true only if the effects of the other three variables were held constant.

Assessing the number of faculty abroad. On the basis of the equation of the multiple regression model 3 and the same numbers and variables used by the OIP, the expected number of faculty can be calculated as:

$$
\begin{aligned}
\operatorname{LogNFac}= & 0.133+(0.32 \log H R)+(0.50 \operatorname{LogNSAProg})+(0.16 \operatorname{LogNPartner}) \\
& -(0.09 \operatorname{LogNEXProg}) \\
= & 0.133+(0.32 \log 5)+(0.50 \log 50)+(0.16 \log 30)-(0.09 \log 20)
\end{aligned}
$$

$N F a c \approx 21$

This number can be used as a benchmark to compare with the actual number of faculty abroad at the institution. If the calculated number is much less than the actual number, the OIP director needs to reexamine the two predictor variables, i.e., the number of number of faculty-led study abroad programs and the number of staff working for faculty abroad, to ensure that: (1) whether there are sufficient study abroad programs, specifically faculty-led study abroad programs to involve faculty members in international programs; (2) whether the OIP has sufficient professional staff to work with faculty members who are interested in going abroad for teaching, research, and service; (3) whether the OIP provides professional training and workshops for faculty development in international dimensions; (4) whether the OIP provides incentives to encourage faculty abroad; and (5) whether the institution has policies that faculty working abroad or participating in other types of international work is considered as an important part for promotion and tenure evaluation.

The following part illustrates the detailed process of assessing each significant predictor variable and the application described below is for illustration purposes only. 
1. Number of study abroad programs (standardized $\beta=.53$ ). The standardized $\beta$-value indicates that as the number of study abroad programs increased by one standard deviation $(S D=99.37)$, the number of faculty abroad would increase by 0.53 standard deviation. Because the standard deviation for the number of faculty abroad was 40.69 , it constituted a change of $21.57(0.53 \times 40.69)$ in the number of faculty abroad. Therefore, for every 99 more study abroad programs established, 22 faculty members would be expected to work abroad. This interpretation was true only if the effects of the other three predictor variables were held constant.

2. Human resources (standardized $\beta=.20$ ). The standardized $\beta$-value of human resources indicates that as human resources increased by one standard deviation $(S D=5.93)$, the number of faculty abroad would increase by .20 standard deviation. Because the standard deviation for the number of faculty abroad was 40.69 , thus, it constituted a change of $8.14(.20 \times 40.69)$ in the outcome variable. In other words, for every 6 FTE staff worked for the study abroad programs, eight faculty members would be expected to participate in teaching, research, and services abroad. This interpretation was true only if the effects of other three predictor variables were held constant.

\section{Recommendations}

Recommendations for future studies. This study is to assess the relationships among institutional input to study abroad programs, the process of the OIP coordinated international programs, and the outcome of these programs. Recommendations to the future studies on study abroad programs and internationalization of higher education and suggestions to the OIP 
directors may help researchers to understand about the administrative process of coordinating study abroad programs and guide professional practitioners to assess their works and efforts.

1. Replicate the study with larger sample size to assess the significant contribution of individual predictor variables. In multiple regression analysis, sample size is an important factor to ensure whether the regression model could be used to explain the same results in a large population. Because sample size in this study did not meet the minimum requirement for multiple regression analysis, assessing the significant contribution of each predictor variable to the outcome variable could be reported only for illustration purposes. Further studies might include liberal art colleges and comprehensive universities into the population to enlarge the sample size.

2. Replicate this study in liberal art colleges by using the same predictor variables and the outcome variables to see whether different patterns would appear and which predictor variable is significantly related to each of the outcome variables. Then, the comparison of the study at liberal art colleges with this study may give us an alternative way to see how these predictor variables affect liberal art colleges toward advancing internationalization.

3. Consider using a different statistical method, such as the structure equation modeling (SPSS Amos) to analyze the data. When using multiple regression analysis to examine the data, the findings showed that some predictor variables were significantly related to the outcome variable based on Pearson's correlation coefficients, but did not significantly correlate with the outcome variable in the regression models. It seemed that these relationships were mediated by the relationships between the outcome variable and other predictor variables. Thus, the 
structure equation modeling analysis may help us figure out which predictor variable is the mediator and to what extent the predictor variable is mediated by other variables.

Recommendations to OIP directors. As executives who direct the OIPs at U.S. research universities may use the multiple regression models and significant predictor variables obtained from this study to assess their efforts of internationalization. More importantly, the OIP director should keep in mind that the assessment is to understand the OIP's current position compared with other research institutions, rather than to judge whether the OIP succeeded or failed toward advancing internationalization.

1. Use multiple regression models to assess the actual work at the OIP. Because three multiple regression models were statistically significant, the numeric numbers (e.g., numbers of study abroad students, numbers of exchange students, and numbers of faculty abroad) obtained from the regression models can be used to compare with the actual numbers the OIP have achieved. If the numbers were much lower than the obtained ones, the OIP director should further examine the most influential predictor variable to ensure whether the OIP has sufficient professional staff members, the budget, and a variety of study abroad and exchange programs to serve the needs of faculty members and students.

2. Use each significant predictor to assess the actual work at the OIP. In practice, the OIP director should focus more on improving the work related to the significant predictor variable, rather than on measuring the exactly numeric numbers obtained from the regression models and standardized $\beta$-values because these numbers work significantly for statistical purposes only. For instance, the findings showed that the 
number of study abroad programs were significantly associated with not only the number of faculty abroad, but also the number of students studying abroad; thus, involving faculty members in different academic fields to participate in faculty-led programs may provide the best way to increase the number of students studying abroad.

3. Be aware of the negative predictor variables. For instance, the number of study abroad programs had a small negative relationship with the number of exchange students. In other words, if an OIP focuses more on increasing the number of study abroad programs, it may cause a negative impact on increasing the number of exchange students. Therefore, the OIP director needs to balance these two types of international programs based on the institutional mission, goals and the strategic plan of internationalization in order to maximize the organizational effectiveness. 


\section{References}

Afonso, J. D. (1990). The international dimension in American higher education. Unpublished Doctoral Dissertation, University of Arizona. Dissertation Abstracts International, 51, 3641A.

Altbach, P. J., \& Teichler, U. (2001, Spring). Internationalizing and exchange in a globalized university. Journal of Studies in International Education, 5(1), 5-25.

American Council on Education (ACE). (2008). Comprehensive internationalization. Retrieved on May 1, 2008, from http://www.acenet.edu/AM/Template.cfm?Section=International\&Template=/CM/HTML Display.cfm\&ContentID $=17732$

Andersen, C. (1988). International studies for undergraduates. Washington, DC: American Council on Education.

Anderson, T., \& Kanuka, H. (2003). e-Research: Methods, strategies, and issues. Boston, New York: Pearson Education.

Andes, J. (1970). A system approach to university organization. Gainesville, Florida: Institute of Higher Education University of Florida.

Arnone, M. (2002). Army's huge distance-education effort wins many supporters in its first year. Chronicle of Higher Education, February. Retrieved on October, 2008 from http://chronicle.com/free/v48/i22/22a03301.htm.

Arum, S., \& Van de Water, J. (1992, November). The need for a definition of international education in U.S. universities. In C. M. Klasek (Eds.). Bridges to the future: Strategies for internationalizing higher education (pp. 191-208). Carbondale, IL: Association of International Education Administrators. 
Backman, E. L. (Ed.). (1984). Approaches to international education. New York: Macmillan.

Banathy, B. H. (1973). Developing a system view of education: The system-model approach. Belmont, California: Lear Siegler/Fearon Publishers.

Belsey, D. A., Kuh, E. \& Welsch, R. (1980). Regression diagnostics: Identifying influential data and sources of collinearity. New York: Wiley.

Burke, J. M. (Eds.). (2009). 2009 higher education directory. Falls Church, Virginia: Higher Education Publications.

Burn, B. B. (1980). Expanding the international dimension of higher education. San Francisco: Jossey-Bass.

Burn, B. B. (Ed.). (1991). Integrating study abroad into the undergraduate liberal arts curriculum: Eight institutional case studies. Westport, CT: Greenwood Press.

Burn, B. B. (1996, Spring). Strengthening internationalism in U.S. higher education. International Higher Education, 4, 19.

Callan, H. (1993). The idea of internationalization in British higher education. In Internationalization: What does it really mean? International Education Magazine, 9(1), 9.

Campanelli, P. (2003). Testing survey questions. In D. de Leeuw, J. J. Hox, \& D. A. Dillman (Eds.), International handbook of survey methodology (pp. 176-200), New York: Taylor \& Francis Groups.

Carnegie Foundation for the Advancement of Teaching. (2009). A classification of institutions of higher education. Princeton, NJ: Author. 
Carr, L. J. (1955). Analytical sociology. In J. W. Getzels, J. M. Liphman, \& R. F. Campbell (1968). Educational administration as a social process: Theory, research, practice (p. 54). New York: Harper \& Row.

Childress, L. K. (2007). Planning for the internationalization of U.S. higher education institutions: The development and monitoring of written commitments of internationalization. Retrieved from http://www.gwu.edu/ esri/Childress_ESR107.pdf

Chronicle of Higher Education (2008, August). Almanac Issue 2008-9. Chronicle of Higher Education, IV (1), 34 .

Davies, J. L. (1992). Developing a strategy for internationalization in universities: Toward a conceptual framework. In C. M. Klasek (Eds.). Bridges to the future: Strategies for internationalizing higher education (pp. 177-190). Carbondale, IL: Association of International Education Administrators.

de Leeuw, E. D., Hox, J. J., \& Dillman, D. A. (2008). (Eds.) International handbook of survey methodology. New York: Taylor \& Francis Groups.

de Wit, H. (Ed.). (1995). Strategies for internationalization of higher education: A comparative study of Australia, Canada, Europe, and the United States of America. Amsterdam: European Association for International Education.

de Wit, H. (1997). Studies in international education: A research perspective. Journal of Studies in International Education, 1(1), 1-8.

de Wit, H. (2002). Internationalization of higher education in the United States of America and Europe: A historical, comparative, and conceptual analysis. Westport, Connecticut: Greenwood.

Dillman, D. A. (2000). Mail and internet survey: Tailored design method. New York: J. Willey. 
Edwards, J. (2007, Fall/Winter). Challenges and opportunities for the internationalization of higher education in the coming decade: Planned and opportunities initiatives in American institutions. Journal of Studies in International Education, 11(3/4), 373-381.

Field, A. (2005). Discovering statistics using SPSS. London: Sage.

Freeman, S. A. (1966). Undergraduate study abroad. In International education: Past, present, problems, and prospects. Washington, DC: U. S. government printing Office.

Getzels, W., Liphman, M., \& Campbell, R. (1968). Educational administration as a social process: Theory, research, practice. New York: Harper \& Row.

Green, M. F. (2005). Measuring internationalization at research universities: The unifying voice for higher education. Washington, DC: American Council on Education.

Green, M. F., \& Olsen, C. (2003). Internationalizing the campus: A user's guide. Washington, DC: American Council on Education.

Green, S. B. (1991). How many subjects does it take to do a regression analysis? Multivariate Behavioural Research, 26, 499-510.

Goodwin, C., \& Nacht, M. (1991). Missing the boat: The failure to internationalize American higher education. Cambridge: Cambridge University Press.

Halpern, S. (1969). The institute of international education: A history. Doctoral dissertation, Columbia University.

Hanson, M. (1972). On social systems theory as a predictor of educational change: The adoption of classroom innovation (ED 065415).

Harari, M. (1972). Global dimensions in U.S. education. New York: Center for War? Peace Studies. Cited by S. Arum and J. Van de Water in "The need for a definition of international education in U.S. universities.” In C. M. Klasek (Eds.). Bridges to the future: 
Strategies for internationalizing higher education. Carbondale, IL: Association of International Education Administrators.

Harari, M. (1977). Internationalization of higher education. In A. S. Knowles (Ed.). The international encyclopedia of higher education. San Francisco: Jossey-Bass.

Harari, M. (1981). Internationalizing the curriculum and the campus: Guidelines for AASCU institutions. Washington, D.C.: American Association of State Colleges and Universities.

Harari, M. (1983). Internationalizing the curriculum and the campus: Guidelines for the AASCU institutions. Washington, DC: American Association of State Colleges and Universities.

Harari, M. (1989). Internationalization of higher education: Effecting institutional change in the curriculum and campus. Long Beach, California: Center for International Education, California State University.

Harari, M., \& Reiff, R. F. (1993). Halfway there: A view from the bridge. International Educators, 3 (1), 16-19.

Hayward, F. W. (2000). Internationalization of U.S. higher education: A preliminary status report 2000. Washington, DC: American Council on Education.

Henson, J. B., Noel, J. C., Gillard-Byers, T. E., \& Ingle, M. D. (1990). Internationalizing U.S. universities: Preliminary summery of a national study. In J. B. Henson, J. C. Noel, T. E. Gillard-Byers, \& M. D. Ingle (Eds.), Internationalizing U.S. universities: A time for leadership (pp. 1-25). Spokane, WA: Washington State University.

Holzner, B., \& Harmon, M. (1998). Intellectual and organizational challenges for international education in the United States: A knowledge system perspective. In H. N. John et al (Eds.), International education in the new global era proceedings of a national policy 
conference on the Higher Education Act, Title VI, and Fulbright-Hays programs (pp. 31-64). Los Angeles, California: University of California.

Hoy, W. K., \& Miskel, C. G. (1987). Educational administration: Theory, research, and practice. ( $3^{\text {rd }}$ ed.). New York: Random House.

Hoy, W. K., \& Miskel, C. G. (1996). Educational administration: Theory, research, and practice. ( $5^{\text {th }}$ ed.). New York: Random House.

Hoy, W. K., \& Miskel, C. G. (2001). Educational administration: Theory, research, and practice. ( $6^{\text {th }}$ ed.). New York: Random House.

Institute of International Education (IIE). (1920). Institute of International Education, Inc., its origin, organization and activities. Bulletin no. 1. New York. Cited by S. Arum and J. Van de Water in C. M. Klasek (Eds.). Bridges to the future: Strategies for internationalizing higher education (1992). Carbondale, IL: Association of International Education Administrators.

Institute of International Education (IIE). (1994). Investing in people linking nations, 1991-1995: The first 75 years of the Institute of International Education. New York: Author. Institute of International Education (IIE). (2007). Open doors 2007 [Electronic version]. Retrieved on November 12, 2007, from http://www.opendoors.iienetwork.org.

Kehm, B. M., \& Teichler, U. (2007, Fall/Water). Research on internationalization in higher education. Journal of Studies in International Education, 11 (3/4), 260-273.

Kelleher, A. (1996). Learning from success: Campus case studies in international program development. New York: Peter Lang.

Kerr, C. (1980). Introduction. In B.B. Burn (1980). Expanding the international dimension of higher education. San Francisco: Jossey-Bass. 
Kerr, C. (1990). The internationalization of learning and nationalization of the purposes of higher education: Two "laws of motion" in conflict? European Journal of Education, 25, 5-22.

Kerr, C. (1994). Higher education cannot escape history: Issues for the twenty-first century. SUNY Series Frontiers in Education. Albany: State University of New York Press.

Klasek, C. (Eds.). (1992). Bridges to the future: Strategies for internationalizing higher education. Washington, D.C.: Association of International Education Administrators.

Knight, J. (1994). Internationalization: Elements and checkpoints. CBIE Research paper No. 7. Ottawa: Canada Bureau for International Education.

Knight, J. (1997). Internationalization of higher education: A conceptual framework. In J. Knight and H. de Wit (Eds.), Internationalization of higher education in Asia pacific countries. Amsterdam: European Association for International Education.

Knight, J. (1999a). Internationalization of higher education: In J. Knight and H. de Wit (Eds.), Quality and internationalization of higher education. Paris: IMHE/OECD.

Knight, J. (1999b). Issues and trends in internationalization: A comparative perspective. In S. L. Bond and Jean-Pierre Lemasson (Eds.), A new world of knowledge: Canadian universities and globalization. Ottawa: International Development Research Center.

Knight, J. (2003, Fall). Updating the definition of internationalization. International High Education, 33, 2-3.

Knight, J. (2004, Spring). Internationalization remodeled: Definition, approaches, and rationales. Journal of Studies in International Education, 8 (1), 5-31.

Knight, J., \& de Wit, H. (1995). Strategies for internationalization of higher education: Historical and conceptual perspectives. In H. de Wit (Ed.), Strategies for internationalization of 
Internationalization of Higher Education 162

higher education: A comparative study of Australia, Canada, Europe and the United States of America. Amsterdam: European Association for International Education.

Krane, M. C. S. (1994). Development of an internationalization index for U.S. liberal arts colleges. Unpublished dissertation, Mississippi State University.

Lambert, R. D. (1989a). International studies and undergraduate. Washington, DC: American Council on Education.

Lambert, R. D. (1989b). Study abroad: where we are, and where we should be. CIEE $41^{\text {st }}$ conference report, Cannes., New York: CIEE.

Lambert, R. D. (1990, Spring). International studies and education: The current state of affairs. International Education Forum, 10 (1), 1-8.

Lambert, R. D. (1992). Foreign student flows and internationalization of higher education. [Working Paper No. 37]. Washington, DC: NAFSA.

Lambert, R. D. (1993). International education and international competency in the United States. In S.J. Moore and C. A. Morfit (Eds.), Language and international studies: A Richard Lambert perspective. Washington, DC: National Foreign Language Center.

Lambert, R. D. (1995). Foreign student flows and the internationalization of higher education. In K. Hanson and J. W. Meyerson (Eds.), International challenges to American colleges and universities: Looking ahead. Phoenix: Oryx Press.

Leinwand, G. (1983). Without a nickel: The challenge of international curriculum and the campus. Washington, DC: American Association of State Colleges and Universities.

Lyman, R. (1995). Overview. In K. H. Hanson and J. W. Meyerson (Eds.), International challenges to American colleges and universities: Looking ahead. American Council on Education. Phoenix, Arizona: Oryx Press. 
Merkx, G. (2003). The two waves of internationalization in U. S. higher education. International Educator, $12(1), 8-12$.

Meyer, M. W. (1978). Introduction: Recent development s in organizational research and theory, in M. W. Meyer et al. (Eds.), Environments and organizations. San Francisco: Jossy-Bass.

Miles, J. \& Shevlin, M. (2001). Appling regression and correlation: A guide for students and researchers. London: Sage.

Nelson, T. (1995). An analysis of study abroad administration at U.S. colleges and universities. Unpublished dissertation (Microform: 9609363). Knoxville, Tenn.: University of Tennessee.

Olson, C. L., Green, M. F., \& Hill, B. A (2005). Building a strategic framework for comprehensive internationalization. Washington, DC: American Council on Education.

Parsons, T. (1965). Structure and process in modern societies. New York: The Free Press.

Siaya, L. \& Hayward, F. (2003). Mapping internationalization on U.S. campuses: Final report 2003. Washington, DC: American Council on Education.

Scherer, R. F., Beaton, S. T., Ainina, M. F. \& Meyer, J. F. (2002). Internationalizing the business curriculum: A field guide (2 ${ }^{\text {nd }}$ ed.). Euclid, OH: Williams Custom Publishing.

Schoorman, D. (1999). The pedagogical implications of diverse conceptualization of internationalization: A U.S.-based case study. Journal of Studies in International Education, 3(2), 19-46.

Schoorman, D. (2000). How is internationalization implemented? A framework for organizational practice. Information Analysis. Retrieved on Oct, 2007, from EDRS (ED444426/ HE 033161). 
Scott, P. (2000). Globalization and higher education: Challenges for the $21^{\text {st }}$ century. Journal of Studies in International Education, 4 (1), 3-10.

Scott, R. W. (1987). Organizations: Rational, natural, and open systems. Englewood Cliffs, NJ: Prentice-Hall, Inc.

Scott, R. W., and Blau, P. M. (1962). Formal organizations: Comparative approach. San Francisco: Chandler Publishing.

Smuckler, R. (2003). A University turns to the world. East Lansing: Michigan State University.

Stone, N. (2006, Winter). Internationalizing the student learning experience: Possible indicators. Journal of Studies of International Education, 10(4), 409-413.

Tabachnick, B. G., \& Fidell, L. S. (2001). Using multivariate statistics (4 ${ }^{\text {th }}$ Ed.). Boston: Allyn \& Bacon.

Tabachnick, B. G., \& Fidell, L. S. (2006). Using multivariate statistics (5 ${ }^{\text {th }}$ Ed.). Boston: Allyn \& Bacon.

Tonkin, H. \& Edwards, J. (1981). The world in the curriculum: Curricular strategies for the twenty-first century. New York: Change Magazine Press.

Tonkin, H., \& Edwards, J. (1990). Internationalizing the university: The arduous road to euphoria. Educational Record, 71(2), 14-17.

Wang, G. (1992). The impact of centralized offices of international programs on the internationalization of curriculum in the United States land grant institutions. Unpublished doctoral dissertation, West Virginia University. 
Appendixes

Appendix A: Cover Letters

Cover Letter I

$<$ Month $>,<$ Date $>, 2009$

609D Allen Hall

P. O. Box 6122

West Virginia University

Morgantown, WV 26506-6122

Email: Chunmei.Yao@mail.wvu.edu

Name of the OIP Executive

Dear $<<$ Title $>><<$ Last Name $>>$ :

Within this week, you are going to receive a questionnaire survey requesting information regarding to Study Abroad Programs coordinated by the Offices of International Programs (OIP) at U.S. Research universities.

The questionnaire can be completed online through the following steps:

Step 1: Please click the following web link: http://studyabroad-survey.co.cc/survey_login.php?uid=wang\&pw=studyabroad

Step 2: Read the directions of the survey and click "Please Start Here ..."

Step 3: Answer the questions page by page and submit the results in the last page.

This questionnaire can be completed in 20-25 minutes. Your answers will be completely confidential since your institution will be anonymously coded into a sequential number. Your participation in this study is voluntary and refusal or withdrawing from this survey will not affect your job status.

This study is a partial fulfillment of requirements for a doctorate in Higher Educational Leadership at West Virginia University.

If you wish to have a copy of the findings of the results, please provide your email address in the last page of the survey.

Thank you for your consideration and assistance.

Sincerely,

Chunmei Yao

Ed. D. Candidate in Higher Educational Leadership 


\section{Cover Letter II}

$<$ Month $>,<$ Date $>, 2009$

609 D Allen Hall

P.O. Box 6122

West Virginia University

Morgantown, WV 26506-6122

Email: Chunmei.Yao@mail.wvu.edu

Name of Executive of an OIP

Name of the Institution

Dear $<<$ Title $>><<$ Last Name $>>$ :

I request your participation in this study exploring the information of Study Abroad Programs coordinated by the Offices of International Programs (OIP) at U.S. Research universities.

The OIP used here is an umbrella term, representing diverse names of the unit, such as Office of International Education, Center for International Studies, Office of Study Abroad, and etc., which develop and coordinate international programs and activities at U.S. research universities.

The questionnaire can be completed online through the following steps:

Step 1: Please click the following web link: http://studyabroad-survey.co.cc/survey_login.php?uid=wang\&pw=studyabroad

Step 2: Read the directions of the survey and click "Please Start Here ..."

Step 3: Answer the questions page by page and submit the results in the last page.

This questionnaire can be completed in 20-25 minutes. Your answers will be completely confidential since your institution will be anonymously coded into a sequential number. Your participation in this study is voluntary and refusal or withdrawing from this survey will not affect your job status.

This study is a partial fulfillment of requirements for a doctorate in Higher Educational Leadership at West Virginia University.

If you wish to have a copy of the findings of the results, please provide your email address in the last page of the survey.

Thank you for your consideration and assistance.

Sincerely,

Chunmei Yao

Ed. D. Candidate in Higher Educational Leadership 
Cover Letter III

(Thank-you or Reminder Letter )

$<$ Month $>,<$ Date $>, 2009$

609 D Allen Hall

P.O. Box 6122

West Virginia University

Morgantown, WV 26506-6122

Email: Chunmei.Yao@mail.wvu.edu

Name of Executive of an OIP

Name of the Institution

Dear $<<$ Title $>><<$ Last Name $>>$ :

Recently, you were sent a questionnaire through e-mail to invite your participation in the study exploring the information of Study Abroad Programs through the Offices of International Programs (OIP) at U.S. Research universities.

Your insights of study abroad programs are very important to this study. If you have already completed the survey, please submit it online or e-mail it back to me. If you didn't finish the questionnaire, please take a few minutes to respond to this questionnaire.

The questionnaire can be completed online through the following steps:

Step 1: Please click the following web link: http://studyabroad-survey.co.cc/survey_login.php?uid=wang\&pw=studyabroad

Step 2: Read the directions of the survey and click "Please Start Here ..."

Step 3: Answer the questions page by page and submit the results in the last page.

This questionnaire can be completed in 20-25 minutes. Your answers will be completely confidential since your institution will be anonymously coded into a sequential number. Your participation in this study is voluntary and refusal or withdrawing from this survey will not affect your job status.

This study is a partial fulfillment of requirements for a doctorate in Higher Educational Leadership at West Virginia University.

If you wish to have a copy of the findings of the results, please provide your email address in the last page of the survey.

Thank you for your consideration and assistance.

Sincerely,

Chunmei Yao

Ed. D. Candidate in Higher Educational Leadership 


\section{Appendix B}

Statistical Abbreviations and Symbols

Statistical Abbreviations and Symbol of Research Variables

\begin{tabular}{|c|c|c|c|}
\hline Types & Names & $\begin{array}{l}\text { Abbreviations } \\
\text { Before } \\
\text { Transformation }\end{array}$ & $\begin{array}{l}\text { Abbreviations } \\
\text { After } \\
\text { Transformation }\end{array}$ \\
\hline & Human Resources & HR & LogHR \\
\hline \multirow{5}{*}{$\begin{array}{l}\text { Independent } \\
\text { Variables }\end{array}$} & Financial Resources & FR & $\operatorname{LogFR}$ \\
\hline & Number of Study Abroad Programs & NSAProg & LogNSAProg \\
\hline & Number of Exchange Programs & NEXProg & LogNEXProg \\
\hline & Number of Partnerships & NPartner & LogNPartner \\
\hline & Number of Study Abroad Students & NSAStu & LogNSAStu \\
\hline \multirow{2}{*}{$\begin{array}{l}\text { Dependent } \\
\text { Variables }\end{array}$} & Number of Exchange Students & NEXStu & LogNEXStu \\
\hline & Number of Faculty Abroad & NFac & LogNFac \\
\hline
\end{tabular}




\section{Appendix C}

\section{Survey Questionnaire}

\section{Directions:}

1. This survey is to collect the information related to institutional input and output regarding to Study Abroad Programs coordinated by the Office of International Programs (OIP) at U.S. research institutions. The OIP is used here as an umbrella term, representing diverse names of the units, such as Office of International Education, Center of International Studies, Office of Study Abroad, and etc. to administer international programs and activities at U.S. research universities.

2. This survey consists of fifteen questions and can be finished in about 30 minutes.

3. If you would like a copy of the findings of this study, please provide your email address at the end of the survey.

1. The name of your institution (choice):

2. Is there an office in your institution to coordinate campus-wide Study Abroad Programs?

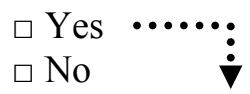

3.1 (If Yes) What is the name of this unit?

3. What is the title of the executive who directs the OIP (select all that apply)?

$\square$ Provost or Vice President of Academic Affairs

$\square$ Associate or Assistant Provost

$\square$ Director/Dean

$\square$ Other (Please specify:

4. To whom does the OIP executive report?

$\square$ President or Chancellor

$\square$ Provost or Vice President of Academic Affairs

$\square$ Vice President of Student Affairs

$\square$ Associate or Assistant Provost

$\square$ Other (Please specify

5. The scope of authority of the OIP at your institution covers which of the following (select all that apply):

$\square$ Study Abroad

$\square$ International Student Recruitment \& Admission

$\square$ International Student \& Scholar Service

$\square$ Internationalization of Curriculum

$\square$ Faculty Abroad

$\square$ Grants and Contracts for International Programs and Activities

$\square$ International Partnerships

$\square$ Other (Please specify:

6. Identify the total number of full-time equivalent staff who work solely for Study Abroad Programs (two half-time staff = one full-time staff): 
Number of FTE professional staff

Number of FTE support staff

Number of Graduate Assistants

7. In academic year 2007-08, estimate the total number of Study Abroad Programs administered by the OIP at your institution:

7.1 Among these programs, estimate the number of following types of Study Abroad Programs:

Number of Exchange Programs

Number of Faculty-led Programs

8. In academic year 2007-08, estimate the total number of students and faculty who participated in Study Abroad Programs through the OIP:

Number of students study abroad (including study abroad for credit, internships abroad, and service learning abroad)

Number of faculty abroad for teaching, research, and service

9. In academic year 2007-08, estimate the number of students who participated in study abroad only through Exchange Programs:

Number of outgoing U.S. students

Number of incoming international students

10. Estimate the number of international partnerships which were established by the OIP and have been active over the last three years:

11. In FY 2007-08, estimate the dollar amount of annual operating budget managed by the OIP and used for Study Abroad Programs (to the nearest thousand):

$$
\begin{aligned}
& \text { \$_Annual operating budget of the OIP } \\
& \$ — \text { Annual budget for Study Abroad Programs }
\end{aligned}
$$

12. In FY 2007-08, estimate the dollar amount of annual operating budget of study abroad programs from the following funding sources (to the nearest thousand):

$\begin{array}{ll}\$ — & \text { Central administration } \\ \$ & \text { Fees generated from students } \\ \$ & \text { Grants and contracts }\end{array}$

13. In academic year 2007-08, estimate the dollar amount of scholarships/incentives used by the OIP to promote Study Abroad Programs (to the nearest thousand):

$\$ —$ Incentives for students abroad

14. Please identify the following international education activities coordinated by the OIP to promote students study abroad (select all that apply):

$\square$ International Festivals 
$\square$ International Residence Hall

$\square$ Foreign Language Residence Hall

$\square$ Language Partner Programs

$\square$ Buddy Programs

$\square$ Meeting place for U.S. and international students to discuss international issues

15. Please indicate the following incentives which have been used by the OIP to promote faculty interest in international education (select all that apply):

$\square$ Included in faculty promotion \& tenure review policy

$\square$ Institutional recognition of faculty contribution to international education

$\square$ Provide funds for international activities

$\square$ Provide workshops for faculty development in international dimension

$\square$ Sabbatical leaves

This is the end of the survey.

Thank you for your participation. If your wish to have a copy of the findings of the results, please provide your contact information below:

Email Address: 


\section{Appendix D}

Histogram Plots for Independent Variables

Histogram Plots for Untransformed and Transformed Data $(N=93)$

\section{Predictor 1: Human Resources}
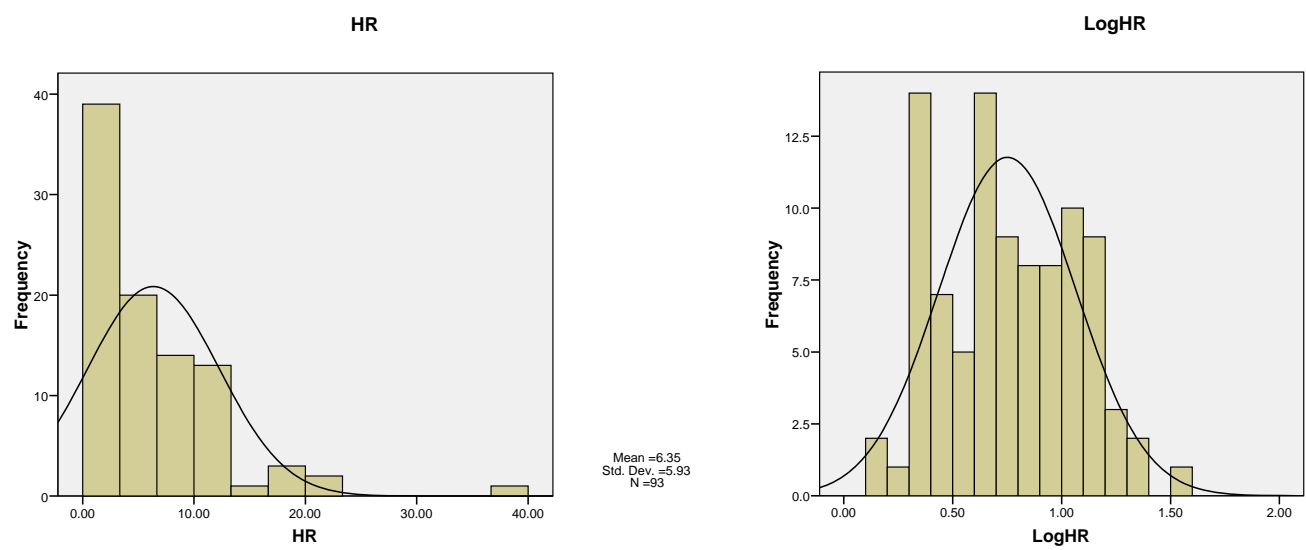

Mean $=0.75$
Std. Dev. $=0.315$
$N=93$

Predictor 2: Financial Resources
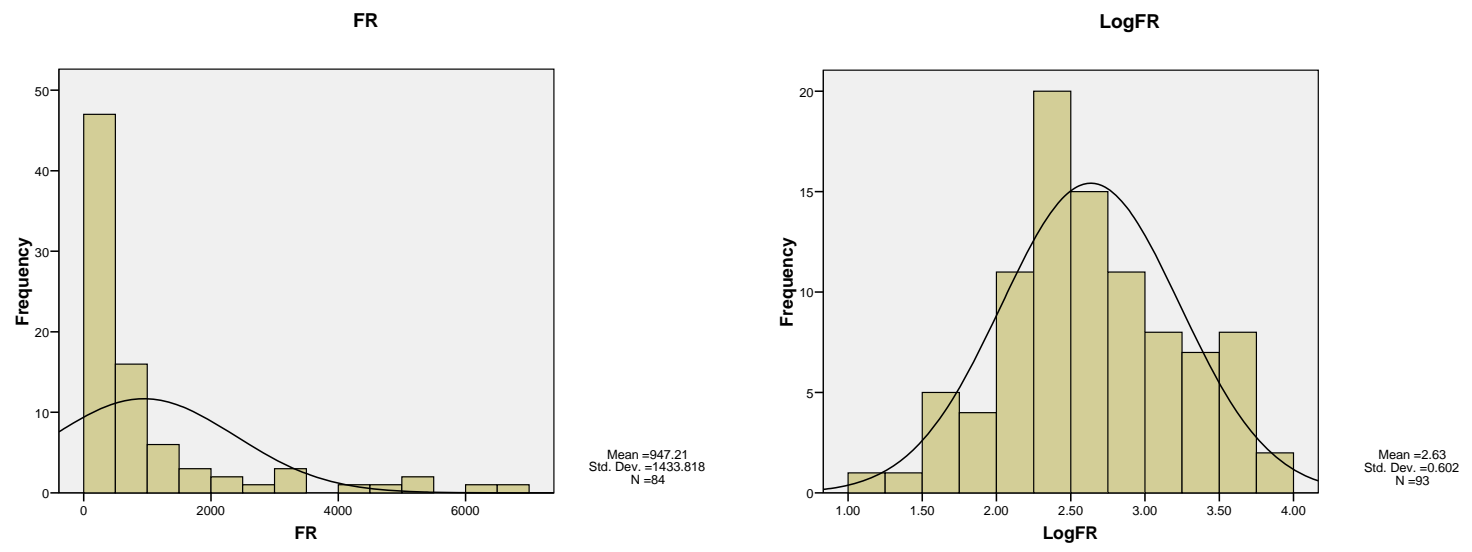


\section{Predictor 3: Number of Study Abroad Programs}
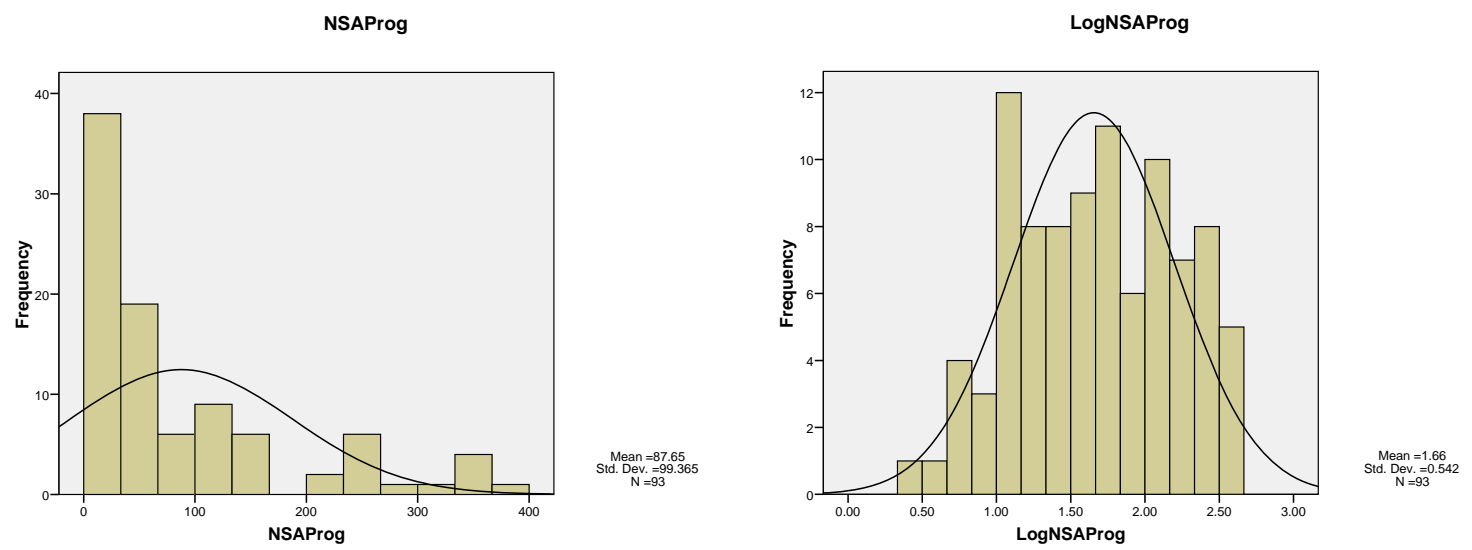

Predictor 4: Number of Exchange Programs
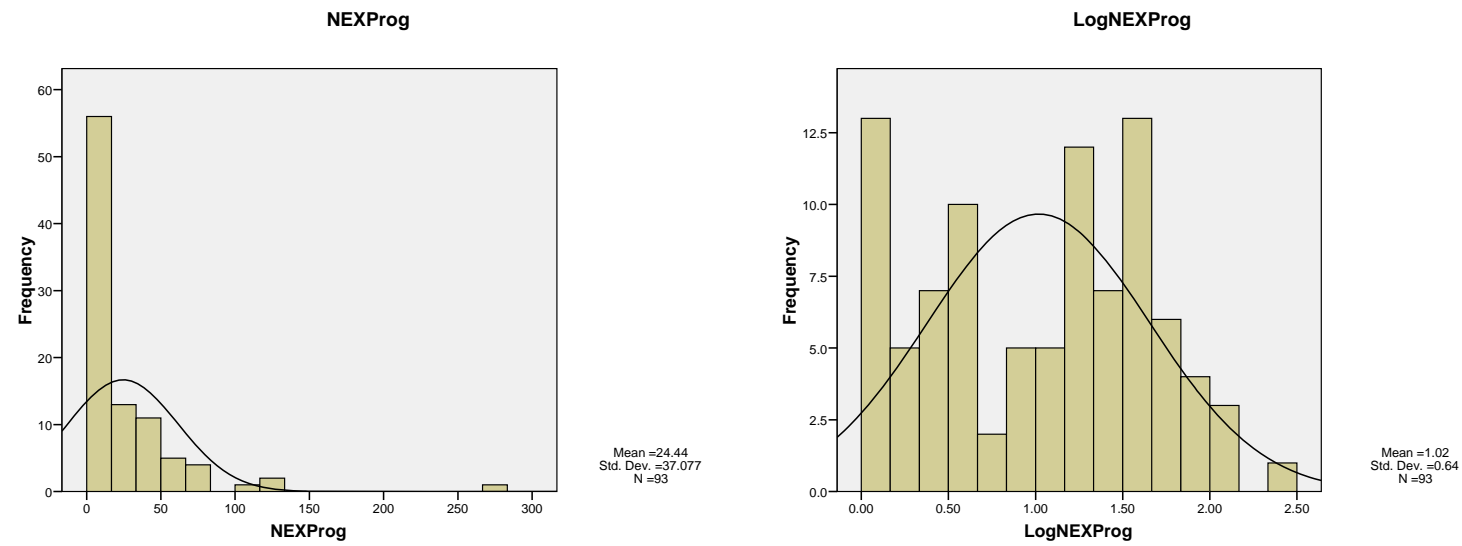

Predictor 5: Number of International Partnerships
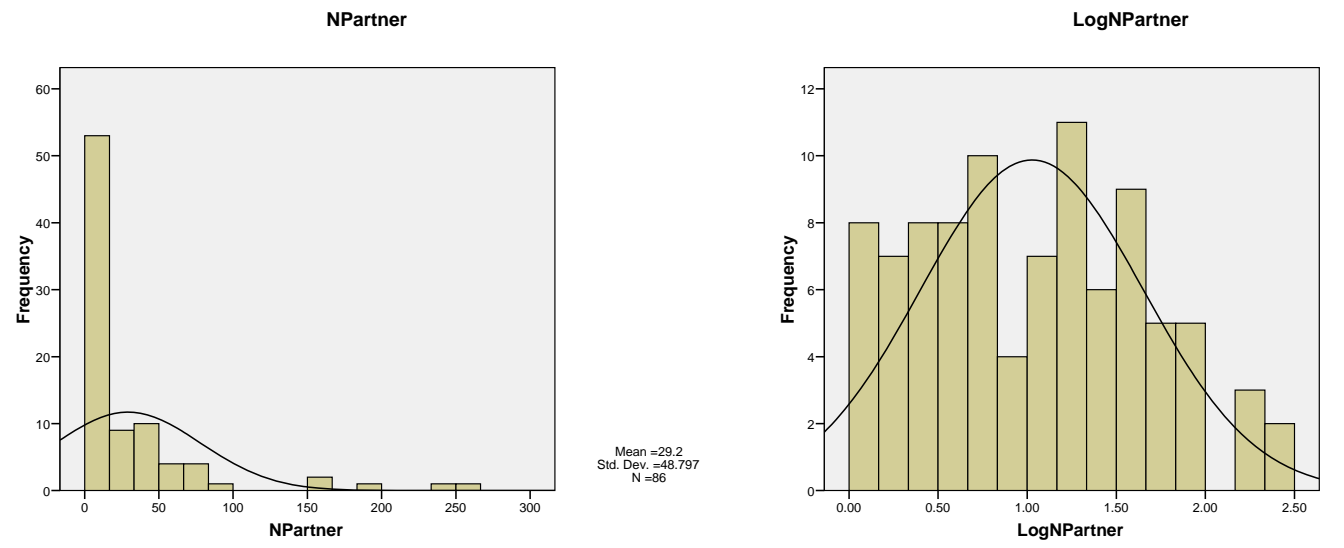


\section{Appendix E}

Histogram Plots for Dependent Variables

Histogram Plots for Untransformed and Transformed Data $(N=93)$

\section{Dependent Variable 1: Number of Study Abroad Students}
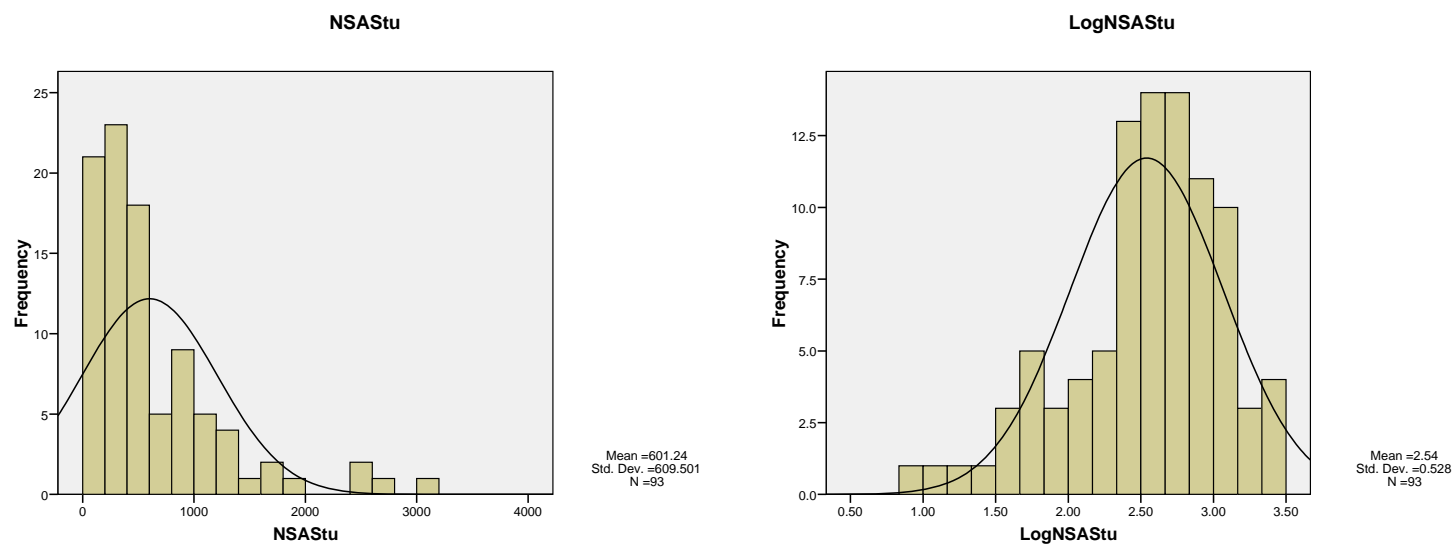

\section{Dependent Variable 2: Number of Exchange Students}
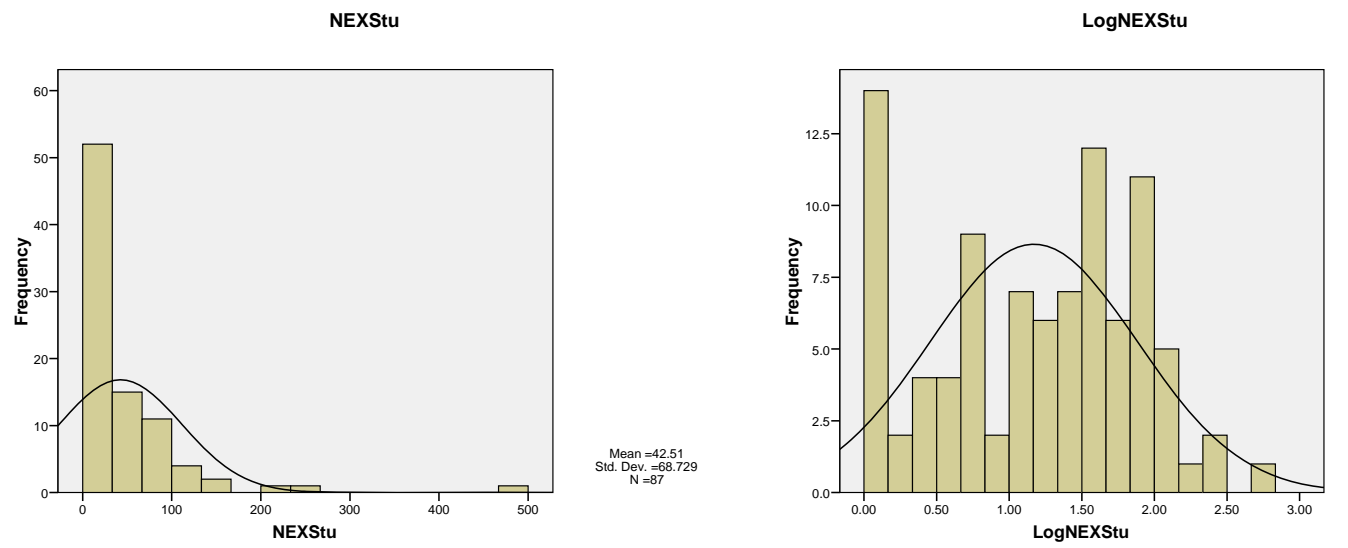

Mean $=1.17$
Std. Dev $=0.715$
$N=93$ 

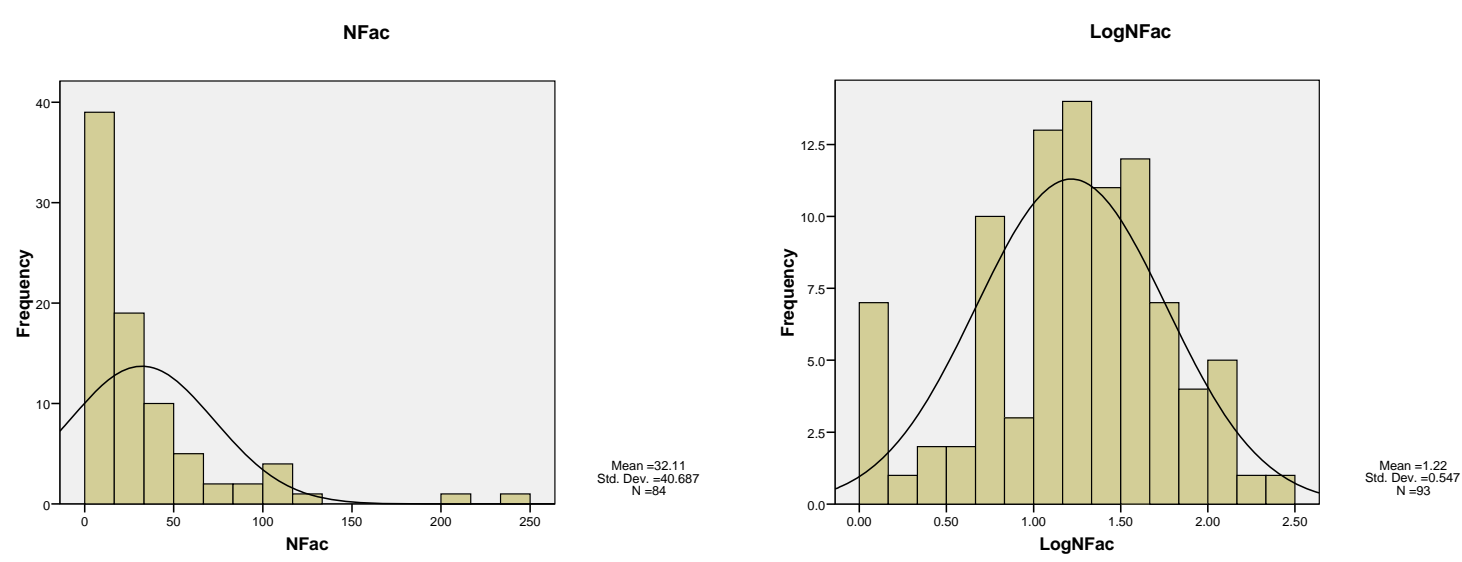

Note. All frequency tables were produced based on data before and after MVA and transformation. The histogram plot of LogNSAStu was produced based on 93 cases; the histogram plot of LogNEXStu was produced based on 92 cases; and the histogram plot of LogNFac was produced based on 90 cases. 


\section{Appendix F}

Frequency Analysis for Untransformed Data

Descriptive Statistics before MVA and Transformation $(N=93)$

\begin{tabular}{|c|c|c|c|c|c|c|c|c|}
\hline & HR & FR & NSAProg & NEXProg & NPartner & NSAStu & NEXStu & NFac \\
\hline $\mathrm{N}$ & 93 & 84 & 93 & 93 & 86 & 93 & 87 & 84 \\
\hline Mean & 6.35 & 947.21 & 87.65 & 24.44 & 29.20 & 601.24 & 42.51 & 32.11 \\
\hline Std. Error of Mean & .62 & 156.44 & 10.30 & 3.85 & 5.26 & 63.20 & 7.37 & 4.44 \\
\hline Median & 4.50 & 325.00 & 47.00 & 12.00 & 10.00 & 425.00 & 20.00 & 19.50 \\
\hline Std. Deviation & 5.93 & 1433.82 & 99.37 & 37.08 & 48.80 & 609.50 & 68.73 & 40.69 \\
\hline Variance & 35.16 & 2055834.85 & 9873.41 & 1374.71 & 2381.17 & 371491.64 & 4723.72 & 1655.42 \\
\hline Skewness & 2.19 & 2.46 & 1.51 & 3.76 & 3.01 & 1.93 & 4.11 & 2.74 \\
\hline Std. Error of Skewness & .25 & .26 & .25 & .25 & .260 & .25 & .26 & .26 \\
\hline Kurtosis & 7.33 & 5.90 & 1.47 & 20.33 & 9.89 & 4.23 & 23.25 & 9.46 \\
\hline Std. Error of Kurtosis & .50 & .52 & .50 & .50 & .51 & .50 & .51 & .52 \\
\hline
\end{tabular}




\section{Appendix G}

Frequency Analysis for Transformed Data

Descriptive Statistics after MVA and Data Transformation $(N=93)$

\begin{tabular}{|c|c|c|c|c|c|c|c|c|}
\hline & LogHR & LogFR & LogNSAProg & LogNEXProg & LogNPartner & LogNSAStu & LogNEXStu & LogNFac \\
\hline $\mathrm{N}$ & 93 & 93 & 93 & 93 & 93 & 93 & 93 & 93 \\
\hline Mean & .75 & 2.63 & 1.66 & 1.02 & 1.03 & 2.54 & 1.17 & 1.22 \\
\hline Std. Error of Mean & .03 & .06 & .06 & .07 & .06 & .055 & .07 & .06 \\
\hline Median & .74 & 2.64 & 1.68 & 1.12 & 1.04 & 2.63 & 1.32 & 1.28 \\
\hline Std. Deviation & .32 & .60 & .54 & .64 & .63 & .53 & .72 & .55 \\
\hline Variance & .10 & .36 & .29 & .41 & .39 & .28 & .51 & .30 \\
\hline Skewness & .19 & -.01 & -.09 & -.13 & .20 & -.79 & -.25 & -.49 \\
\hline Std. Error of Skewness & .25 & .25 & .25 & .25 & .25 & .25 & .25 & .25 \\
\hline Kurtosis & -.68 & -.38 & -.95 & -1.06 & -.78 & .55 & -.99 & .079 \\
\hline Std. Error of Kurtosis & .50 & .50 & .50 & .50 & .50 & .50 & .50 & .50 \\
\hline
\end{tabular}




\section{Appendix $\mathrm{H}$}

Level of Skewness and Kurtosis for Untransformed Data

Diagnosis of Level of Skewness for Untransformed Data $(N=93)$

\begin{tabular}{lccccc}
\hline & Std. Deviation & Skewness & Std. Error of Skewness & Level of Skewness & N \\
\hline HR & 5.93 & 2.19 & .25 & 8.75 & 93 \\
FR & 1433.82 & 2.46 & .26 & 9.37 & 84 \\
NSAProg & 99.37 & 1.51 & .25 & 6.05 & 93 \\
NEXProg & 37.08 & 3.76 & .25 & 15.03 & 93 \\
NPartner & 48.80 & 3.01 & .26 & 11.60 & 86 \\
NSAStu & 609.50 & 1.93 & .25 & 7.72 & 93 \\
NEXStu & 68.73 & 4.11 & .26 & 15.90 & 87 \\
NFac & 40.69 & 2.74 & .26 & 10.44 & 84 \\
\hline
\end{tabular}

Diagnosis of Level of Kurtosis for Untransformed Data $(N=93)$

\begin{tabular}{lccccc}
\hline & Std. Deviation & Kurtosis & Std. Error of Kurtosis & Level of Kurtosis & N \\
\hline HR & 5.93 & 7.33 & .50 & 14.81 & 93 \\
FR & 1433.82 & 5.90 & .52 & 11.36 & 84 \\
NSAProg & 99.37 & 1.47 & .50 & 2.97 & 93 \\
NEXProg & 37.08 & 20.33 & .50 & 41.06 & 93 \\
NPartner & 48.80 & 9.89 & .51 & 19.25 & 86 \\
NSAStu & 609.50 & 4.23 & .50 & 8.53 & 93 \\
NEXStu & 68.73 & 23.25 & .51 & 45.49 & 87 \\
NFac & 40.69 & 9.46 & .52 & 18.21 & 84 \\
\hline
\end{tabular}




\section{Appendix I}

Level of Skewness and Kurtosis for Transformed Data

Diagnosis of Level of Skewness for MVA and Transformed Data $(N=93)$

\begin{tabular}{lccccc}
\hline & Std. Deviation & Skewness & Std. Error of Skewness & Level of Skewness & N \\
\hline HR & .32 & .19 & .25 & .77 & 93 \\
FR & .60 & -.01 & .25 & -.03 & 93 \\
NSAProg & .54 & -.09 & .25 & -.36 & 93 \\
NEXProg & .34 & -.13 & .25 & -.54 & 93 \\
NPartner & .63 & .20 & .25 & .78 & 93 \\
NSAStu & .53 & -.79 & .25 & -3.17 & 93 \\
NEXStu & .72 & .25 & .25 & -1.10 & 93 \\
NFac & .55 & -.49 & .25 & -1.97 & 93 \\
\hline
\end{tabular}

Diagnosis of Level of Kurtosis for MVA and Transformed Data $(N=93)$

\begin{tabular}{lccccc}
\hline & Std. Deviation & Kurtosis & Std. Error of Kurtosis & Level of Kurtosis & N \\
\hline HR & .32 & -.68 & .50 & -.38 & 93 \\
FR & .60 & -.38 & .50 & -.76 & 93 \\
NSAProg & .54 & -.95 & .50 & -1.92 & 93 \\
NEXProg & .34 & -1.06 & .50 & -2.14 & 93 \\
NPartner & .63 & -.78 & .50 & -1.58 & 93 \\
NSAStu & .53 & -.55 & .50 & 1.11 & 93 \\
NEXStu & .72 & -.99 & .50 & -.199 & 93 \\
NFac & .55 & .08 & .50 & .16 & 93 \\
\hline
\end{tabular}




\section{Appendix J}

Assessment of Outliers

Outlier Diagnostics for the Regression Model $2(N=93)$

\begin{tabular}{ccccc}
\hline $\begin{array}{c}\text { Case } \\
\text { Number }\end{array}$ & Std. Residual & LogNEXStu & Predicted Value & Residual \\
\hline 32 & -4.461 & 0 & 1.78 & -1.799 \\
\hline
\end{tabular}

Note. Dependent Variable: the number of exchange students (LogNEXStu).

Outlier Diagnostics for the Regression Model $3(N=93)$

\begin{tabular}{ccccc}
\hline $\begin{array}{c}\text { Case } \\
\text { Number }\end{array}$ & Std. Residual & LogNFac & Predicted Value & Residual \\
\hline 6 & -3.466 & 0 & 1.5137 & -1.5137 \\
87 & -3.304 & 0 & 1.34 & -1.337 \\
75 & -3.333 & 0 & 1.27 & -1.265 \\
\hline
\end{tabular}

Note. Dependent Variable: the number of faculty abroad (LogNFac). 


\section{Appendix K}

Histogram Plots for Standardized Residuals

Dependent variable: LogNSAStu

Histogram

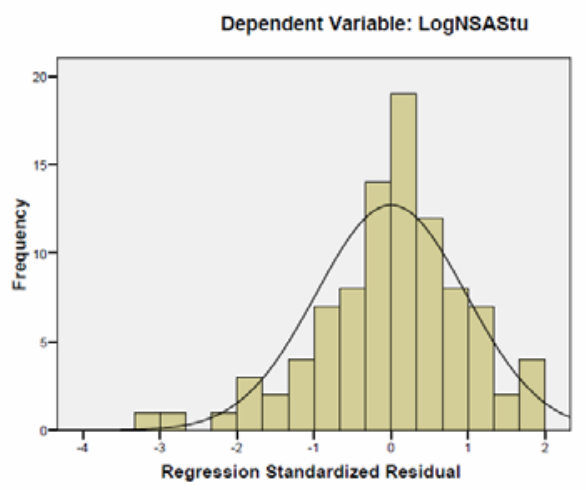

Dependent Variable: LogNEXStu
Normal P-P Plot of Regression Standardized Residual

Dependent Variable: LogNSAStu

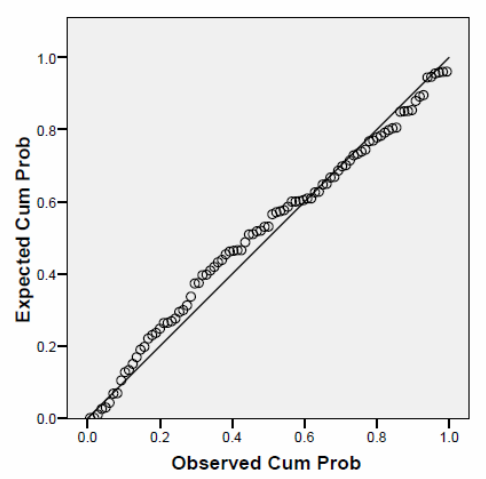

Normal P-P Plot of Regression Standardized Residual

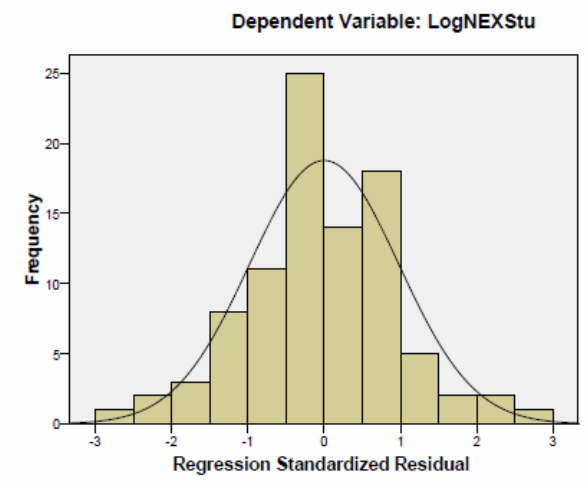

Mean $=-1.23 E-15$
Std. Dev $=0.978$
$N=92$

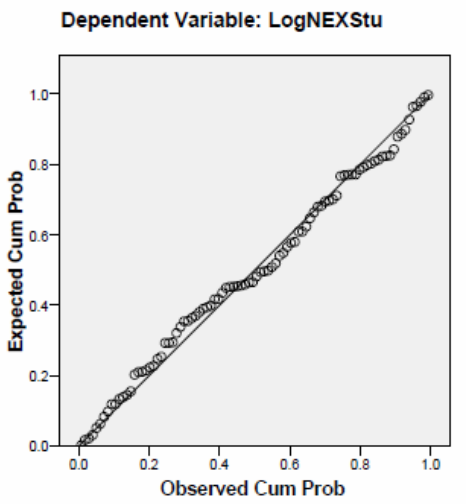




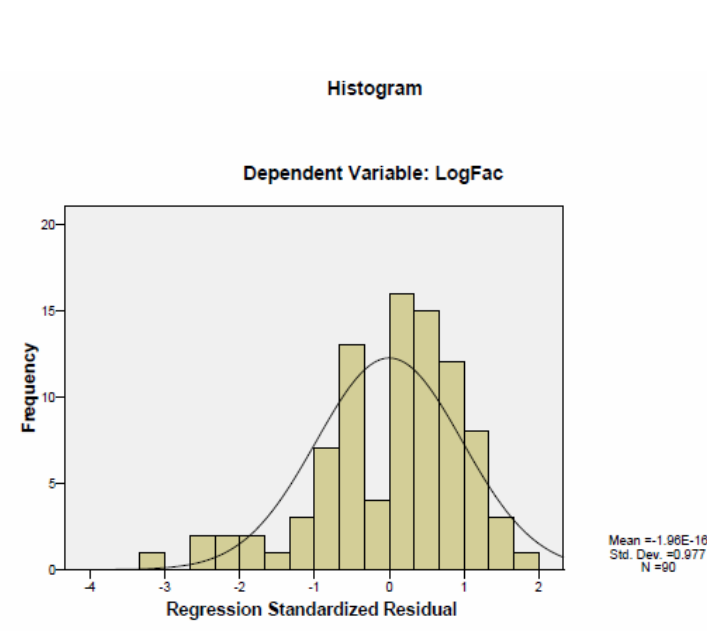

Normal P.P Plot of Regression Standardized Residual

Dependent Variable: LogFac

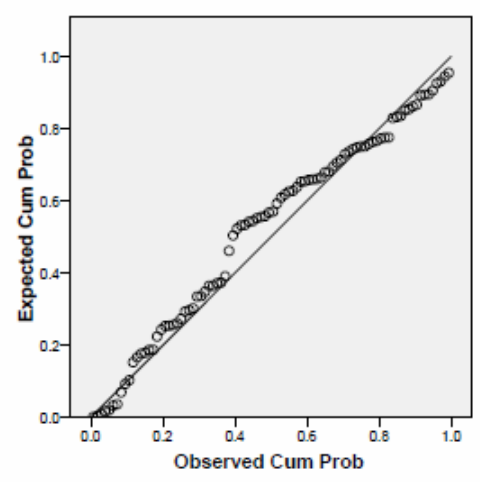

Note. The histogram plot of LogNSAStu was produced based on 93 cases; the histogram plot of LogNEXStu was produced based on 92 cases; and the histogram plot of LogNFac was produced based on 90 cases. 


\section{Appendix L}

Other Findings Obtained form the Internet Survey

\section{Administrative Structures of International Education}

The following part addressed a general picture and findings of the administrative structures of international education and programs at U.S. research universities.

1. A diversity of names of the offices coordinating study abroad programs. There were 93 responses in total. Accordingly, slightly more than one-third of sampled research institutions (33.3\%) used the Office of International Programs as an official name to administer and coordinate study abroad programs on campus; the second popular name was the Office of Study Abroad, consisting of 11.8 percent institutions; the Office of International Education and the Center for International Education consisted of 5.4 percent and 3.2 percent, respectively; other 46.2 percent institutions had a diversity of names to deal with study abroad programs, such as the Center for International Education, the Office of Global Studies, the Office of International Studies, and so forth. In this study, OIP was used as an umbrella term referring the office in charge of study abroad programs at U.S. research universities.

2. The title of the executive who directed the OIP. There were a total of 93 responses. First of all, more than two-third of executives who directed the OIPs was titled as the directors or the deans, consisting of 75.3 percent of sampled institutions. Secondly, fifteen administrators who were titled as associate or assistant provost which consisted of 16.1 percent of sampled respondents; among them, five respondents had dual titles of associate or assistant provost for international programs and director/dean of OIP. Moreover, there were 5.4 percent respondents who titled as 
provost or vice president of academic affairs. Finally, other kinds of titles consisted of 3.2 percent respondents, such as Associate Provost for Global Strategies and International Affairs, Vice Provost of Globalization and Multicultural Affairs, and assistant dean for study abroad, and so forth. It was interesting to see that almost onethird (29\%) of executives who supervised international programs were from the central administration, which pointed out that if a centralized administration was a trend in the future to coordinate international programs across campus, an executive who supervised international programs would be appropriate to work close to the central administration, and this arrangement would definitely strengthen the development of international programs. The results were consistent with the findings of ACE's study (Siaya \& Hayward, 2003).

3. The report-line of the executive who directed the OIP. A total of 91 out of 93 respondents answered this question. The survey indicated that more than four-fifth (83.9\%) of executive directors of the OIPs reported to the central administration directly, including presidents or chancellor, provost or vice president of academic affairs, or associate or assistant provost; among them, more than half (59.21\%) of OIP directors reported directly to provost or vice president of academic affairs, and nearly one-third (27.63\%) reported to associate or assistant provost directly. Moreover, another 16.1 percent of OIP directors reported to deans of undergraduate studies, or deans of academic affairs. The high percentage of OIP directors reporting to the central administration indicated that centralized administration and coordination of international programs required strong supervision and support from 
the senior administrators. The results were consistent with the findings of ACE's study (Siaya \& Hayward, 2003).

\section{The Scope of Authority of the OIP}

The survey showed that the top-five scope of authorities of OIPs at U.S. research universities consisted of: (1) administration and coordination of study abroad programs (100\%), (2) establishment of international partnerships (67.71\%), (3) administration and coordination of faculty abroad for teaching, research, and service (56.25\%), (4) generating grants and contracts to support international programs (46.88\%), and (5) providing services for international students and scholars (34.38\%). Other responsibilities included: international students recruitment and admission (16\%), coordination of international service learning and international internships, administration of Fulbright programs, providing language training for exchange students, such as Intensive English and/or English as Second Language (ESL), development of international curriculum and international studies, and so forth.

\section{International Programs and Activities}

This part addressed the dollar amount of scholarship and/or incentives used by research universities to support students and faculty members going abroad, as well as strategies and programs used by the OIP to promote students and faculty abroad.

1. A dollar amount of scholarships to support students studying abroad. A total of 71 out of 93 institutions responded this question. The results indicated that the average dollar amount of scholarships used by research universities to support students studying abroad was $\$ 70.52$ thousand dollars in academic year of 2007-08; (2) The highest dollar amount of scholarships offered by the institution was $\$ 750$ thousand dollars in academic year of 2007-08; and (3) 16 out of 71 respondents did not offer any 
incentives to support students studying abroad, which consisted of 22.5 percent of responded institutions.

2. A dollar amount of incentives to support faculty abroad for teaching, research, and service. A total of 55 out of 93 institutions responded this question. The finding showed that: (1) the average of dollar amount of incentives to support faculty abroad for teaching, research, and service was $\$ 14.9$ thousand dollars in academic year of 2007-08; (2) the highest dollar amount of incentives provided by an institution for promoting faculty abroad was $\$ 300$ thousand dollars; and (3) 25 out of 55 (or 40\%) respondents did not offer any incentive at all for faculty working abroad.

3. Programs and activities to promote students studying abroad. Promotion of international education on campus consisted of a variety of programs and efforts provided by the OIP to support international climate on campus. The research literature review indicated that programs and activities for promoting students studying abroad included international festivals, international residence hall programs, language partner programs and buddy programs to bond international students and scholars and American students. Based on 93 sampled institutions, the results showed that (1) 79.6 percent of institutions provided international festivals to promote international climate on campus; (2) 40.9 percent of institutions offered international residence hall programs and service for both international students and American students; and (3) 24.7 percent institutions had language partner programs and 26.9 percent institutions provided buddy programs to bond American students with international students. Moreover, there were 38.7 percent of sampled institutions offered other types of international programs and activities to support study abroad, 
such as study abroad fairs, study abroad posters, fliers, and e-letters, classroom visits, information sessions/tables, social networking (such as Facebook) for students who studied abroad, or were interested in going abroad.

4. Programs and activities to promote faculty going abroad for teaching, research, and service. Based on literature review, programs and activities for promoting faculty abroad included (1) including international experience and work in faculty promotion and tenure review policy; (2) proving funds for faculty participating in international programs abroad, (3) providing workshop and training for faculty to develop in international dimension; and (4) providing sabbatical leaves for faculty who participated in international programs abroad. The results indicated that: (1) only 8.6 percent sampled institution included international working experience in the policy of faculty promotion and tenure review; (2) 53.8 percent sampled institutions offered funds for faculty members working abroad; (3) 39.8 percent institutions provided training and workshops for faculty to develop in international dimensions; and (4) 19.4 percent of sampled institutions allowed faculty members taking sabbatical leaves for teaching, research, and service abroad. In addition, 9.7 percent sampled institutions also offered other types of supports for faculty abroad, such as awards and recognitions for those faculty members who made contribution on international education and programs on and off-campus; offering faculty members who engaged in international education an extra credit for faculty promotion, and so forth.

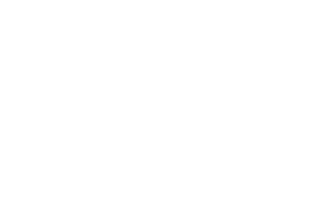

